POLIANE TORRES MEGDA

\title{
DETECÇÃO E CLASSIFICAÇÃO DE OBSTÁCULOS APLICADOS AO PLANEJAMENTO DE TRAJETORIAS PARA VEÍCULOS DE PASSEIO EM AMBIENTE URBANO
}

Dissertação apresentada à Escola de Engenharia de São Carlos da Universidade de São Paulo, como parte dos requisitos para obtenção do título de Mestre em Engenharia Mecânica.

Área de concentração: Dinâmica de Máquinas e Sistemas.

Orientador: Prof. Assoc. Marcelo Becker

São Carlos
ESTE EXEMPLAR TRATA-SE

DA VERSÃO CORRIGIDA. A VERSÃO ORIGINAL ENCONTRA-SE DISPONÍVEL JUNTO AO DEPARTAMENTO DE ENGENHARIA MECÂNICA DA EESC-SP 


\section{AUTORIZO A REPRODUÇÃO E DIVULGAÇÃO TOTAL OU PARCIAL DESTE TRABALHO, POR QUALQUER MEIO CONVENCIONAL OU ELETRÔNICO, PARA FINS DE ESTUDO E PESQUISA, DESDE QUE CITADA A FONTE.}

Megda, Poliane Torres.

Detecção e classificação de obstáculos aplicados ao planejamento de trajetórias para veículos de passeio em ambiente urbano. / Poliane Torres Megda; orientador Marcelo Becker. São Carlos, 2011.

Dissertação (Mestrado - Programa de Pós-Graduação em Engenharia Mecânica e Área de Concentração em Dinâmica de Máquinas e Sistemas) -- Escola de Engenharia de São Carlos da Universidade de São Paulo, 2011.

1. Robótica móvel. 2. Detecção e classificação de obstáculos. 3. Planejamento de trajetórias. 4. Veículos de passeios autônomos. I. Título. 


\section{FOLHA DE JULGAMENTO}

Candidato: Engenheiro POLIANE TORRES MEGDA

Título da dissertação: "Deteç̧ão e classificação de obstáculos aplicados ao planejamento de trajetórias para veículos de passeio em ambiente urbano".

Data da defesa: 20/10/2011:

\section{Comissão Julgadora:}

Prof. Associado Marcelo Becker (Orientador)

(Escola de Engenharia de São Carlos/EESC)

Prof. Dr. Daniel Varela Magalhães

(Escola de Engenharia de São Carlos/EESC)

Prof $^{a}$. Associada Roseli Aparecida Francellin Romero

(Instituto de Ciências Matemáticas e Computação/ICMC)
Resultado:

APROVADA

APROVADA

APROVADA

Coordenador do Programa de Pós-Graduação em Engenharia Mecânica:

Prof. Associado Marcelo Areias Trindade

Presidente da Comissão de Pós-Graduação:

Prof. Associado Paulo Cesar Lima Segantine 
Dedico esta realização a minha família pelo carinho e ao Cleber pelo amor incondicional e compreensão principalmente nos momentos mais dificeis. 



\section{AGRADECIMENTOS}

Em primeiro lugar a Deus por me dar à vida, me iluminar e mostrar os caminhos certos a perseguir.

A toda a minha família pelo apoio, carinho e compreensão.

Ao Cleber, meu namorado, por todo amor e dedicação.

A todos os professores, pelo apoio e por me mostrarem o caminho. Em especial ao Prof. Assoc. Marcelo Becker, pela confiança depositada e pela oportunidade de realizar esta etapa importante de minha formação.

A todos os amigos da Pós-Graduação, principalmente ao Kléber de Oliveira Andrade, André Carmona Hernandes, Rafael Coronel Bueno Sampaio pelas horas de incentivo e por toda ajuda.

É importante salientar que o desenvolvimento do sistema de navegação do Projeto SENA contou e ainda conta com a valiosa colaboração de vários membros de uma equipe de pesquisadores. Entre eles, a seguir serão citados os que tiveram uma maior interação com o tema desenvolvido neste trabalho. A pesquisa e o desenvolvimento das rotinas de trackers foram feitas com a cooperação do aluno de Iniciação Científica (I.C.). Breno Almeida Esteves, bolsista do CNPq. O estudo das rotinas de planejamento de trajetórias contou com a ajuda do aluno Gabriel Queiroz Silva Abrahão, aluno de I.C., também bolsista do CNPq. A pesquisa e desenvolvimento do algoritmo $E^{*}$ contaram com a colaboração do aluno de Mestrado do Programa de Pós-graduação em Engenharia Elétrica José Miguel Vilca, bolsista do CNPq. E a visualização que foi desenvolvida em conjunto com o aluno de graduação Airton Conceição Júnior.

A todos que leram este trabalho e me ajudaram a desenvolver uma pesquisa melhor e chegar ao fim dessa importante etapa.

À Fundação de Amparo á Pesquisa do Estado de São Paulo (FAPESP), processo $\mathrm{n}^{\circ}$ 2009/04787-0, ao Instituto Nacional de Ciência e Tecnologia de Óptica e Fotônica (INOF) pelo apoio financeiro. 

"Porque o Senhor dá a sabedoria, e da sua boca vem a inteligência e o entendimento"

Provérbios 2:6 



\section{RESUMO}

MEGDA, P. T. (2011). Deteç̧ão e Classificação de Obstáculos Aplicados ao Planejamento de Trajetórias para Veículos de Passeio em Ambiente Urbano. Dissertação (Mestrado) - Escola de Engenharia de São Carlos, Universidade de São Paulo, São Carlos, 2011.

Todos os dias a quantidade de veículos nas estradas em todo o mundo está aumentando. Este crescimento combinado com a negligência dos motoristas e alguns fatores externos, tais como estradas mal conservadas e condições climáticas adversas resultaram em um enorme aumento na quantidade de acidentes e, conseqüentemente, de mortes. Atualmente muitos grupos de pesquisa e empresas automotivas estão desenvolvendo e adaptando tecnologias que podem ser incorporadas nos veículos para reduzir esses números. Um exemplo interessante dessas tecnologias é a detecção e classificação de obstáculos móveis (veículos, pessoas, etc.) em ambientes urbanos. Este trabalho apresenta o desenvolvimento de algoritmos para identificação, rastreamento e previsão de obstáculos móveis, determinação de direções proibidas para tráfego do veículo e cálculo de trajetórias livres de colisões. Para isso, foram utilizados dados do sistema de medidas de distância, SICK LMS 291-S05, para monitorar o ambiente a frente do veículo de teste (um automóvel de passeio modificado). Com base nesses dados foi realizado um tratamento computacional através da técnica de Trackers para classificar todos os obstáculos detectados em duas classes principais: os obstáculos estáticos e móveis. Uma vez identificado o obstáculo, este será acompanhado mesmo no caso em que saia do campo de visão do sensor. Após a classificação dos obstáculos presentes no ambiente, suas posições são analisadas e direções proibidas para tráfego são determinadas pelo algoritmo Velocity Obstacle Approach. Finalmente é aplicada a técnica de cálculo de trajetórias $\mathrm{E}^{*}$ que gera um caminho suave e livre de colisões. No caso de algum obstáculo obstruir ou gerar risco de colisão com o caminho gerado é possível recalcular a rota sem que o mapa do ambiente seja novamente completamente analisado. Os resultados obtidos demonstraram a aplicabilidade da metodologia utilizada. $\mathrm{O}$ algoritmo de Trackers detectou pedestres e veículos e determinou suas características dinâmicas. O algoritmo Velocity Obstacle Approach conseguiu acompanhar os obstáculos e foi capaz de determinar as direções proibidas e, finalmente, o algoritmo $E^{*}$ foi capaz de gerar trajetórias livre de obstáculos em ambientes desconhecidos.

Palavras-chave: Detecção e classificação de obstáculos. Planejamento de Trajetórias. Veículos de Passeio Autônomos. Robótica Móvel. 



\begin{abstract}
MEGDA, P. T. (2011). Detection and Classification of Obstacles apply to Path Planning for Passenger Vehicles in Urban Environment. M.Sc Dissertation (Master) - São Carlos School of Engineering, São Paulo University, São Carlos, 2011.
\end{abstract}

Every day the number of vehicles on the roads around the world is increasing. This growth combined with the negligence of drivers and some external factors such as poorly maintained roads and adverse weather conditions resulted in a huge increase in the number of accidents and hence casualties. Currently many research groups and automotive companies are developing and adapting technologies that can be incorporated into vehicles to reduce these numbers. An interesting example of these technologies is the detection and classification of moving obstacles (vehicles, people, etc.) in urban environments. This dissertation presents the development of algorithms which main objective are identify, track and predict moving obstacles, determine prohibited directions of traffic and calculate collision free trajectories. In order to accomplish with such task, data from the laser sensor SICK LMS 291-S05 later treated using computational resources such as the Trackers technique was used to monitor the environment ahead of the test vehicle (a modified passenger car). The Trackers technique was used to classify all the hurdles identified in two main classes: static and mobile obstacles. Once the obstacle was identified, this still been followed even if they leave the field of vision sensor. After classification of obstacles in the environment, their positions are analyzed and prohibited for traffic directions are determined by the algorithm Velocity Obstacle Approach. Finally the technique is applied to calculate trajectories of $\mathrm{E}^{*}$ that generates a smooth path and free of collisions. If any obstacle block, or create a risk of collision through the generated path, the trajectory can be recalculated without the need to fully re-analyze de environment map. The results demonstrated the applicability of the methodology used. The Trackers algorithm has detected pedestrians and vehicles determining their dynamic characteristics. The algorithm Velocity Obstacle Approach keep up with the obstacles and was able to determine the prohibited directions and, finally, $\mathrm{E}^{*}$ the algorithm was able to generate obstacle-free paths in unknown environments.

Keywords: Detection and classification of obstacles. Path Planning. Autonomous Passenger Cars. Mobile Robots. 



\section{PUBLICAÇÕES COMPLETAS}

1. MEGDA, P. T.; LUliO, L. C.; TRONCO, M. L.; CAURIN, G. A. P.; BECKER, M. Controle de Trajetórias para Robôs Móveis utilizando Lógica Fuzzy. VI Congresso Nacional de Engenharia Mecânica (ABCM/CONEM 2010), 2010, Campina Grande, Brasil.

2. ABRAHÃO, G. Q. S; MEGDA, P. T.; BECKER, M. O Uso de Algoritmos $A^{*}$ e Field $A^{*}$ em um Robô Agrícola. VI Congresso Nacional de Engenharia Mecânica (ABCM/CONEM 2010), 2010, Campina Grande, Brasil.

3. ESTEVES, B. A.; MEGDA, P. T.; BECKER, M. Autonomous Embedded Navigation System - Detection, Monitoring and Position and Trajectory Prediction of Obstacles in Urban Environments Based on Laser Sensor Data and Kalman Filter. In Proceedings of COBEM 2011: $21^{\text {st }}$ International Congress of Mechanical Engineering, 2011, Natal, Rio Grande do Norte, Brasil.

4. ABRAHÃO, G. Q. S; MEGDA, P. T.; BECKER, M. AgriBOT Project-Comparison Between the $A^{*}$, Field $A^{*}$ and $D^{*}$ Navigation Algorithms. In Proceedings of COBEM 2011: $21^{\text {st }}$ International Congress of Mechanical Engineering, 2011, Natal, Rio Grande do Norte, Brasil.

5. MEGDA, P. T.; ESTEVES, B. A.; BECKER, M. Determining Forbidden Steering Directions for a Passenger Car in Urban Environments based on the Velocity Obstacle Approach and use of Trackers. In Proceedings of IEEE LARC \& CCAC 2011: XI Latin American Robotics Competition \& Colombian Conference on Automatic Control \& II Industry Applications Society Colombian Workshop, 2011, Bogotá, Colombia. 


\section{RESUMOS}

6. ESTEVES, B. A.; MEGDA, P. T.; BECKER, M. Sistema Embarcado de Navegação Autônoma Detecção, Acompanhamento e Predição de Pedestres em Ambientes Urbanos com Sensor Laser. In: $18^{\circ}$ SIICUSP - Simpósio Internacional de Iniciação Científica da USP, 2010, São Carlos, 2010. Anais do $18^{\circ}$ SIICUSP - USP, 2010.

7. ABRAHÃO, G. Q. S.; MEGDA, P. T.; BECKER, M. Navegadores para Robôs Móveis Agrícolas Comparação entre os Algoritmos $A^{*}$, FIELD $A^{*}$ e $D^{*}$. In: $18^{\circ}$ SIICUSP - Simpósio Internacional de Iniciação Científica da USP, 2010, São Carlos, 2010. Anais do $18^{\circ}$ SIICUSP - USP, 2010. 


\section{LISTA DE FIGURAS}

Figura 1 - Idéia Conceitual do Projeto SENA a curto prazo. Em (a) uma visão de satélite da área do Campus 1 da USP em São Carlos. Em (b), um mapa CAD georeferenciado do Campus e em (c), detalhe de uma área do Campus com os nós que formam o mapa topológico desta região.

Figura 2 - Três vistas do protótipo utilizado no Projeto SENA - Sistema Embarcado de Navegação Autônoma. Detalhe do posicionamento dos sensores.

Figura 3: SICK LMS 291-S05 empregado para fazer as aquisições de dados.

Figura 4: Fluxo de operações para navegação de robôs autônomos. Adaptado de (Siegwart et al, 2011).

Figura 5: Arquitetura geral de um sistema de controle para robôs móveis. Em destaque o foco do trabalho desenvolvido nesta dissertação: Desvio de Obstáculos e Planejamento de Trajetórias.

Figura 6: Planejamento Local de trajetórias.

Figura 7: Fluxograma das rotinas que constituem o algoritmo desenvolvido. Sendo que o algoritmo de manobras evasivas não foi desenvolvido neste trabalho.

Figura 8: Representação de uma leitura do laser SICK LMS 291-S05 e alguns dos seus parâmetros.

Figura 9: Regras para detecção de obstáculos.

Figura 10: Modelo genérico de um carro com esterçamento frontal.

Figura 11: Caminhos previstos para os obstáculos detectados. Em (a) o curso do obstáculo está ao longo do eixo y, com apresentação de 7 caminhos possíveis, que vão da esquerda para a direita considerando os ângulos de direção máxima. Em (b), estimação do ângulo de direção atual e os caminhos previsto com base neste (Becker et al, 2007).

Figura 12: Estrutura do Velocity Obstacle Approach.

Figura 13: Ilustração do Velocity Obstacle Approach.

Figura 14: Ilustração Final do conjunto $\mathrm{VOB}_{i}$ do Velocity Obstacle Approach (a). Em (b) é apresentado o conjunto de velocidades que podem ser atingidas (RAV): área interna ao polígono PQRS (Becker, Dantas e Macedo 2005).

Figura 15: Heurística de seleção de velocidade: em (a) TG e em (b) MV (Becker, Dantas e Macedo 2005). 
Figura 17: (a) e (b) conjunto de velocidades em direções proibidas calculadas no espaço de velocidades (Becker, Dantas e Macedo 2005).

Figura 18: (a) dois obstáculos representados por dois $V O_{B}\left(V O_{B i}\right.$ e $\left.V O_{B j}\right)$. (b) Espaço de Velocidades e três conjuntos de velocidades em direções perigosas (Becker, Dantas e Macedo 2005).

Figura 19: Efeito da variação do módulo de velocidade nos intervalos de DVDs. O círculo I representa a velocidade de cruzeiro, no círculo II o veículo é acelerado e no círculo III é freado (Becker, Dantas e Macedo 2005).

Figura 20: Ilustração da onda de propagação (wavefront) continua no domínio. Contornos são varridos por fora da meta, levando em contas as informações dos obstáculos......... 46

Figura 21: Ilustração da wavefront. (a) Algoritmo prestes a descobrir uma passagem bloqueada e (b) a função de navegação repara o mapa

Figura 22: Fluxograma geral do programa de Trackers.

Figura 23: Segmentação com valores não convenientes da distância limiar.

Figura 24: Exemplo de deteç̧ão e acompanhamento de uma leitura do sensor SICK LMS 291-S05. (a) detecção de pedestre, (b) detecção de veículo, (c) imagens do pedestre detectado e classificado, (d) imagens do veículo detectado e classificado.

Figura 25: Deteç̧ão de vegetação alta sob ação do vento.

Figura 26: Cenário de cruzamento entre veículos.

Figura 27: Exemplo de muitos obstáculos juntos, neste caso pedestres caminhando juntos. .58

Figura 28: Motocicleta detectada, classificada como veículo e acompanhada pelo algoritmo.

Figura 29: Exemplos de nuvens de probabilidades para (a) veículo, (b) agrupamento de pedestres e (c) carros que se cruzam em frente ao sensor.

Figura 30: Fluxograma geral do programa de estimação de direções proibidas.

Figura 31: (a) Determinação do range mínimo e máximo para vias de 6 m de largura e velocidades do veículo variando de 1 a $11,1 \mathrm{~m} / \mathrm{s}$. Em (b) direção Proibida sem o uso do range.

Figura 32: Exemplo de veículos com velocidades acima da considerada para o protótipo SENA e pedestres fora do alcance máximo para as direções proibidas.

Figura 33: Exemplo de direções proibidas para tráfego do veículo, (a) detecção de motocicleta com velocidade abaixo de $11,1 \mathrm{~m} / \mathrm{s}$, (b) aglomeração de pedestres, (c) veículos com velocidade abaixo de $11,1 \mathrm{~m} / \mathrm{s}$, e (d) cones de indicação de direções 
proibidas em casos que vegetação alta é identificada temporariamente como obstáculo móvel.

Figura 34: Primeira trajetória calculada para mapa estático.

Figura 35: Trajetória calculada para mapa com novo obstáculo detectado.

Figura 36: Cálculo da rota na fusão dos algoritmos.

Figura 37: Testes de simulação com o robô Pionner. Resultados para o primeiro teste com o mapa estático (a) trajetória gerada pelo algoritmo $E^{*}$, (b) trajetória percorrida pelo robô, e no teste com o novo obstáculo estático (c) e (d) as mesmas situações (Vilca, 2011) 



\section{LISTA DE SIGLAS}

Bidimensional

ABD Adaptive Breakpoint Distance

ABS Antilock Brake Systems

ACC Adaptive Cruise Control

DARPA Defense Advanced Projects Research Agency

DWA Dynamic Window Approach

EKF $\quad$ Extended Kalman Filter

GDWA Global Dynamic Window Approach

GPS Global Positioning System

HIDS Honda Intelligent Driver Support System

IBGE Instituto Brasileiro de Geografia e Estatística

IMU Inertial Measurement Unit

IPS Intelligent Parking Assist

KF Kalman Filter

KFBS Kalman Filter BaSed

LIDAR Ligth Detection and Ranging

MVOA Modified Velocity Obstacle Approach

NHTSA US National Center for Statistics and Analysis

NNSF Nearest-Neighbor Standard Filter

OTG Optimal Trajectory Generation

PDBS Point Distance BaSed

SENA Sistema Embarcado de Navegação Autônoma

SLAM Simultaneous Localization and Mapping

SPARC Secure Propulsion using Advanced Redundant Control

VFH Vector Field Histogram 
$\mathrm{VFH}^{+} \quad$ Vector Field Histogram ${ }^{+}$

$\mathrm{VFH}^{*} \quad$ Vector Field Histogram ${ }^{*}$

VOA Velocity Obstacle Approach 


\section{LISTA DE SÍMBOLOS}

pontos de segmentação

$\mathrm{N}$

número de pontos da segmentação

$\Delta \alpha$

resolução angular do sensor

$[\mathrm{rad}]$

$S_{i} \quad$ segmento formado pelos pontos capturados pelo sensor

$D_{\text {lim }} \quad$ distância limite máxima para que dois pontos

pertençam ao mesmo obstáculo

$D\left(r_{i}, r_{i+1}\right)$ distância Euclidiana entre dois pontos consecutivos

$C_{0} \quad$ constante usada para redução de ruído

$\sigma_{r} \quad$ variância que endereça o comportamento aleatório da seqüência dos pontos lidos pelo sensor e o ruído associado

$\vec{v}_{\text {estado }} \quad$ vetor que determina o estado do obstáculo também

$F(\Delta t) \quad$ matriz de transição de tempo discreto

$Q(\Delta t) \quad$ matriz de covariância do ruído do filtro

$z(t+\Delta t) \quad$ medições nas coordenadas $x$ e $y$

$u$

ruído do processo

$w$

ruído da medição

matriz de medição

$\Delta t \quad$ intervalo de tempo

[s]

$P$

covariância do estado

S

covariância da inovação

$R$

matriz de covariância do ruído da medição

W

ganho do filtro

$m$

distância de Mahalanobis

$\mu_{X}$

valor da média em $x$ 
$\mu_{Y} \quad$ valor da média em $y$

$\sigma_{X}^{2} \quad$ desvio padrão dos pontos em $x$

$\sigma_{Y}^{2} \quad$ desvio padrão dos pontos em $y$

Norma norma do desvio padrão

$L \quad$ distância entre a roda dianteira e traseira

r raio da curva descrita pelo veículo

d

distância percorrida pelo veículo através do arco de circunferência

mudança de orientação do veículo

$\omega \quad$ velocidade angular do veículo

ângulo de esterçamento do veículo

A representação do veículo por circulo

$\mathrm{B}_{\mathrm{i}} \quad$ representação dos obstáculos por círculos

$\mathrm{t}_{0} \quad$ instante de tempo

$\mathrm{V}_{\mathrm{A}} \quad$ velocidade do veículo

$\mathrm{V}_{\mathrm{Bi}} \quad$ velocidade dos obstáculos

$\mathrm{CC}_{\mathrm{Abi}} \quad$ cone de colisão

$\mathrm{V}_{\mathrm{ABi}} \quad$ velocidade relativa de $\hat{\mathrm{A}}$ com relação a $\hat{\mathrm{B}}_{\mathrm{i}}$

$\lambda_{\mathrm{f}}$ e $\lambda_{\mathrm{r}} \quad$ tangentes de $\hat{\mathrm{A}}$ a $\hat{\mathrm{B}}_{\mathrm{i}}$ (concêntricos a $\mathrm{B}_{\mathrm{i}}$ )

$\mathrm{VO}_{\mathrm{Bi}}$ translação do conjunto $\mathrm{CC}_{\mathrm{ABi}}$ entre os pontos $\mathrm{A}$ e $\mathrm{B}_{\mathrm{i}}$

$\mathrm{T}_{\mathrm{h}} \quad$ horizonte de tempo

$\left\|\mathrm{V}_{A}\right\| \quad$ módulo da velocidade

ângulo de direção

$G$

grafo não direcionado

C

configuração do espaço

$v(\mathrm{c}) \geq 0 \quad$ amostra do mapa em passagem de tempo contínua no nó $c$, ou a "altura" da função de navegação 
$r$ c c custo transversal ou risco do nó c

$m(c) \quad$ informações da meta a partir de c

rhs-value tempo de travessia

$[\mathrm{s}]$

$u$

novo valor do nó $c$

$Q$ (c) propagador de $c$ no momento de expansão

$N(c) \quad$ conjunto de nós vizinhos (adjacentes) de $c$ 



\section{SUMÁRIO}

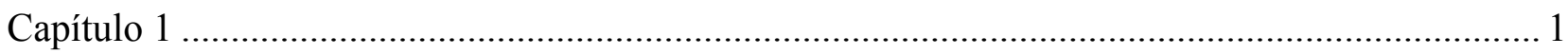

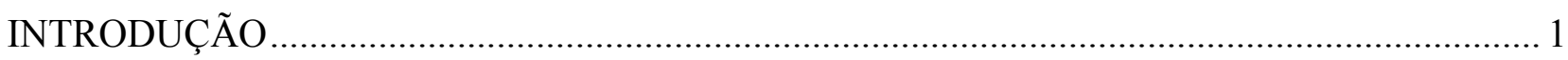

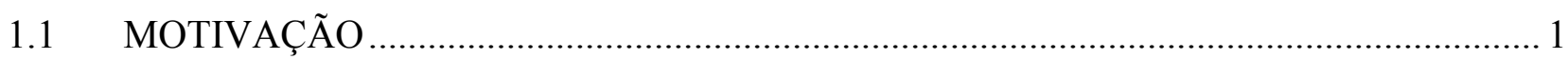

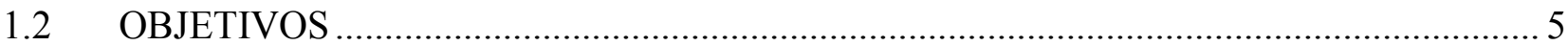

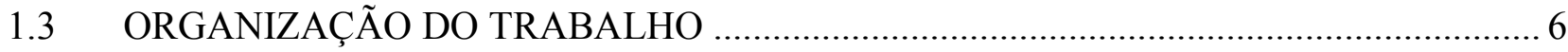

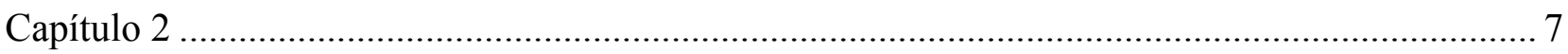

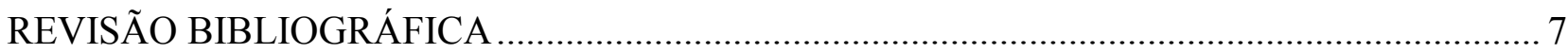

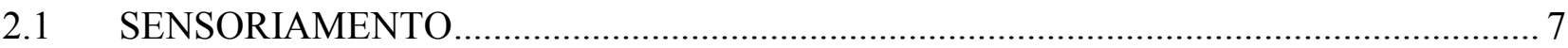

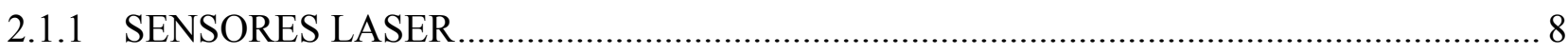

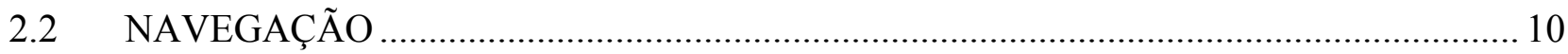

2.2.1 DETECÇÃO DE OBSTÁCULOS ….......................................................................... 13

2.2.2 TÉCNICAS DE PLANEJAMENTO LOCAL DE TRAJETÓRIAS ................................. 14

2.2.3 NAVEGAÇÃO EM VEÍCULOS DE PASSEIO AUTÔNOMOS .................................... 17

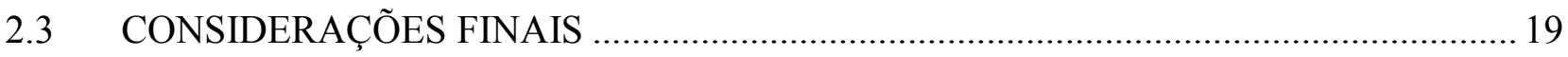

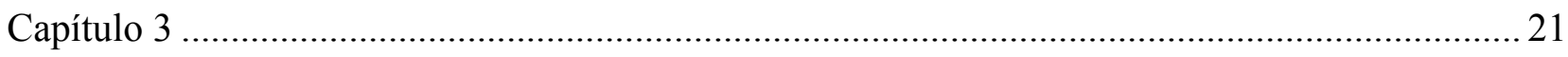

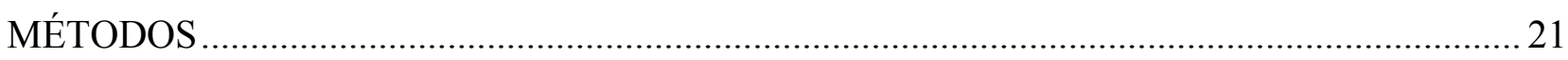

3.1 ESTRUTURA DO ALGORITMO DE MONITORAMENTO ..................................... 21

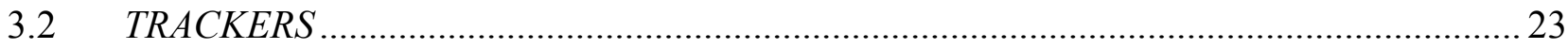

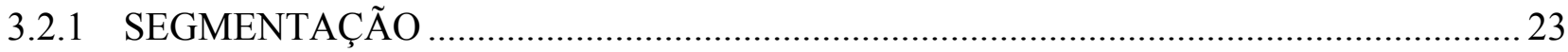

3.2.1.1 SEGMENTAÇÃO BASEADA NA DISTÂNCIA ENTRE PONTOS .......................... 25

3.2.1.2 SEGMENTAÇÃO BASEADA NO FILTRO DE KALMAN...................................... 26

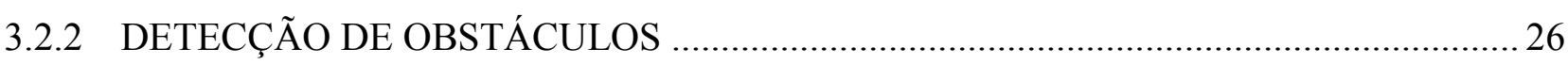

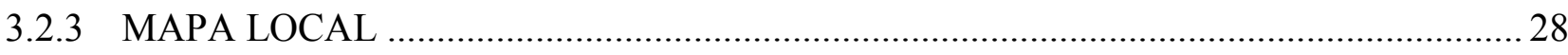

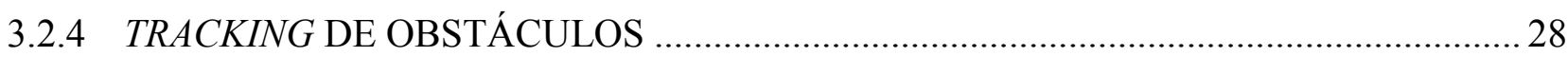

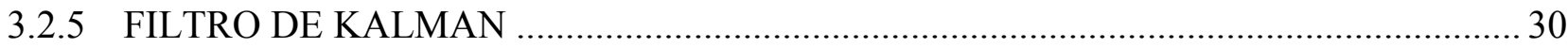

3.2.6 ASSOCIAÇÃO DOS DADOS E CLASSIFICAÇÃO DE OBSTÁCULOS ....................... 32

3.2.7 TRAJETÓRIA DE OBSTÁCULOS - NUVEM DE PROBABILIDADES ....................... 34

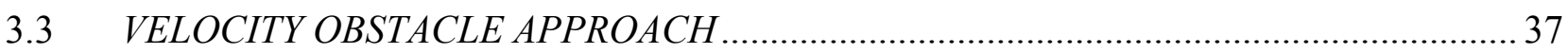

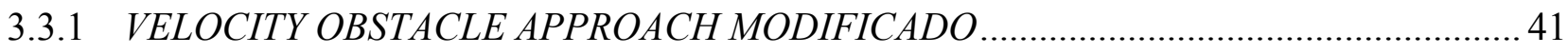

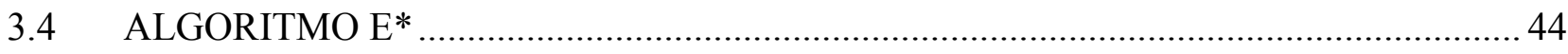

3.4.1 ONDA DE PROPAGAÇÃO E UPWIND ….............................................................. 46 


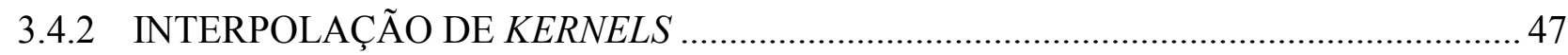

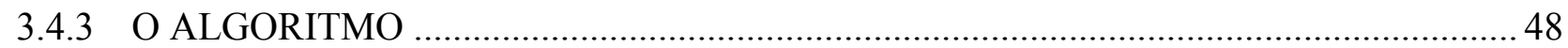

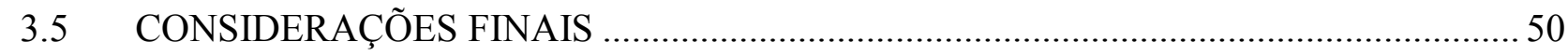

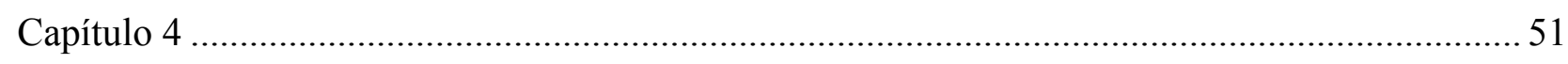

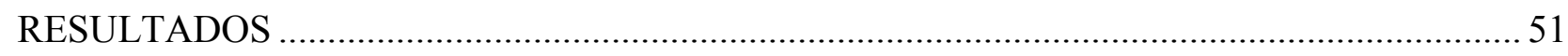

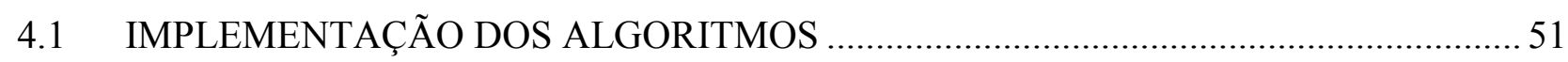

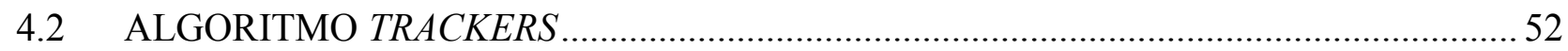

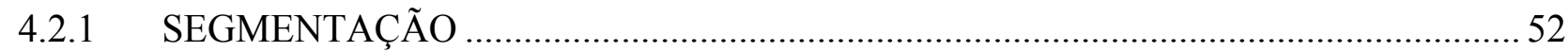

4.2.2 DETECÇÃO, ACOMPANHAMENTO DE OBSTÁCULOS E NUVEM DE

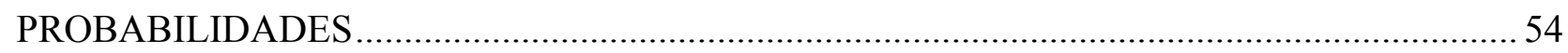

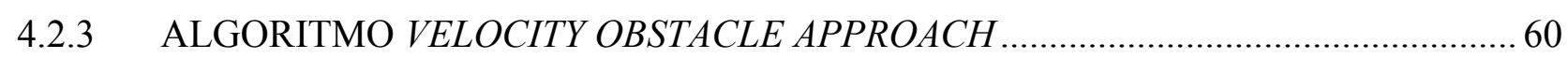

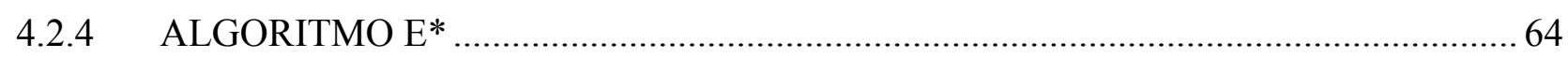

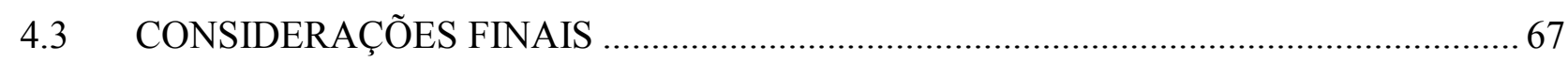

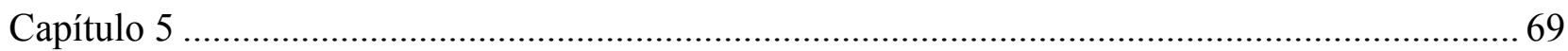

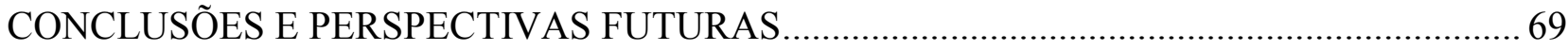

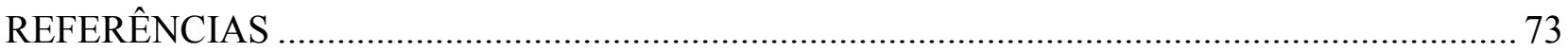




\section{Capítulo 1}

\section{INTRODUÇÃO}

Neste capítulo é apresentada tanto a motivação para o desenvolvimento deste trabalho e a sua relevância no desenvolvimento de veículos autônomos, como os objetivos e as contribuições obtidas. Em seguida é descrita a organização dos capítulos desta dissertação.

\subsection{MOTIVAÇÃO}

A quantidade de acidentes e o índice de fatalidade nas vias públicas no mundo inteiro estão aumentando ano a ano (Brookhuis et al, 2001). A combinação entre péssimas condições das estradas, bebidas alcoólicas, situações meteorológicas adversas, fadiga, desatenção e sonolência ao volante causam dramáticas perdas de vida e prejuízos anuais no mundo inteiro da ordem de bilhões de dólares. No ano de 2009 o Brasil se encontrava na $5^{a}$ posição mundial no tamanho de frota (Fenabrave, 2009). As estimativas de Fevereiro de 2011 afirmavam que 57,24\% dos veículos que compunham a frota brasileira eram automóveis e 21,61\%, motocicletas, ambos são os dois tipos de veículos que mais se envolveram em acidentes de trânsito no Brasil (Boselli, 2009). Em comparação com países desenvolvidos, pesquisas no ano de 2007 , indicam que o trânsito brasileiro mata 2,5 vezes mais que nos Estados Unidos e 3,7 vezes mais que em países da União Européia. Deve-se frisar que no Brasil, os feridos levados para hospitais que vêem a falecer após o acidente não são contabilizados nessa taxa. Isso claramente se tornou um problema de saúde pública sendo necessária a aplicação de leis mais rígidas e sistemas embarcados nos veículos para prevenção de acidentes que possam até mesmo interferir na ação do motorista em situações de risco.

O projeto de veículos de passeio autônomos (ou simplesmente, "carros inteligentes") que sejam capazes de lidar com situações reais de tráfego em áreas 
urbanas é certamente um dos grandes desafios nesse início do século XXI. Mas, desde meados da década de 1980, com o enorme desenvolvimento da eletrônica embarcada nos automóveis de passeio, a cada ano novos sistemas mecatrônicos embarcados nos veículos estão se tornando itens de série. Os chamados "eSafety systems" (p.e.: freios ABS, controle de tração nas rodas, air-bags, controle de rolagem, etc.) tornaram-se possíveis graças à miniaturização de sensores e elementos eletro-mecânicos, regulamentações governamentais mais rígidas e, principalmente, às maiores exigências dos clientes por maior qualidade, melhor performance e menor preço. A introdução dos eSafety systems contribuiu para reduzir os índices de acidentes e fatalidades mas, devido principalmente à imprudência e à grande incidência de motoristas alcoolizados, percebe-se que ainda é necessária a adoção de sistemas assistivos que possam detectar e atuar em situações de risco iminente.

Segundo a NHTSA (US National Center for Statistics and Analysis) em 2009 nos Estados Unidos, ocorreram aproximadamente 5,5 milhões de acidentes reportados a policia, resultando em 1,5 milhões de feridos e 30.797 mortos (NHTSA, 2009). O prejuízo total nos Estados Unidos foi estimado em aproximadamente 230,6 bilhões de dólares anuais. No Brasil a situação é ainda pior, visto que a grande maioria das vias públicas federais e estaduais está deteriorada e a fiscalização dos motoristas infratores é precária (deve-se observar que a recente adoção da "lei seca" no Brasil ainda não permite uma avaliação de seu impacto em médio e longo prazos). Segundo o jornal O Estado de São Paulo, as mortes no trânsito no ano de 2008 chegaram a 87,6 mortes a cada 100 mil motos no país e 32,5 mortes a cada 100 mil veículos no país (O Estado de São Paulo, 2011). Na cidade de São Paulo foi atingida a marca de 17,01 mortes por 100 mil habitantes em 2007, para uma frota estimada em 5,3 milhões de veículos (O Estado de São Paulo, 2007).

Em adição a esses dados de acidentes, têm-se uma população mundial que está envelhecendo o que acaba por limitar sua independência e autonomia devido às dificuldades inerentes de acessibilidade, saúde e insegurança ao volante. Segundo o Instituto Brasileiro de Geografia e Estatística - IBGE, em 2000, 11,29\% da população brasileira tinha mais de 55 anos. Em 2050, esse percentual atingirá a cifra de 36,73\%, ou aproximadamente, 79 milhões de pessoas (IBGE, 2008). É notório que pessoas idosas e portadoras de limitações físicas têm cada vez mais dificuldades em dirigir veículos em grandes cidades e rodovias onde o ambiente é extremamente dinâmico e, 
até mesmo, agressivo. Assim, uma pequena falta de atenção pode causar acidentes muito graves. Por isso, é praxe que ao menor sinal de limitação, o idoso não tem a sua habilitação para dirigir renovada. Isso causa uma falta de mobilidade que provoca o isolamento e a falta de socialização do indivíduo, o que pode também provocar o surgimento de depressão e outras doenças.

Por outro lado, graças ao desenvolvimento observado nas últimas décadas nas áreas correlatas à robótica, hoje existem várias técnicas de robótica móvel e inteligência artificial (I.A.) que podem ser aplicadas em veículos de passeio, p.e.: visão artificial, detecção, classificação e acompanhamento de obstáculos, planejamento de trajetórias, etc. Nesse contexto, a aplicação efetiva dessas tecnologias pode contribuir de maneira decisiva para aumentar a segurança nas vias públicas, diminuindo drasticamente o índice de acidentes e, conseqüentemente, de fatalidades.

Diversos grupos de robótica em todo o mundo voltaram-se para esses problemas, visando a aplicação de tecnologias desenvolvidas para área de robótica móvel em veículos de passeio. Como resultado, vários eventos ocorreram nos Estados Unidos, DARPA $1^{\text {st }}$ e $2^{\text {nd }}$ Great Challenge - respectivamente em 2005 e 2007 (DARPA Great Challenge, 2005) e Europa, C-ELROB e M-ELROB (ELROB, 2011), respectivamente em anos ímpares e anos pares, desde 2006). Muito mais que meras competições e demonstrações, esses eventos estão pavimentando a tecnologia que será embarcada em breve nas novas gerações dos automóveis de passeio.

Observa-se na literatura e no mercado consumidor que sistemas assistivos estão se tornando mais comuns em veículos de passeio. Tome-se, por exemplo, a tecnologia IPS (Intelligent Parking Assist) da Toyota embarcada no Toyota Prius. Esse sistema, tipicamente mecatrônico, utiliza sensores e atuadores para realizar o estacionamento automático do veículo sem a intervenção do motorista. De acordo com a Mobile Magazine (MobileMagazine, 2006), aproximadamente 80\% dos compradores japoneses do Prius optam por essa tecnologia (que é vendida como opcional no mercado japonês). Outro exemplo é o projeto SPARC (Secure Propulsion using Advanced Redundant Control) desenvolvido por um consórcio de empresas da área automotiva $\mathrm{e}$ universidades européias (SPARC, 2011). Esse projeto visa o desenvolvimento de tecnologias embarcadas para aumentar a segurança no transporte de cargas por caminhões pesados. Como na grande maioria das aplicações em tempo real, o grande desafio é balancear corretamente as exigências computacionais com o custo final a ser 
repassado ao consumidor. Com isso, espera-se que em um futuro próximo carros já possuam sistemas de navegação robótica que irão auxiliar o motorista em situações de risco e buscar mais conforto na direção destes.

Nesta linha, o projeto SENA ${ }^{1}$ - Sistema Embarcado de Navegação Autônoma desenvolvido pelo Laboratório de Robótica Móvel do Grupo de Mecatrônica do Departamento de Engenharia Mecânica da Escola de Engenharia de São Carlos (LabRoM -SEM - EESC - USP), tem como meta tanto o desenvolvimento de um sistema aplicado a ambientes urbanos que possa auxiliar os motoristas, evitando acidentes em situações que apresentem risco iminente, como também melhorar a dirigibilidade através de assistência cooperativa, e em casos extremos assumindo o controle de movimentação do veículo de forma autônoma.

Inicialmente todos os experimentos reais com o veículo de testes estão sendo realizados dentro dos dois Campi da USP em São Carlos - SP. Assim, consegue-se aumentar tanto o nível de segurança dos testes, como o controle do cenário no qual os testes estão sendo realizados. A idéia central da fase inicial do Projeto SENA pode ser visualizada na Fig. 1 abaixo.

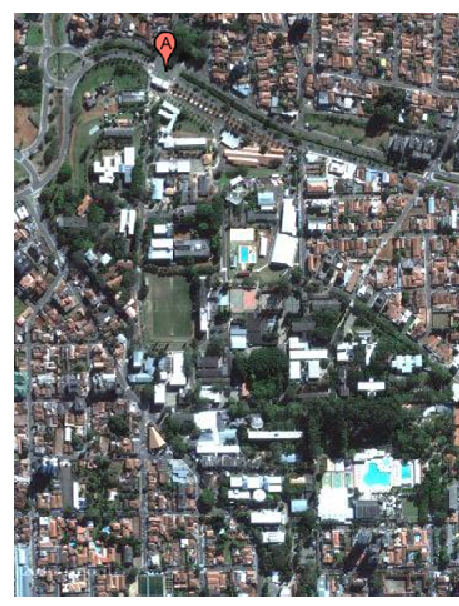

Ambiente Real Campus 1 USP São Carlos

(a)

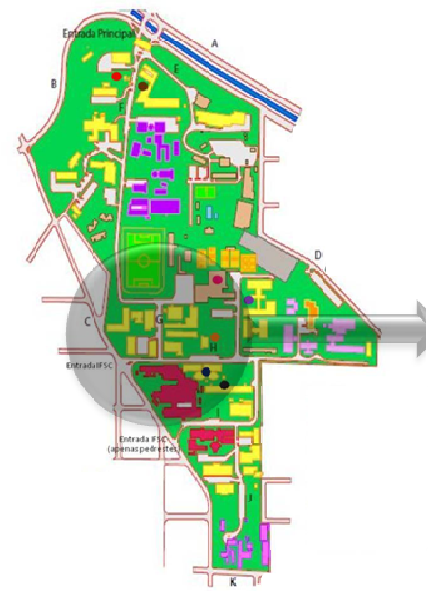

Mapa Georeferenciado Campus 1 USP São Carlos

(b)

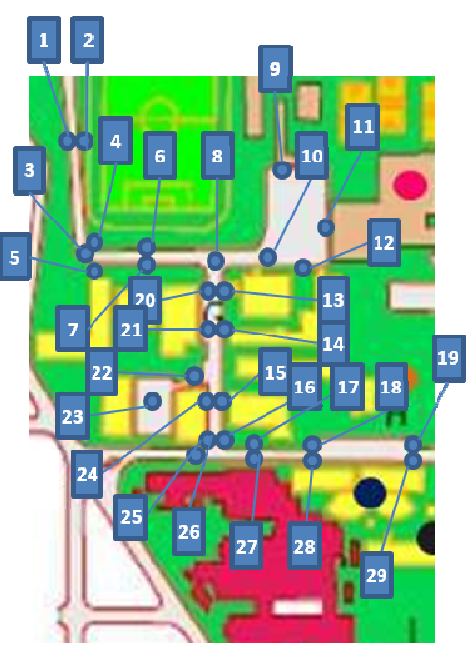

Mapa Topológico Campus 1 USP São Carlos

(c)

Figura 1 - Idéia Conceitual do Projeto SENA a curto prazo. Em (a) uma visão de satélite da área do Campus 1 da USP em São Carlos. Em (b), um mapa CAD georeferenciado

\footnotetext{
${ }^{1}$ http://www.eesc.usp.br/sena/
} 
do Campus e em (c), detalhe de uma área do Campus com os nós que formam o mapa

topológico desta região.

Baseado nos mapas georeferenciados dos dois Campi da USP São Carlos, devese definir os mapas topológicos com nós que representam pontos de interesse (p.e.: entradas de prédios, vagas em estacionamento, cruzamentos de ruas, rotatórias, faixas de pedestres, etc.). Esses nós serão empregados para, através da aplicação do algoritmo de Dijsktra (Dijsktra, 1959), definir a rota (seqüência de nós do mapa topológico) entre a posição inicial e a posição final do veículo de testes, ou seja, a navegação global do veículo. Na matriz de conexão dos nós do mapa topológico utilizada pelo algoritmo de Dijsktra é que são definidas as possíveis rotas entre dois pontos distintos do mapa. Em caso de rotas estarem bloqueadas, é necessário realizar atualizações nessa matriz. A auto-localização do veículo de testes é baseada na aplicação de filtro de Kalman estendido (EKF) juntamente com sinais de sensores GPS, IMU e odometria.

Deve-se aqui ressaltar que esses tópicos não serão cobertos neste texto, sendo que foram mencionados apenas para ilustrar uma idéia mais geral do projeto SENA. O foco desta dissertação é a navegação local do veículo, em especial, o procedimento de reconhecimento de situações que necessitem de desvio de obstáculos durante a execução da tarefa definida pelo navegador global.

\subsection{OBJETIVOS}

Assim, a contribuição do projeto atual é o desenvolvimento de um sistema a ser futuramente embarcado em um veículo de passeio que permita o monitoramento da área frontal do mesmo através de um sistema de medidas de distância, SICK LMS 291-S05. Desta forma, será feita não apenas a detecção, a classificação e o acompanhamento de obstáculos (outros veículos, pedestres, etc.) ao redor do veículo, mas também a estimativa de posicionamento desses obstáculos dentro de um horizonte de predição pré-definido, para perceber situações de risco e gerar trajetórias livres de colisões com pedestres, carros, etc. O algoritmo desenvolvido seleciona os obstáculos e os classifica, realizando o acompanhamento em uma janela de tempo (mesmo que eles estejam oclusos por outros obstáculos posicionados na frente do sensor). Com base nessas rotinas é gerada uma trajetória local livre de colisões, assistindo o motorista em 
situações de risco iminente. $\mathrm{O}$ algoritmo utiliza técnicas conhecidas na literatura da área como Trackers (para acompanhamento dos obstáculos), Velocity Obstacles (para definir ângulos proibidos de esterçamento do veículo) e $E^{*}$ (para obter uma trajetória local livre de colisões).

\subsection{ORGANIZAÇÃO DO TRABALHO}

Os capítulos da dissertação estão divididos em:

Capítulo 2 - Revisão Bibliográfica: apresenta técnicas de navegação em diferentes tipos de ambientes consolidadas pela literatura, as aplicações em veículos inteligentes, e o tipo de sensoriamento necessário para o mesmo.

Capítulo 3 - Metodologia: descrição das técnicas utilizadas para o desenvolvimento do algoritmo de monitoramento da área frontal do veículo.

Capítulo 4 - Resultados: apresenta os resultados obtidos com os algoritmos.

Capítulo 5 - Conclusões e Perspectivas Futuras: confronta o que foi proposto com os resultados obtidos e apresenta possíveis soluções para os problemas encontrados. 


\section{Capítulo 2}

\section{REVISÃO BIBLIOGRÁFICA}

Neste capítulo são apresentados conceitos básicos sobre robótica móvel e uma revisão sobre o estado da arte da navegação de robôs móveis para compreensão das diversas técnicas empregadas. Também é descrito o que é sensoriamento para sistemas autônomos, a caracterização e utilização dos sensores laser. Em seguida, é apresentada uma revisão bibliográfica dos sistemas de navegação em veículos de passeio autônomos em pesquisas recentes.

\subsection{SENSORIAMENTO}

O sensoriamento é utilizado para obtenção de informações, do ambiente no qual o robô irá operar. Em geral, robôs móveis autônomos devem possuir um sistema de controle mais complexo quando comparados com robôs cujas funções são préprogramadas, pois precisam ter uma flexibilidade maior para lidar com diversas situações que nem sempre foram previstas. Assim, o emprego de diferentes tipos de sensores é necessário para habilitar um sistema robótico com a capacidade de reagir ao ambiente em que está inserido. Este comportamento determina o tipo de controle e de informações necessárias para alcançar algum objetivo, mesmo sem o conhecimento completo do ambiente.

Neste contexto, a realização de tarefas pode ser descrita da seguinte forma: o robô recebe dados sobre seu estado (posição, velocidade, e orientação) através dos sensores proprioceptivos, que são aqueles que medem os parâmetros internos do sistema, e do ambiente (obstáculos móveis ou estáticos) com os sensores exteroceptivos que medem os parâmetros externos ao sistema (Siegwart e Nourbakhsh, 2004). Então o 
sistema de controle faz a associação entre esses dados dos sensores e determina a forma como o robô irá interagir para alcançar o objetivo estabelecido.

Neste trabalho foram desenvolvidas rotinas baseadas em dados de sensores laser. Por isso, a seguir será apresentada uma breve descrição de seu funcionamento onde será focado o sensor utilizado, SICK LMS 291-S05.

\subsubsection{SENSORES LASER}

Um sensor laser é um sensor exteroceptivo de medição de distâncias. O sensor emite um pulso de luz, que é refletido por algum elemento do ambiente externo e captado de volta pelo próprio sensor. Esses equipamentos são de ampla aplicação porque podem gerar feixes com fontes de baixa energia, e também os raios infravermelhos não atrapalham leituras de outros sensores e conseguem detectar pequenos obstáculos (Christensen et al, 2008). São também muito utilizados em navegação e desvio de obstáculos porque são capazes de detectar com boa precisão obstáculos a longas distâncias, e com suas leituras é possível determinar a forma de obstáculos e estimar as distâncias entre os mesmos. Existem três formas básicas de funcionamento para os sensores laser, (Fisher et al, 2008):

- Triangulação: neste tipo, os sensores laser e de captação do sinal são separados, um feixe de laser é projetado sobre uma superfície, o ponto criado é reconhecido pelo sensor de captação, que se encontra em uma posição diferente do sensor de feixes. Conhecendo-se as posições e orientações relativas dos sensores, é possível se encontrar a posição 3D do ponto. $\mathrm{O}$ processo de triangulação pode alcançar precisão de até 0,1 pixels.

- Modulação de fase: são sensores divididos em dois tipos onde o sinal de laser é contínuo, mas a amplitude ou a freqüência são moduladas. Considera-se o deslocamento de fase entre os sinais de saída e retorno para se determinar o tempo de transito do sinal, com isso é possível encontrar a distância percorrida pelo feixe. Normalmente a fase do sinal 
se repete a cada $2 \pi$, e estes sensores apresentam uma ambigüidade de intervalo.

- Tempo de vôo: princípio bastante conhecido, o princípio da reflexão da luz. Um feixe de laser é emitido pelo sensor, este incide sobre o objeto a sua frente e é refletido pela superfície do corpo de volta ao sensor. Como a velocidade do laser é conhecida, é medido o intervalo de tempo que o feixe demora a voltar ao sensor, e assim pode-se calcular a distância ao obstáculo.

O sensor utilizado neste trabalho, SICK LMS 291-S05, emprega a última forma para cálculo de distâncias. Para o monitoramento da área frontal do veículo em $2 \mathrm{D}$, são utilizados dados oriundos do sistema de medidas de distância SICK, montado na altura do pára-choque frontal do veículo conforme pode ser observado na Figura 2.

Este sensor é provido de um espelho giratório, onde utilizando apenas um emissor de luz é possível direcionar o feixe, e assim medir distâncias de objetos em uma faixa de $180^{\circ}$. Possui boa precisão, podendo medir distâncias com uma resolução de $10 \mathrm{~mm}$. Quando programado no alcance máximo ele consegue detectar objetos que estão distantes em até $80 \mathrm{~m}$. Outra configuração que pode ser alterada de acordo com a aplicação é o intervalo angular entre cada medida. Pode-se optar por $0,25^{\circ}, 0,5^{\circ}$ ou $1,0^{\circ}$ entre cada dado medido. Por ter sido desenvolvido inicialmente para aplicações industriais, necessita de uma alimentação de $24 \mathrm{~V} \mathrm{DC}$, sendo seu consumo de energia igual ou inferior a $20 \mathrm{~W}$. Os dados obtidos são enviados para um computador utilizando comunicação serial RS 232/RS 422 (Sick Product Database, 2009). 


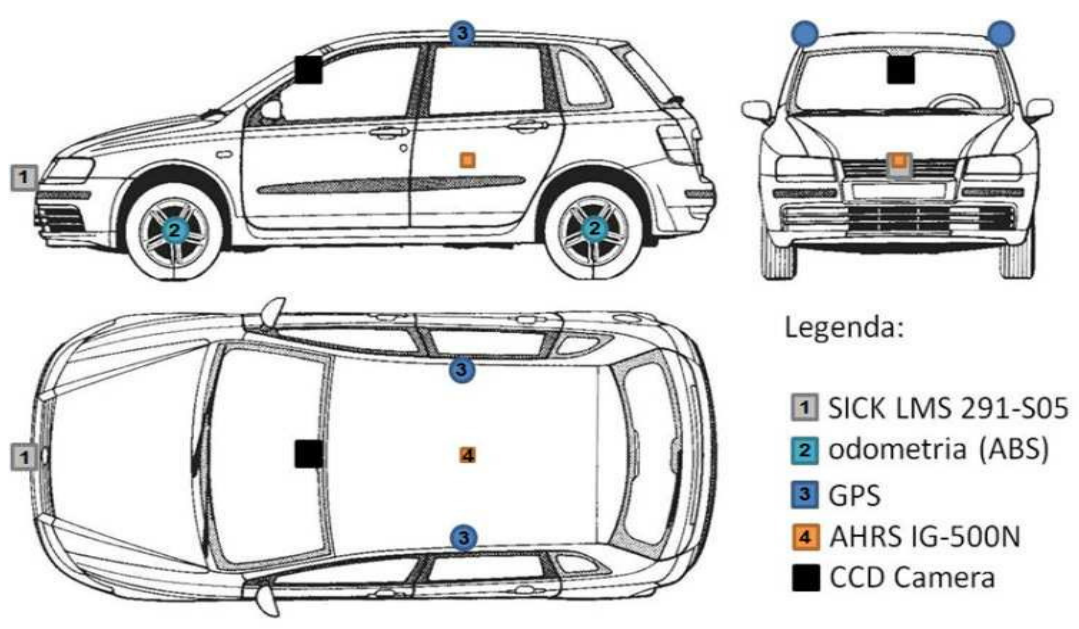

Figura 2 - Três vistas do protótipo utilizado no Projeto SENA - Sistema Embarcado de Navegação Autônoma. Detalhe do posicionamento dos sensores.

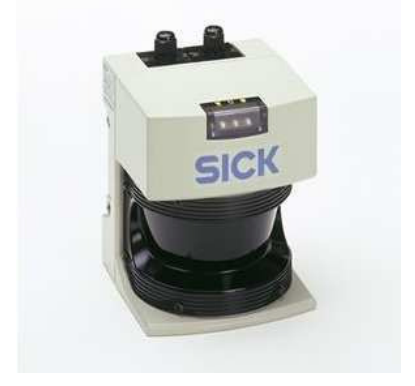

Figura 3: SICK LMS 291-S05 empregado para fazer as aquisições de dados.

\subsection{NAVEGAÇÃO}

A navegação robótica deve prover o robô com a capacidade de realizar ações planejadas de modo seguro para o robô e para o ambiente (i.e.: quaisquer obstáculos presentes como outros robôs, pessoas, móveis, paredes, veículos, etc.). As três perguntas fundamentais de Leonard e Durrant-Whyte (1992) devem ser respondidas para que um robô móvel tenha mobilidade autônoma: "Onde ele se encontra?", "Para onde vai?”, “Como fazer isso?”. Para respondê-las é necessário obter ou possuir um modelo do ambiente, observar e analisar o ambiente, encontrar a posição no mesmo e planejar e executar uma trajetória livre de colisões. Portanto, deve-se controlar o deslocamento do robô móvel de um ponto inicial até o ponto de destino, sem riscos para o robô e nem para o ambiente. 
Com os objetivos definidos, deve-se ter um fluxo de informações para executar a navegação. São necessárias a observação e extração de informações do ambiente real, formando a percepção do robô. Com esses dados são construídos o modelo do ambiente e um mapa local, constituindo assim a tarefa de mapeamento e localização. Depois de encontrada a posição do robô, inicia-se a tarefa de planejamento de trajetórias. Este tipo de tarefa pode ser executada através de mapas de um ambiente previamente conhecido ou de dados de sensores, e de decisões tomadas com base nos mesmos (Wolf et al, 2009). No controle de movimento é executada a trajetória através de comandos para os atuadores que realizarão a movimentação do robô no ambiente real. O fluxo de tarefas a serem realizadas para a navegação é apresentado na Figura 4.

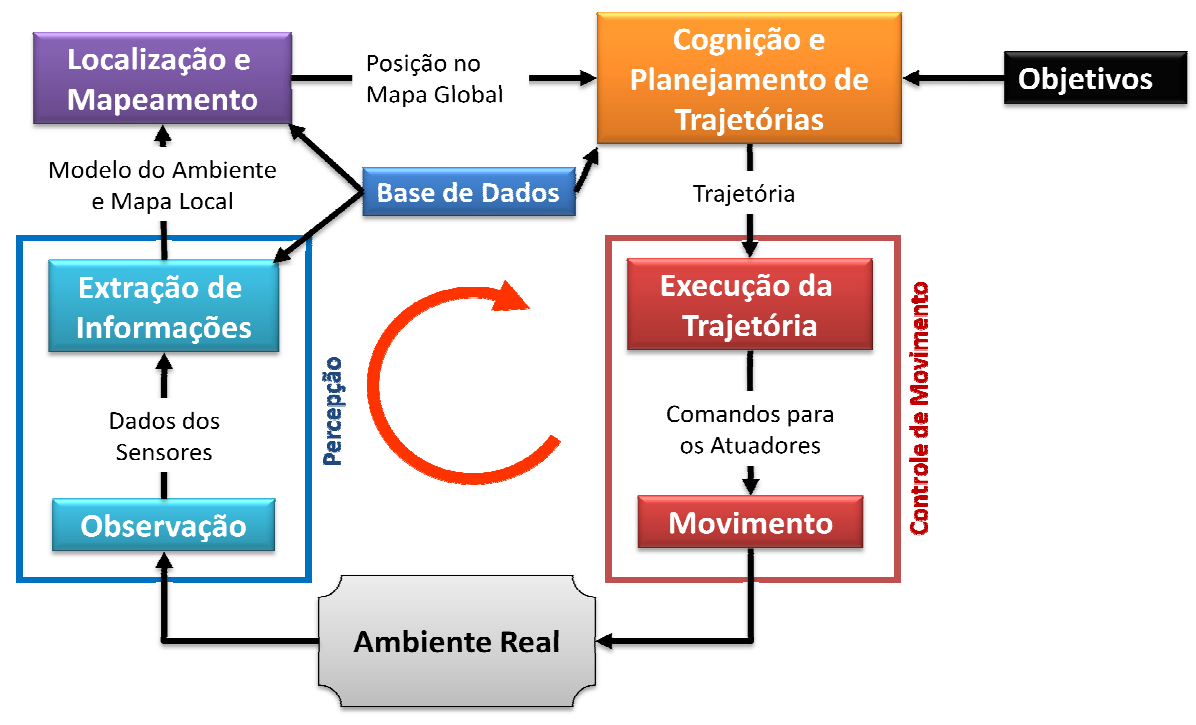

Figura 4: Fluxo de operações para navegação de robôs autônomos. Adaptado de

(Siegwart et al, 2011).

O desenvolvimento de robôs autônomos é uma grande fonte de motivação para o desenvolvimento de pesquisas em otimização de rotas e trajetórias. Neste contexto, temse que o desvio de obstáculos fixos e móveis, é um dos fatores de maior significância a serem considerados pelos sistemas de navegação (Foresti e Regazzonni, 2002). Mas deve ser ressaltado que ainda existe uma série de limitações nesta área em robôs móveis mesmo em ambientes conhecidos previamente. Isto ocorre devido às várias situações que o robô móvel se expõe, como adaptações a novos cenários do ambiente, melhores caminhos para o tráfego, ajuste das estratégias de navegação e aos recursos computacionais e de sensoriamento limitados mesmo diante do atual avanço tecnológico (Pinheiro et al 2009). 
Existem duas linhas de trabalho bem definidas em navegação encontradas na literatura: o planejamento da trajetória a ser percorrida e o desvio dos obstáculos. Vários métodos para controle de sistemas robóticos móveis têm sido desenvolvidos e geralmente são classificados em planejamento global e local (Benreguieg et al, 1997). No planejamento global, as informações são completas e os ambientes de navegação são estáticos e bem conhecidos. Por outro lado, no planejamento local, os dados são obtidos através de sensores que captam dados do ambiente, dotando o navegador de conhecimento sobre distâncias, localizações e obstáculos (Becker, 2000; Kmiotek e Ruichek, 2008). A vantagem existente em abordagens globais é que o cálculo da trajetória a ser percorrida pode ser obtido off-line. No entanto, se existirem obstáculos móveis, se o ambiente conhecido for incompleto ou sofrer mudanças durante um período de tempo, a melhor aplicação passa a ser a abordagem local. Isto ocorre pois, com os dados coletados dos sensores, o navegador poderá tomar as devidas decisões sobre a melhor trajetória, controlando o esterçamento de rodas, o ajuste de velocidades, etc.

Como o ambiente do veículo autônomo no Projeto SENA - Sistema Embarcado de Navegação Autônoma é externo, o conceito de planejamento local é utilizado, pois a navegação em um ambiente urbano é caracterizada como um problema mais complexo do que apenas seguir um conjunto de coordenadas georeferenciadas que formariam uma trajetória. Assim, além de desviar dos obstáculos (fixos e móveis) presentes ao longo da trajetória desejada (o que pode gerar um conflito de comportamento do veículo em relação aos vários obstáculos que se movem em direções e velocidades diferentes) é necessário também o reconhecimento do terreno a ser trafegado, seguir as regras de trânsito e obter a chegada do veículo à posição desejada.

Assim, deve-se frisar que, tomando-se como base a arquitetura geral de um sistema de controle de navegação (apresentada na Figura 5), esta dissertação concentrase nas tarefas de desvio de obstáculos e planejamento de trajetórias, com dados de testes realizados em ambiente similar a ambientes urbanos (a área de testes utilizada foi o campus 1 da USP em São Carlos). 


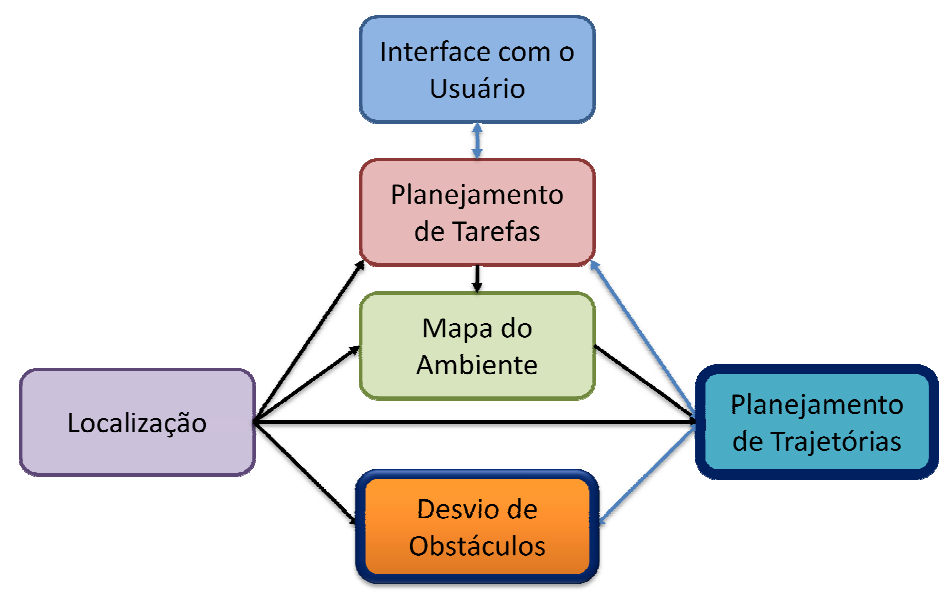

Figura 5: Arquitetura geral de um sistema de controle para robôs móveis. Em destaque o foco do trabalho desenvolvido nesta dissertação: Desvio de Obstáculos e Planejamento de Trajetórias.

\subsubsection{DETECÇÃO DE OBSTÁCULOS}

A detecção de obstáculos pode ser feita de várias formas, dependendo do tipo de sensor e mapas utilizados. Possuindo mapas globais conhecidos, os obstáculos estáticos podem ser determinados previamente, o que facilita a filtragem dos dados dos sensores. Esses mapas podem ser obtidos através de radares, imagens de satélite, utilização de câmeras embarcadas no robô, entre outros sensores. Os obstáculos estáticos podem ser determinados por extração de linhas e reconhecimento de bordas em imagens, determinação de posição entre vários dados em sensores laser $(\mathrm{Xu}$, Zhuang e Chen 2006; Yu e Zhang 2007). Depois disto, a separação entre a via a ser trafegada e o ambiente em torno do veículo pode ser realizada.

A detecção de obstáculos através de sensores laser depende do tipo de sensor empregado. Por exemplo, o número de feixes do sensor, a angulação máxima de varredura, a densidade de pontos próximos nas várias leituras, entre outros, influencia muito a estratégia a ser adotada nos algoritmos para detectar os obstáculos (Discant et al, 2007). Na maioria das pesquisas relacionadas à detecção e tracking de objetos, o maior desafio é separar objetos móveis dos estáticos. Quando o sensor se encontra parado, a detecção de obstáculos é relativamente simples, já que basta comparar duas leituras consecutivas e concluir quais pontos se moveram (Becker et al, 2009). Os dados 
que são lidos e passados ao computador consistem de medidas de distâncias feitas espaçadas do mesmo ângulo. É muito provável que dois pontos lidos pelo sensor que se encontram próximos um do outro façam parte de um mesmo corpo. Se esses pontos permanecerem juntos após algumas leituras, então eles pertencem ao mesmo objeto. Assim, pode-se concluir que se depois de alguma leitura algum ponto se separe dos outros, este não pertence ao objeto representado anteriormente. Portanto, é importante a análise de uma distância máxima entre pontos para que se possam uni-los em um mesmo grupo.

Aplicação aqui discutida é composta por um sensor embarcado em um veículo de passeio. Por esse motivo, a tarefa de detecção de obstáculos se torna mais complexa, devido aos movimentos de rotação e translação do mesmo. Como localização não é o foco deste trabalho este assunto não será discutido em detalhes aqui. Ao invés disto, deve-se destacar que uma boa estimativa de localização baseada em filtros probabilísticos é essencial para o funcionamento do sistema como um todo.

\subsubsection{TÉCNICAS DE PLANEJAMENTO LOCAL DE TRAJETÓRIAS}

As técnicas de planejamento local de trajetórias geralmente se baseiam em mapas locais. Elas podem ser implementadas como tarefas independentes e as situações de desvio de obstáculos devem levar em conta a posição final desejada, as velocidades do veículo e dos obstáculos presentes no ambiente, a dinâmica do robô durante sua movimentação, e os ricos atuais e futuros de colisões, como ilustrado na Figura 6. Nesta figura, tem-se um veículo autônomo aproximando-se de um "cruzamento em $T$ " que detecta outro veículo que também está no cruzamento. Baseado em mapas locais, nas regras de trânsito e de uma estimativa de seu posicionamento, o veículo deve planejar a ação a ser executada (p.e.: tendo ele a preferência na manobra por estar à direita, ele pode entrar no cruzamento). Mas, caso o outro veículo não respeite as regras de trânsito, ou alguma outra situação ocorra, o veículo autônomo deve também tomar alguma ação evasiva que evite um acidente (seja alterando a trajetória, seja realizando uma parada de emergência). 


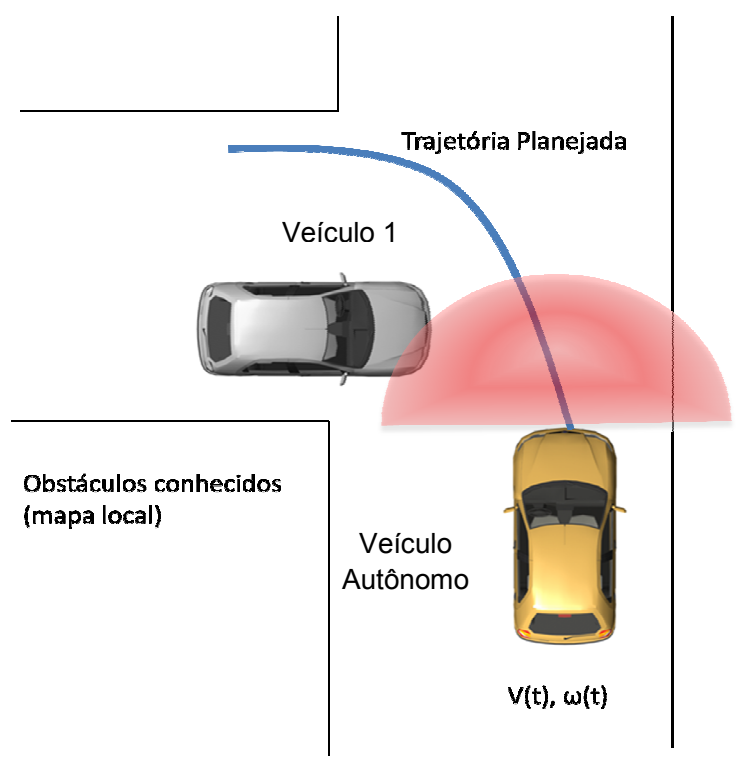

Figura 6: Planejamento Local de trajetórias.

$\mathrm{Na}$ literatura, é possível encontrar diversas técnicas clássicas empregadas em robótica móvel para auxílio na geração de trajetórias livres de colisões (Borenstein et al, 1991). Entre elas, pode-se destacar a detecção de quinas, mapas de células e campos de potencial. Moravec e Elfes (Moravec et al,1985) foram pioneiros no conceito de mapas de células (certainty grids), que é uma forma de representar um mapa da região entorno do robô por células que podem, ou não, estar ocupadas. Já o método Campos de Potencial (Moravec et al,1985 e Borenstein et al, 1991) em inglês, potential field method, é baseado na idéia de que os obstáculos exercem uma força repulsiva no robô, enquanto que a posição objetivo do robô, exerce uma força atrativa. Na década de 1990, Koren e Borenstein (Borenstein et al, 1991) desenvolveram o método de Vector Field Histogram (VFH) e, após alguns anos foi melhorado por Ulrich e Borenstein (Ulrich et al, 1998 e Ulrich et al, 2000) desenvolvendo os métodos $\mathrm{VFH}^{+}$e $\mathrm{VFH}^{*}$. O método VFH e suas variantes são baseados em um mapa local de células da região entorno do robô criado através da leitura de seus sensores embarcados.

Infelizmente, a grande dificuldade de aplicação desses métodos em ambientes urbanos, é que eles não consideram as velocidades dos obstáculos quando calculam a melhor trajetória para o robô. Isso pode gerar situações em que colisões se tornam inevitáveis. Por isso, para aplicações de robôs móveis em ambientes altamente dinâmicos são recomendados métodos chamados Steer Angle Field. Em 1997, Fox, Burgard e Thrun (Fox et al, 1997) propuseram o método Dynamic Window Approach (DWA). Nesse caso, as características cinemáticas do robô são consideradas para 
calcular um conjunto com todas as possíveis velocidades do robô $(v, \omega)$ no espaço das velocidades.

Em 1999, Brock e Khatib (Brock e Khatib, 1999) propuseram um melhoramento significativo no DWA, o Global Dynamic Window Approach (GDWA). Eles adicionaram uma técnica de expansão de bolhas em forma de ondas para encontrar rotas mínimas entre a posição atual e a desejada em mapas de células. Em 2002, o grupo de pesquisadores do Autonomous System Lab (ASL-EPFL) propôs o ASL Approach para o sistema de navegação do Robox durante o EXPO.02 (Swiss National Exhibition 2002²). Durante esta exposição 10 robôs Robox trabalharam juntos apresentado o acervo para os visitantes durante 8 horas diárias por um período de aproximadamente seis meses. No total, foram 180 mil visitantes. O ASL Approach (Philippsen et al, 2003) é basicamente a fusão entre três técnicas, DWA, Elastic Bands e NF1, que formam um sistema que executa movimentos suaves dos robôs e o direcionamento da trajetória ao objetivo.

Em sistemas de navegação cuja representação do meio é baseada em grids, existem diversas ferramentas que são empregadas para planejar o caminho de uma posição inicial para a posição desejada através da busca do menor custo (custo esse que pode ser representado por distância, tempo, energia necessária, etc.). A representação dos custos pode ser binária, em que o grid ocupado é inicializado com valor unitário (1) e o vazio como nulo, ou conter custos associados a cada grid representando o grau de dificuldade de atravessar a área representada do ambiente variando entre 0 e $1((0 ; 1))$. Muitos algoritmos encontrados na literatura utilizam esta técnica de planejamento, como por exemplo, o algoritmo A* (Nilsson, 1980) que utiliza uma heurística para focalizar a busca de um caminho mínimo de forma eficiente. $\mathrm{O}$ algoritmo Field $D^{*}$ (Ferguson e Stentz, 2005) é uma extensão do algoritmo A* que gradativamente atualiza o caminho solução de acordo com as alterações do ambiente. Este tipo de algoritmo é amplamente utilizado em robótica para a navegação de robôs móveis em ambientes desconhecidos ou dinâmicos (Ferguson et al, 2005). Esse algoritmo já foi empregado em diversas aplicações de robôs móveis, inclusive nos Rovers Spirit e Opportunity enviados a Marte (Singh et al, 2000 e Ferguson et al, 2005).

\footnotetext{
${ }^{2} \mathrm{http}: / /$ www.expo-archive.ch/eng/html/index.html?siteSect=200
} 


\subsubsection{NAVEGAÇÃO EM VEÍCULOS DE PASSEIO AUTÔNOMOS}

Com a competição DARPA (Defense Advanced Projects Research Agency) Grand Challenge que começou em 2005 (Özgüner et al, 2007), a imprensa mundial conheceu e divulgou a tecnologia de carros autônomos (entende-se por carro autônomo aquele que trafega em ambientes complexos e que toma decisões sem intervenção humana). O emprego destes veículos pode gerar, em longo prazo, condições melhores de tráfego, maior conforto no trânsito e condições de condução mais eficientes.

Já existem diversos sistemas mecatrônicos embarcados em veículos de passeio que auxiliam o motorista e aumentam a sua segurança, como por exemplo, sistemas ABS (Antilock Brake Systems), controles de velocidade de cruzeiro, assistentes de estacionamento, entre outros. Mas com as recentes pesquisas, em breve outros sistemas poderão ser adicionados, como dispositivos de alerta de colisão e sistemas de auxilio em situações de emergência (p.e.: em situações de acidente iminente em que o motorista não conseguiria evitar devido ao seu período de reação ser mais lento do que o tempo de resposta de um sistema mecatrônico, (Brookhuis et al, 2001)). Para que isso seja possível, os veículos devem ser dotados de sistemas de sensoriamento e software embarcados para percepção do ambiente e para tomada de decisão.

Há vários anos, muitas empresas do setor automotivo estão produzindo veículos com itens de auxilio a motoristas derivados de sistemas autônomos, não tirando a autonomia dos motoristas. Pode ser citado o Mitsubishi Diamante de 1995 e a Toyota que em 1996, tinham o sistema ACC (Adaptive Cruise Control). Este sistema consiste na utilização de sensores LIDAR ou radares para medição de distâncias, posições angulares e velocidades de outros veículos. Desse modo, ele se comporta como um controle de cruzeiro convencional quando uma via encontra-se livre. Se um veículo mais lento for detectado, uma distância de condução segura é assumida até que ocorram mudanças na via. Também os modelos Mercedes S-Class, o Jaguar XKR (ambos em 1999) e o BMW série 7 no início de 2000, utilizaram o sistema ACC (chamado DISTRONIC). Desde aquela época o sistema ACC teve grande aceitação em veículos de alto custo. Existem também sistemas de detecção de faixas através de câmeras para avisar condutores quando uma mudança inapropriada de faixa acontece. A utilização de sistemas de visão noturna para situações com pouca visibilidade em veículos da GM 
como em seu Lincoln Navigator empregando uma câmera de espectro infravermelho distante. Outros exemplos são o BMW série 7, de 2005 e o Mercedes S-Class, ambos com câmeras infravermelhas. Em 2002, a Honda introduziu no mercado japonês um sistema para seguir faixas, denominado HIDS (Honda Intelligent Driver Support System), combinando o ACC com um seguidor de faixas. Auxílios anti-colisão são encontrados em veículos da Honda, com ativação de sinais de aviso, e até intervenção de aceleração ou desaceleração, quando o motorista não tem reação rápida o suficiente para evitar o acidente, mesmo que isso não o evite. Em 2005, no Mercedes S-Class foi introduzido um sistema baseado em radar e assistência ativa de frenagem, para evitar colisões frontais. Sistemas de informação tipo Blind spot, que mostram quando um carro está no ponto cego evitando que o carro mude de faixa, foram introduzidos em 2006 em vários carros da Volvo utilizando câmeras de vídeo e na Audi com base em radar de curto alcance em 2005 (Özgüner et al, 2007).

$\mathrm{Na}$ área de pesquisas acadêmicas existem projetos como o francês Praxitele (Garnier et al, 1995), que consiste em uma frota de veículos elétricos para serem utilizados pela população, no lugar de transportes coletivos, evitando estacionamentos lotados. Este projeto utiliza técnicas como Lógica Fuzzy e linhas de fuga em um controle híbrido. Outro tipo de proposta com Lógica Fuzzy e controles híbridos que podem ser encontradas em (Ramírez et al, 2007, Huang et al, 2010, Long et al, 2007, Farhi, 2008 e Llorca, et al, 2011). Em pesquisas recentes pode-se encontrar na literatura algoritmos como o OTG (Optimal Trajectory Generation), aplicado no protótipo Alice, o veículo autônomo da Caltech, que participou do Darpa Urban Challenge 2007. Este é um algoritmo que trabalha on-line e foi desenvolvido para resolver o problema de trajetórias em tempo real para carros em presença de obstáculos. Ele considera vários tipos de restrições como o ângulo de direção do veículo (Schwartz et al, 2008). Pode ser citada também a utilização de sensores inerciais e visão com algoritmo de SLAM (Simultaneous Localization and Mapping), para compensar divergências na navegação inercial (Sazdovski et al, 2010). Ou a utilização de sensores multi-camada que tratam o ambiente como um grid. Isto visa facilitar a detecção de obstáculos móveis no ambiente urbano (Moras et al, 2010). Em adição a isto, tem-se o grupo Gator, da Universidade da Flórida, que em 2007 no desafio Darpa Urban Challenge, apresentou o Navigator. Este sistema também utiliza grids e sensores laser SICK LMS 291 para detecção de 
obstáculos, classificando assim as células do grid em livres e ocupadas (Yoon et al, 2008).

Podem ser encontradas na literatura várias técnicas para navegação e várias combinações entre diferentes tipos de sensores. Por exemplo, tem-se o emprego de GPS, bússola digital e sensores laser com técnica de campos potenciais, onde um carro elétrico navega em um ambiente conhecido e controlado (Wuthishuwong et al, 2009). Outro exemplo é a técnica de deformação de trajetórias, onde um caminho é calculado $a$ priori, e através de sensores, o ambiente é sempre comparado para detecção de obstáculos. Quando estes surgem, a trajetória é deformada para que o robô continue navegando (Delsart et al, 2008). E, por fim, tem-se o uso de redes neurais para geração de comandos para atuadores em veículos para que os mesmos desviem de obstáculos e alcancem seus objetivos (Farooq et al, 2010).

\subsection{CONSIDERAÇÕES FINAIS}

Neste capítulo, foi apresentada de forma sucinta a revisão bibliográfica sobre o estado da arte referente ao tema deste trabalho. Não é factível descrever todas as contribuições na solução de problemas de detecção, desvio de obstáculos e geração de trajetórias. Foi relatada a utilização de sensores laser para navegação de veículos autônomos, tanto para a detecção de obstáculos como para o reconhecimento de ambientes. No próximo capítulo serão descritas as técnicas utilizadas para o monitoramento da área frontal do veículo. 


\section{Capítulo 3}

\section{MÉTODOS}

Neste capítulo são apresentados os métodos utilizados nas rotinas que formam o algoritmo de monitoramento desenvolvido nesta pesquisa. Foram utilizadas as rotinas de Trackers, Velocity Obstacle Approach e $E^{*}$, para detecção e acompanhamento de obstáculos, determinação de direções proíbidas e cálculo de rotas seguras para o veículo.

\subsection{ESTRUTURA DO ALGORITMO DE MONITORAMENTO}

O uso de trackers (Hall, 2006) visa minimizar dificuldades encontradas em ambientes urbanos, onde é comum a situação em que veículos obstruem os sensores do robô e obstáculos antes "invisíveis”, por estarem obstruídos, aparecem subitamente, ou obstáculos antes visíveis que "desaparecem" e reaparecem subitamente após alguns instantes, podendo confundir os controladores embarcados. Essa técnica é baseada no emprego de filtros de Kalman (KF) e de Kalman Estendido (EKF) para estimar a posição de obstáculos móveis em ambientes urbanos. Basicamente, informações relativas a obstáculos móveis são extraídas dos dados dos sensores que monitoram o ambiente. Cada obstáculo é então classificado em diferentes categorias (como por exemplo: carros, motos, bicicletas, pedestres, etc.) e cada um recebe um marcador (“Tracker") que será empregado para acompanhar o obstáculo e prever sua posição e velocidade em um horizonte de tempo pré-definido (como citado anteriormente, para tal são utilizados filtros tipo KF e EKF). Caso o obstáculo não seja mais observado pelos sensores do robô, o tracker ainda é mantido, durante um intervalo de tempo também 
pré-definido, para que ele possa ser considerado no planejamento de trajetórias livres de colisões. Caso o obstáculo volte a ser observado pelos sensores, o tracker deve reconhecê-lo como sendo o obstáculo inicialmente observado e não criar um novo “tracker" para acompanhá-lo. Já o algoritmo Velocity Obstacle (Prassler et al, 1999, e Prassler et al, 2001) é uma técnica desenvolvida para a robótica móvel na década de 1990, que consiste essencialmente em três sub-algoritmos: um para detecção de movimento, outro para acompanhar, ou monitorar este movimento (motion tracking) e o último para gerar manobras evasivas que evitam colisões, baseadas na velocidade dos obstáculos monitorados. Por fim, o algoritmo $E^{*}$ (Philippsen, 2004) destina-se ao planejamento de trajetórias. Assim, gradativamente a trajetória ótima é atualizada em função das alterações observadas no ambiente pelos sensores embarcados. Este tipo de algoritmo é amplamente utilizado para a navegação de robôs em ambientes parcialmente conhecidos e dinâmicos.

É possível observar na Fig. 7 o fluxograma do algoritmo de detecção e classificação de obstáculos aplicados ao planejamento de trajetórias para veículos de passeio em ambiente urbano. Deve-se frisar que a rotina de Geração de Manobras Evasivas não foi desenvolvida neste trabalho. Nos próximos itens as três rotinas principais serão descritas.

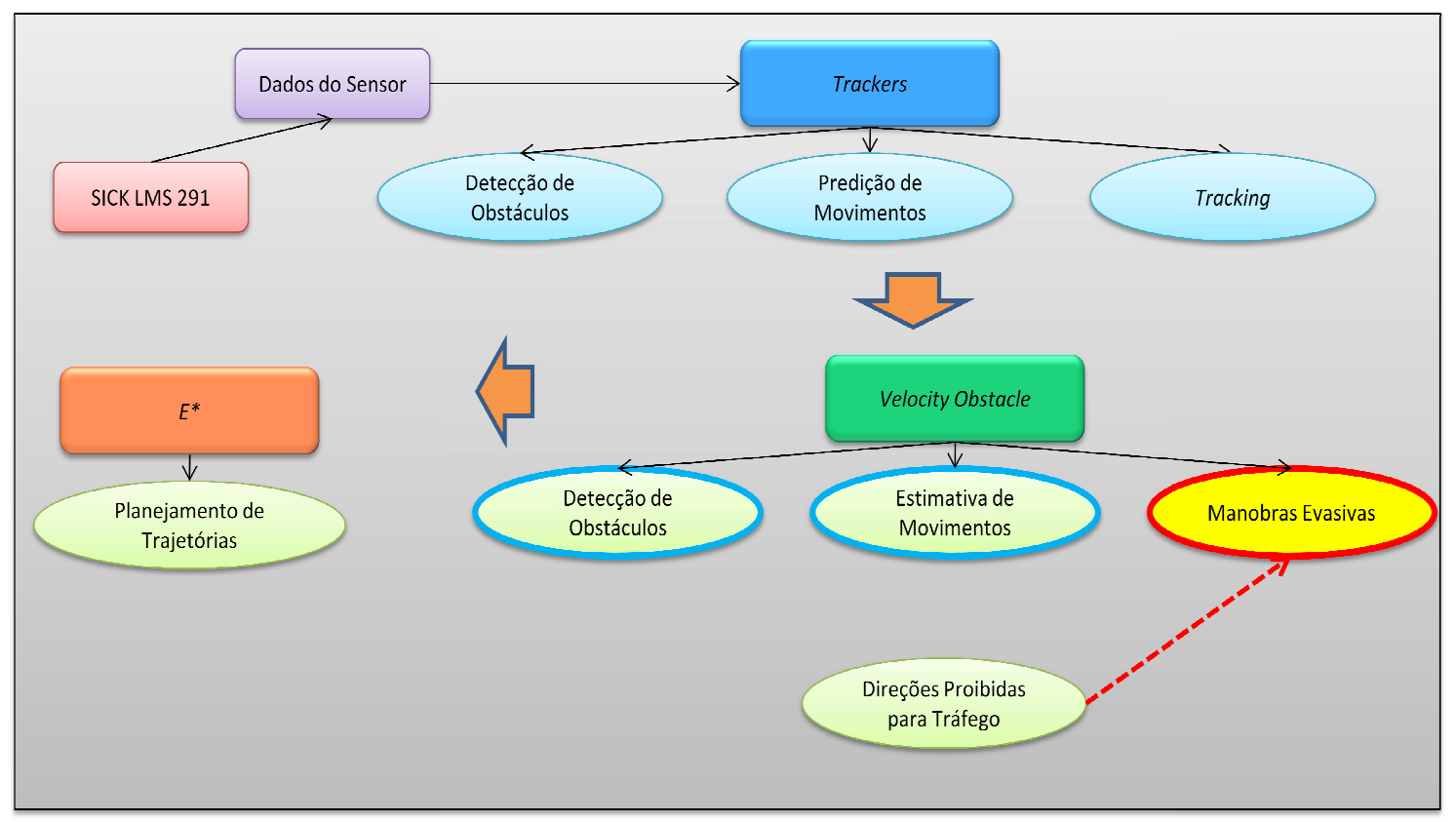

Figura 7: Fluxograma das rotinas que constituem o algoritmo desenvolvido. Sendo que o algoritmo de manobras evasivas não foi desenvolvido neste trabalho. 


\subsection{TRACKERS}

Para a aplicação da rotina de trackers baseado no trabalho de Hall (Hall, 2006), inicialmente os dados do ambiente adquiridos pelo sensor laser embarcado no veículo de testes devem sofrer um processo de segmentação (item 3.2.1). Na literatura é possível encontrar várias formas de realizar esse processo, entre elas, a segmentação por distância entre pontos (item 3.2.1.1) e a segmentação por Filtro de Kalman (item 3.2.1.2). Após os dados serem segmentados os obstáculos são detectados através de duas regras (item 3.2.2). A seguir para detecção de obstáculos móveis é utilizado um mapa bidimensional em forma de grid (item 3.2.3). Para conhecimento das características dinâmicas dos obstáculos é realizado o tracking dos mesmos (item 3.2.4), e para diminuição de ruídos nas leituras do sensor é utilizado um filtro de Kalman (item 3.2.4). Com novas medidas adquiridas os dados devem ser associados para que os obstáculos possam continuar sendo acompanhados (item 3.2.6). E finalmente, para a classificação dos obstáculos em pedestres ou veículos utiliza-se a diferenciação por tamanho (item 3.2.7).

\subsubsection{SEGMENTAÇÃO}

Os dados de leitura de sensores laser consistem em distâncias entre o mesmo e o obstáculo, medidas com resolução angular fixa (por exemplo, $1^{\circ}, 0,5^{\circ}$, etc.) e em intervalos de tempo quase constantes. Para facilitar a análise destes dados é recomendado que os mesmos sejam agrupados de forma que dados que fazem parte de um mesmo corpo pertençam a um mesmo conjunto. A esse processo de agrupamento, dá-se o nome de segmentação. Neste trabalho foi utilizado o SICK LMS 291-S05 que possui uma leitura completa em $180^{\circ}$, com seqüência ordenada de $\mathrm{N}$ pontos $(P)$, podendo ser definidos em coordenadas cartesianas $\left(x_{n}, y_{n}\right)$ ou polares $\left(r_{n}, \alpha_{n}\right)$. Assim, tem-se que (Premebida et al, 2005):

$P=\left\{P_{n}=\left(\begin{array}{l}r_{n} \\ a_{n}\end{array}\right)\right\}, n \in(1, N)$ 
Seguindo a representação ilustrada na Fig. 8, onde $\Delta \alpha$ representa a resolução angular do sensor, se o sensor fornecer uma seqüência completa de dados $(P)$, baseado na equação (1), um segmento $\left(S_{i}\right)$ pode ser descrito como:

$S_{i}=\left\{\left(x_{i}, y_{i}\right)\right.$ ou $\left.\left(r_{i}, \alpha_{i}\right), \quad i=k: n\right\}$, onde $1 \leq k<n<N$

Sendo o segmento de saída formado como pares de valores de $i$ que representam o ponto inicial e final de cada segmento detectado.

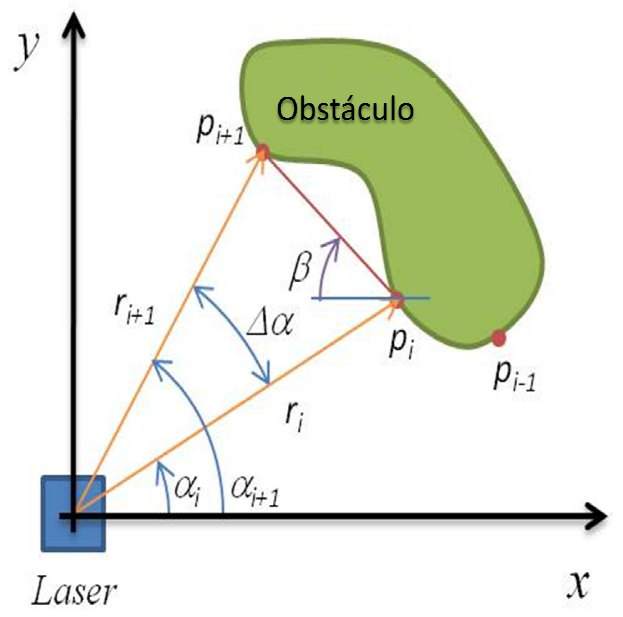

Figura 8: Representação de uma leitura do laser SICK LMS 291-S05 e alguns dos seus parâmetros.

Como citado anteriormente, os métodos de segmentação podem ser separados em dois grupos distintos para aplicações com sensores laser em 2D (Premebida e Nunes, 2005, Rebai et al, 2009):

- Segmentação baseada na distância entre pontos (Point-Distance-BaSed PDBS)

- Segmentação baseada na aplicação do Filtro de Kalman (Kalman Filter BaSed - KFBS) 


\subsubsection{SEGMENTAÇÃO BASEADA NA DISTÂNCIA ENTRE PONTOS}

Como apresentado em (Premebida e Nunes, 2005, Rebai et al, 2009 e Kheyruri e Frey, 2010), os algoritmos PDBS têm a seguinte forma geral:

Se $D\left(r_{i}, r_{i+1}\right)>D_{\text {lim }}$ tem-se que os pontos analisados não pertencem ao mesmo segmento, caso contrário os pontos pertencem a um mesmo segmento. Onde $D_{\text {lim }}$ é a distância limite máxima para que dois pontos pertençam a um mesmo segmento e $D\left(r_{i}, r_{i+1}\right)$ é a distância Euclidiana entre dois pontos consecutivos, que é dada por:

$D\left(r_{i}, r_{i+1}\right)=\sqrt{r_{i}^{2}+r_{i+1}^{2}-2 r_{i} r_{i+1} \cos \Delta \alpha}$

É possível encontrar na literatura diversas formas de determinar $D_{\text {lim }}$. Tomandose como base o que foi apresentado em (Premebida e Nunes, 2005), tem-se a seguinte definição para este valor limite:

$D_{\text {lim }}=C_{0}+C_{1} \min \left\{r_{i}, r_{i+1}\right\}$

onde: $C_{1}=\sqrt{2(1-\cos \Delta \alpha)}=D\left(r_{i}, r_{i+1}\right) / r_{i}$, e $C_{0}$ é uma constante usada para aumentar a margem de segurança e conseqüentemente reduzir a influência de ruídos.

Segundo Santos et al (2003) pode-se incluir um novo parâmetro ( $\beta$ ) na equação (4) com o intuito de diminuir a dependência do processo de segmentação em relação à distância do sensor ao objeto. Assim, a distância limite pode ser representada pela seguinte expressão:

$D_{\text {lim }}=C_{0}+\frac{C_{1} \min \left\{r_{i}, r_{i+1}\right\}}{\operatorname{cotg}(\beta)[\cos (\Delta \alpha / 2)-\operatorname{sen}(\Delta \alpha / 2)]}$

Existem outros métodos encontrados na literatura para determinar o valor de $D_{\text {lim. }}$. Um método simples para definir o $D_{\text {lim }}$ é apresentado em Lee (2001):

$D_{\text {lim }}=\left|\frac{r_{i}-r_{i+1}}{r_{i}+r_{i+1}}\right|$

Também foi proposto um método chamado de Adaptive Breakpoint Distance (ABD) que define a distância limite como (Borges et al, 2004): 
$D_{\text {lim }}=r_{i} \frac{\operatorname{sen} \Delta \alpha}{\operatorname{sen}(\lambda-\Delta \alpha)}+\sigma_{r}$

onde: $\lambda$ é um parâmetro auxiliar e $\sigma_{r}$ é a variância que endereça o comportamento aleatório da sequência dos pontos lidos pelo sensor e o ruído associado.

\subsubsection{SEGMENTAÇÃO BASEADA NO FILTRO DE KALMAN}

A segmentação baseada em Filtro de Kalman ou no Filtro de Kalman Estendido tem como objetivo detectar pontos de interrupção através de equações diferenciais estocásticas em processos dinâmicos no tempo (Premebida e Nunes, 2005). Tendo em vista que a convergência de um Filtro de Kalman depende fortemente do número de pontos pertencentes a cada obstáculo e a cada segmento, verifica-se que isso poder vir a tornar o custo computacional de seu emprego superior ao PDBS (Rebai et al, 2009). Neste, a maior dificuldade encontrada foi o ajuste de alguns parâmetros off-line e a qualidade de resultados obtida foi satisfatória, Assim, neste trabalho a aplicação do Filtro de Kalman foi descartada.

\subsubsection{DETECÇÃO DE OBSTÁCULOS}

A detecção e classificação de obstáculos em ambientes urbanos, através do emprego de sensores laser, são tarefas árduas pois, podem existir inúmeros objetos no ambiente movimentando-se em diferentes velocidades e direções. O maior desafio neste processo é a classificação dos obstáculos detectados em diferentes categorias, por exemplo, obstáculos estáticos e móveis. Para sensores fixos, esta tarefa é muito fácil, uma vez que a simples comparação entre duas leituras consecutivas pode indicar se os objetos são estáticos ou móveis. No entanto, o uso de sensores laser a bordo de veículos em movimento nas estradas torna essa tarefa mais complexa e dependente de um sistema preciso de auto-localização do veículo. Por isso, o veículo deve ter incorporado um conjunto de sensores composto por GPS, IMU, encoders, etc. para que seus dados sejam combinados através da aplicação de algum algoritmo de fusão de dados para estimar a posição do veículo. Como este não é o foco deste trabalho, este assunto não 
será discutido aqui. Mas, pode-se citar que no veículo de testes do Projeto SENA é empregado um sensor IMU (AHRS / IG-500N) que possui filtro EKF embarcado que pode combinar os seus dados com o de um GPS e estimar posição e deslocamentos com precisão na ordem de $\mathrm{cm}$.

Para a detecção dos dados dos sensores laser foram empregadas duas regras (Wang e Thorpe, 2002 e Wang, 2004).

- Regra 1: Detecção de Objetos que se aproximam Baseado em leituras anteriores, sabe-se que algum espaço não está ocupado. Se algum objeto aparece nesse espaço, este objeto deve estar em movimento. Um exemplo desse caso pode ser visto na Fig. 9, na qual se chega à conclusão que o Objeto A provavelmente está em movimento.

- Regra 2: Detecção de Objetos que se afastam

Na Fig. 9, não se pode concluir que o objeto B está se movendo. Uma vez que ele pode ser um novo obstáculo fixo que estava sendo ocultado pelo Objeto $\boldsymbol{C}$. Porém, pode-se concluir que o Objeto C está se movendo. Para realmente saber se o Objeto $\boldsymbol{B}$ é estático, são necessárias mais de duas leituras. As leituras anteriores ajudam a concluir quais são as características de $\boldsymbol{B}$.

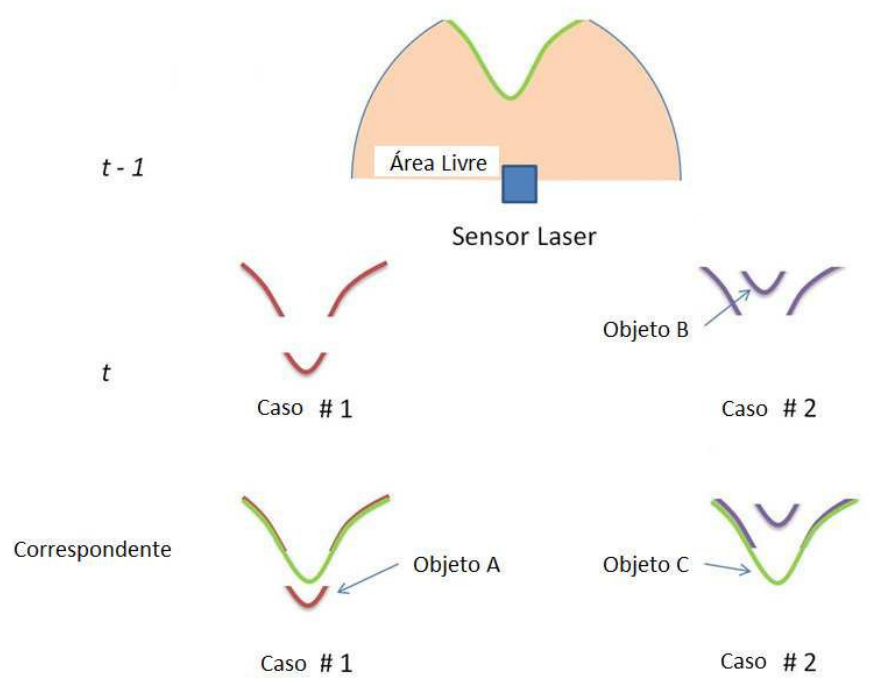

Figura 9: Regras para detecção de obstáculos. 


\subsubsection{MAPA LOCAL}

Para que o robô móvel consiga navegar em um ambiente, ele precisa saber o maior número possível de informações sobre o mesmo, e ter essas informações armazenadas de alguma forma. O mapeamento local é uma técnica muito utilizada em aplicações de SLAM (em inglês, Simultaneous Localization And Mapping), porém, nesse projeto ela será utilizada com o intuito de detectar os obstáculos dinâmicos. O método consiste basicamente em criar um mapa bidimensional do ambiente e verificar alterações nesse mapa que possam indicar a presença de obstáculos móveis. Esse mapa é representado em forma de grid, no qual cada célula contém um valor que indica a probabilidade de que exista ou não um objeto naquela posição através de interpretações das leituras do sensor empregado (Elfes, 1989).

Uma vez que o mapa é uma representação discreta do ambiente, é necessário que seja escolhido o intervalo de decomposição (“discretização"). Essa decisão se torna importante já que se deve escolher um valor adequado para a aplicação desejada. Porém, não se pode deixar de levar em conta que, quanto menor o intervalo de discretização, maior será o custo computacional. Para diminuir o custo computacional, é utilizado um mapa de tamanho determinado. Para o bom funcionamento do mapa, é necessário que exista um ponto de referência que possua uma boa precisão na localização, já que o mapa irá se movimentar junto com o sensor (fixo ao veículo de testes que se move no ambiente).

\subsubsection{TRACKING DE OBSTÁCULOS}

Uma vez que os obstáculos presentes no ambiente em que o robô se encontra foram detectados, é de extrema importância conhecer as características dinâmicas dos mesmos. Essas características são necessárias para que seja feito o planejamento de trajetória e, dessa forma, o robô consiga atingir o seu destino com segurança.

Siegwart, Nourbakhsh e Scaramuzza (Siegwart, Nourbakhsh e Scaramuzza, 2011) apresentam alguns métodos que são utilizados para o planejamento de trajetória. Alguns sistemas agem de maneira simplista e apenas proíbem o movimento em uma 
direção que os deixe mais próximo dos obstáculos, sem se preocupar como os obstáculos estão se movendo. Porém, para um planejamento de trajetória mais eficiente é necessário levar em consideração como os obstáculos se movem. Isso pode ser feito através da estimativa das características dinâmicas dos objetos que estão em torno do veículo. Para que o planejamento se torne ainda mais eficiente, pode-se fazer uma estimativa dos estados futuros que eles irão possuir, dessa maneira, é possível tomar decisões de forma mais antecipada diminuindo o risco de colisões (Hall, 2006).

Assim, tem-se que o tracking de obstáculos é de grande importância quando o veículo navega em um ambiente urbano, pois várias situações de risco podem ser evitadas. É comum que em alguns momentos obstáculos fiquem ocultos dos sensores embarcados no veículo devido à presença de outros obstáculos mais próximos aos sensores. Isso pode fazer com que o veículo considere que o obstáculo que está escondido não existe mais. Com o tracking, é possível continuar acompanhando obstáculos ocultos durante uma janela de tempo (por exemplo, 1 ou 2 s) e fazer uma estimativa da sua posição até que ele volte a ser detectado pelos sensores do veículo. Para tal, deve-se frisar, é necessário determinar as características dinâmicas dos obstáculos, isto é, posições e velocidades (Blanc et al, 2005). Utilizando essa técnica, o planejamento de trajetória pode ser feito de forma mais eficiente evitando colisões com obstáculos que estejam oclusos por outros.

Assim, neste trabalho assumiu-se que cada obstáculo pode ser caracterizado pelo centro de gravidade dos seus pontos que foram detectados pelo sistema de medidas de distância (é importante ressaltar que raramente o obstáculo é completamente detectado pelo sensor). Como o SICK em questão fornece uma leitura em duas dimensões do ambiente, cada obstáculo necessita de duas coordenadas para que sua posição no espaço esteja bem determinada. Tendo em vista que se deseja informações relativas também ao modo com o qual os obstáculos se movem, também é necessário determinar as componentes da velocidade em $x$ e em $y$. Essas características são representadas em um único vetor que determina o estado do obstáculo. Esse vetor é dado por:

$\vec{v}_{\text {estado }}=\left(\begin{array}{c}x \\ v_{x} \\ y \\ v_{y}\end{array}\right)$ 
Por simplicidade, a partir de agora esse vetor será denotado apenas por $x$. O vetor que contém as medições nas coordenadas $x$ e $y$ será o vetor $z$.

No tipo de ambiente em que o veículo de testes se movimenta, as medições realizadas pelo sensor laser são muito susceptíveis a presença de ruídos. Para que a influência desses ruídos nos comportamento do algoritmo seja minimizada é utilizado um Filtro de Kalman.

\subsubsection{FILTRO DE KALMAN}

O filtro de Kalman (Kalman, 1960) é uma técnica amplamente utilizada quando é necessário prever os estados futuros de um sistema dinâmico a partir de medições com ruído. Ele funciona de forma recursiva, onde são utilizadas as medições do passo anterior para realizar uma estimativa das características dinâmicas do sistema no próximo passo. Assim, é possível resolver os problemas repetidamente somente tratando as saídas do mesmo processo.

O filtro consiste basicamente de duas etapas. Em primeiro lugar, uma estimativa é feita com base nas características dinâmicas do sistema tendo em vista os dados do passo anterior. Então, ele executa uma atualização da estimativa baseada em dados de uma nova medição. É necessário destacar que os filtros de Kalman são recomendados apenas para sistemas lineares. Se o sistema não é linear, o uso de filtros mais complexos, como o EKF, ou o Unscented Kalman Filter (UKF), é recomendado. Deste ponto em diante, os vetores de estado e de medição estimados serão denotados, respectivamente, por $\hat{x}$ e $\hat{z}$.

Para a implementação do filtro de Kalman visando a predição dos obstáculos é necessária a adoção de um modelo dinâmico para o sistema em questão. Neste trabalho foi utilizado o modelo apresentado por (Kohler, 1997) e (Jensen, 2004) e já utilizado em (Becker et al, 2009). Este modelo baseia-se no fato de que o sistema a ser modelado possui uma velocidade linear constante. Neste trabalho esta é uma aproximação factível, tendo-se em vista que os dados do sensor são adquiridos a uma taxa de $75 \mathrm{~Hz}$. Logo, as variações entre as velocidades dos obstáculos entre 2 medidas consecutivas dos sensores laser são muito pequenas. Desta forma, as equações que descrevem esse modelo são 
lineares e pode-se aplicar o filtro de Kalman com facilidade. As matrizes de transição de tempo discreto e de covariância do ruído do filtro são dadas, respectivamente, por:

$F(\Delta t)=\left(\begin{array}{cccc}1 & \Delta t & 0 & 0 \\ 0 & 1 & 0 & 0 \\ 0 & 0 & 1 & \Delta t \\ 0 & 0 & 0 & 1\end{array}\right)$

$Q(\Delta t)=\left(\begin{array}{cccc}\Delta t^{3} / 2 & \Delta t^{2} / 2 & 0 & 0 \\ \Delta t^{2} / 2 & \Delta t & 0 & 0 \\ 0 & 0 & \Delta t^{3} / 2 & \Delta t^{2} / 2 \\ 0 & 0 & \Delta t^{2} / 2 & \Delta t\end{array}\right)$

$\mathrm{Na}$ literatura, é possível encontrar outros modelos que podem ser usados. Um deles é a velocidade angular constante e produz uma estimativa mais precisa do movimento de veículos durante a realização de curvas. No entanto, o sistema de equações utilizadas neste modelo é não-linear, de modo que seria necessário o emprego do EKF, a fim de prever os estados do veículo. Como o EKF é mais complexo e computacionalmente mais "custoso" quando comparado com o filtro de Kalman, decidiu-se manter o uso de um modelo mais simples e de dinâmica mais genérica para os obstáculos. Outro benefício em utilizar um modelo mais simples e genérico é o fato de que se está lidando com obstáculos que apresentam características dinâmicas distintas, como é o caso de carros e pedestres. Uma vez que essas matrizes foram fixadas, a evolução do sistema dinâmico pode ser descrita pelas equações:

$x(t+\Delta t)=F(\Delta t) x(t)+u(t+\Delta t)$

$z(t+\Delta t)=H x(t+\Delta t)+w(t+\Delta t)$

onde: $u$ representa o ruído do processo, $w$ o ruído da medição e $H$ a matriz de medição, a qual faz a transformação de um vetor de estado em um vetor de medição e é dada por:

$H=\left(\begin{array}{llll}1 & 0 & 0 & 0 \\ 0 & 0 & 1 & 0\end{array}\right)$

Inicia-se a partir de agora a etapa de predição do filtro de Kalman, onde o estado estimado passado medido no intervalo de tempo, $\Delta t$, vai ser utilizado para fazer uma nova estimativa. Também são realizadas predições da covariância do estado, $P$, e da covariância da inovação, $S$. A matriz de inovação representa o erro encontrado entre o 
valor estimado e o medido. Assim, a etapa de previsão é calculada com base nas seguintes equações:

$\hat{x}(t+\Delta t)=F(\Delta t) \hat{x}(t)$

$\hat{z}(t+\Delta t)=H \hat{x}(t+\Delta t)+Q(\Delta t)$

$P(t+\Delta t)=F(\Delta t) P(t) F(\Delta t)^{T}$

$S(t+\Delta t)=H P(t+\Delta t) H^{T}+R$

A matriz $R$ representa a covariância do ruído da medição e é calculada pelo produto da variância pela matriz identidade, $R=I \sigma^{2}$. Visando a melhoria da estimativa já realizada, é utilizada uma nova medição do sensor tornando a predição mais precisa. Esse é o passo de atualização do filtro de Kalman. A inovação, v, pode então ser calculada como a diferença entre a o valor obtido na nova leitura e o valor estimado no passo anterior. Assim, o ganho do filtro, $W$, é obtido utilizando a covariância do estado e da inovação estimadas no passo anterior. Dessa forma, a predição pode ser atualizada com base nas seguintes equações:

$v(t+\Delta t)=z(t+\Delta t)-\hat{z}(t+\Delta t)$

$W(t+\Delta t)=P(t+\Delta t) H^{T} S^{-1}(t+\Delta t)$

$\hat{x}(t+\Delta t)=\hat{x}(t+\Delta t)+W(t+\Delta t) v(t+\Delta t)$

$P(t+\Delta t)=P(t+\Delta t)-W(t+\Delta t) S(t+\Delta t) W^{T}(t+\Delta t)$

\subsubsection{ASSOCIAÇÃO DOS DADOS E CLASSIFICAÇÃO DE OBSTÁCULOS}

Como novas medidas vão sendo adquiridas a cada varredura do laser (lembrando que o sensor empregado tem uma taxa de aquisição de $75 \mathrm{~Hz}$ ), elas devem ser associadas a um determinado tracker. Na literatura são descritos alguns métodos existentes para a associação de dados em diferentes condições. Um desses métodos é conhecido por “Joint Probability Method”. Este método é geralmente aplicado quando a aquisição de 
dados é realizada em ambientes com multidões ou tumultuados (por exemplo, estações de trens, metrô, etc.) porque ele considera que os dados mais próximos nem sempre pertencem a um mesmo obstáculo que está sendo seguido. Entretanto, percebe-se que o mais compatível com o ambiente estudado (ambiente urbano, ruas, estradas, etc.) é o "Nearest-Neighbor Standard Filter", (NNSF), que consiste na análise de distâncias entre os obstáculos já detectados e as novas medições. Para a escolha de um método que apresentasse resultados coerentes, foram levadas em consideração algumas limitações no ambiente em que o tracker trabalha. As principais limitações são listadas a seguir (Hall, 2006):

- Apenas uma quantidade limitada de obstáculos detectados é relevante no mesmo intervalo de tempo em função do alcance do sensor e às regras de trânsito, como por exemplo, mão e contra mão de vias, faixas de pedestres, paragem obrigatórias, preferências em cruzamentos e rotatórias, etc.;

- Na maioria dos casos, os obstáculos estão suficientemente distantes um dos outros;

- Se houver qualquer dúvida na associação de dados, é preferível o sistema continuar o acompanhamento de vários obstáculos até ter certeza de que eles são na realidade o mesmo obstáculo.

Assim, o sistema aplica iterativamente o NNSF e calcula todas as distâncias entre os obstáculos rastreados e as novas medições. A distância entre eles é então calculada pela distância de Mahalanobis, $m=v S^{-1} v^{T}$. Onde $m$ é a distância de Mahalanobis, $v$ a inovação, $S^{-1}$ é a matriz inversa da covariância da inovação, e $v^{T}$ é a matriz transposta da inovação, todas vindas do Filtro de Kalman. Dessa forma, cada tracker é associado às novas medições mais próximas que estejam dentro de uma faixa de valores limite pré-definida.

Para que seja possível realizar o acompanhamento e predição dos obstáculos, deve-se classificá-los em classes diferentes a fim de que se possa escolher o modelo dinâmico mais adequado. Como os principais atores em ambientes urbanos são veículos (carros, ônibus, motocicletas etc.) e pessoas, os obstáculos serão classificados nestas duas classes: veículo e pedestre. 
Analisando-se os dados fornecidos por sensores laser em ambientes urbanos, verifica-se que há uma diferença marcante entre as dimensões dos conjuntos de dados segmentados que compõem as classes de veículos e pedestres. Em todas as leituras em que foram identificados pedestres estes apareciam na maioria das vezes como dois ou três dados apenas. Isso acontece devido ao fato de que o sensor estava posicionado a uma altura de aproximadamente $0,5 \mathrm{~m}$ e conseguia capturar apenas a região das pernas dos pedestres (Mendes et al, 2004, Becker et al, 2007). Para distinguir entre os tipos de obstáculos decidiu-se diferenciá-los pelo tamanho. Isso pode ser feito através do cálculo do desvio padrão dos pontos de um mesmo obstáculo:

$\mu_{X}=\frac{1}{n} \sum_{i=1}^{n} x_{i}$

$\mu_{Y}=\frac{1}{n} \sum_{i=1}^{n} y_{i}$

$\sigma_{X}^{2}=\frac{1}{n} \sum_{i=1}^{n}\left(\mu_{X}-x_{i}\right)^{2}$

$\sigma_{Y}^{2}=\frac{1}{n} \sum_{i=1}^{n}\left(\mu_{Y}-y_{i}\right)^{2}$

Nas equações acima, $x$ e $y$ são as coordenadas dos pontos medidos de um determinado obstáculo, $n$ é o número de pontos que foram detectados como sendo dele, $\mu$ é o valor da média e $\sigma$ é o desvio padrão dos pontos.

Calculando a norma do desvio padrão, conseguiu-se comparar com valores previamente ajustados a fim de determinar se o objeto poderia ser classificado com veículo ou pedestre. Esses valores foram obtidos através da realização de testes experimentais.

Norma $=\sqrt{\sigma_{X}^{2}+\sigma_{Y}^{2}}$

\subsubsection{TRAJETÓRIA DE OBSTÁCULOS - NUVEM DE PROBABILIDADES}

Para que se possa melhorar o planejamento de trajetória, é possível aplicar modelos dinâmicos aos obstáculos e dessa forma, definir regiões cujas probabilidades de serem ocupadas por obstáculos no futuro são maiores. Faz-se isso calculando 
possíveis posições futuras para os obstáculos e adicionando incertezas em intervalos de tempo futuros.

Neste contexto, tem-se que modelar os movimentos de pessoas é uma tarefa extremamente difícil, já que seus movimentos podem ser imprevisíveis. Por exemplo, uma pessoa pode parar ou mudar a direção de movimento de repente. Porém, como as pessoas se movimentam com uma velocidade relativamente pequena, a aplicação do modelo de velocidade linear constante se mostra eficaz para prever seus movimentos.

Para os carros será utilizado um modelo simplificado apresentado em (Becker et al, 2009 e Hall, 2006). Esse modelo é baseado no fato de que grande parte dos carros utiliza apenas as rodas da frente para fazer curvas, e o ângulo de esterçamento, $\theta$, tem valores muito menores que $90^{\circ}$. Quando o veículo mantém um ângulo de esterçamento constante, ele descreve uma trajetória circular. A figura abaixo apresenta os parâmetros que descrevem o modelo.

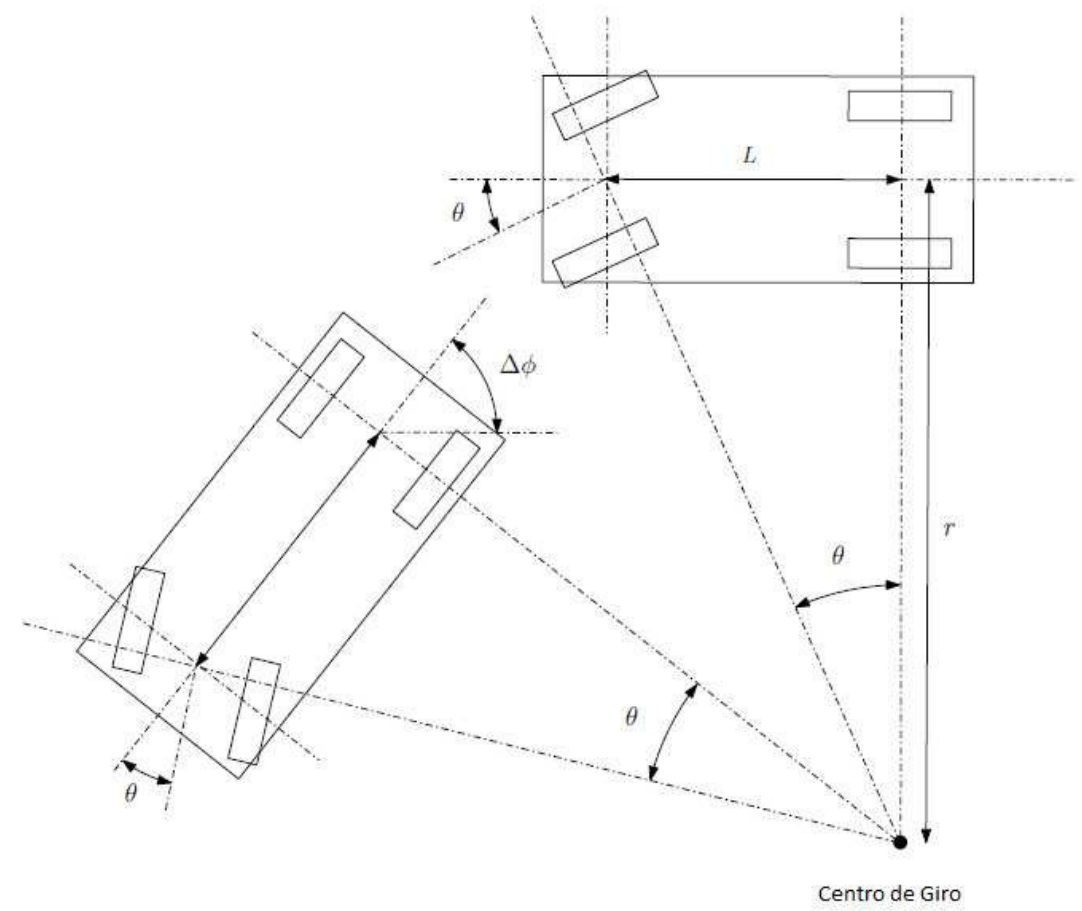

Figura 10: Modelo genérico de um carro com esterçamento frontal.

Observando a Fig. 10 e aplicando conceitos de geometria, é possível chegar a seguinte relação:

$\tan \theta=\frac{L}{r}$ 
onde: $L$ é a distância entre a roda dianteira e traseira e $\mathrm{r}$ é o raio da curva descrita pelo veículo. A distância percorrida pelo veículo através do arco de circunferência pode ser dada por:

$\mathrm{d}=\Delta \phi \cdot \mathrm{r}$

onde: d é a distância percorrida ao longo do caminho circular e $\Delta \phi$ é a mudança de orientação do veículo. Das equações de cinemática do movimento circular obtém-se:

$\omega=\frac{\mathrm{v}}{\mathrm{r}}$

E combinando as equações (27) e (29) obtém-se a seguinte equação:

$\omega=\frac{\mathrm{v}}{\mathrm{L}} \tan \theta$

A Eq. (30) mostra que se pode calcular a velocidade angular de um veículo conhecendo sua velocidade, ângulo de esterçamento e a distância entre seus eixos. Sabese que a distância entre-eixos dos carros varia bastante, porém é possível utilizar um valor médio que seja satisfatório para todos os veículos. A fim de simplificar o modelo, um ângulo de esterçamento máximo das rodas de veículos foi criado definido. Outra restrição que foi aplicada para limitar o modelo foi o fato de que ângulos agudos na direção do veículo são improváveis em alta velocidade. Isto está relacionado a aceleração centrípeta, pois, estendendo-a ao extremo, o carro poderia passar a tomar uma curva íngreme com velocidade muito alta. A equação para a aceleração centrípeta é:

$a_{c}=\frac{v^{2}}{r}$

Combinadas as equações (29) e (31):

$\omega_{\max }=\frac{a_{c_{\max }}}{v}$

A velocidade angular máxima angular é agora dada como o menor valor a partir das equações (30) e (32). Então é escolhido um número de valores no intervalo $\left(\omega_{\max }, \omega_{\min }\right)$ e então são calculados os caminhos previstos para cada um dos obstáculos, isso nos dá um conjunto de localizações possíveis. Uma limitação no tracker é que ele não fornece velocidade angular para as pistas. A fim de fazer isso com precisão, uma aplicação do Filtro de Kalman Estendido se torna 
necessária, mas não é utilizada neste trabalho. Por esta razão, são utilizadas as mudanças de velocidade prevista de cada obstáculo rastreado a fim de estimar as velocidades angulares dos obstáculos. Assim, as faixas previstas centram-se na taxa de esterçamento estimatimada (Fig. 11). O valor maior probabilidade é atribuído para a

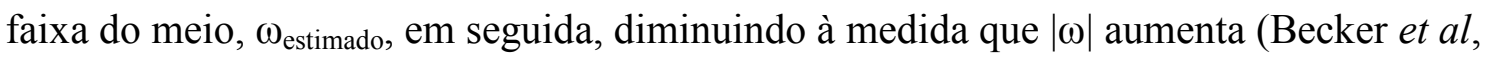
2007).

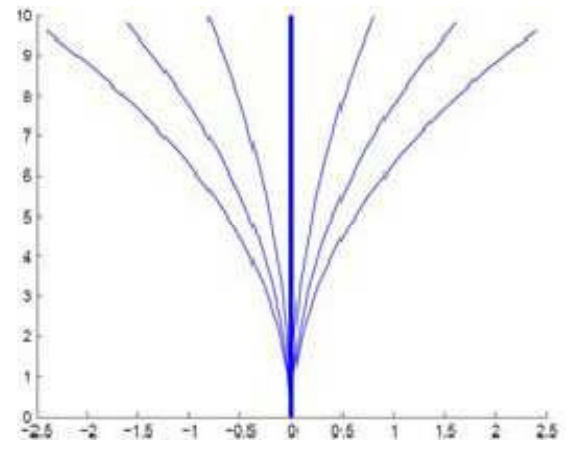

(a)

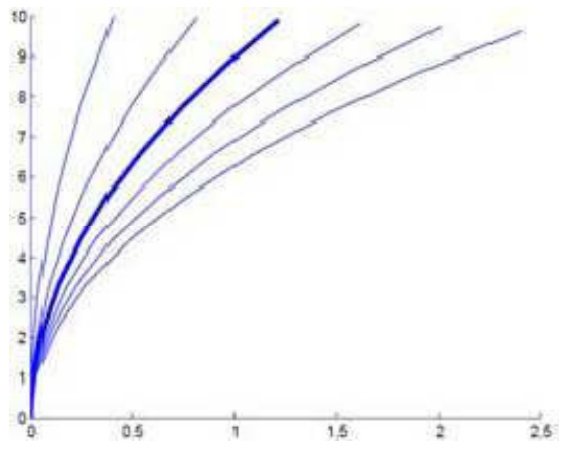

(b)

Figura 11: Caminhos previstos para os obstáculos detectados. Em (a) o curso do obstáculo está ao longo do eixo y, com apresentação de 7 caminhos possiveis, que vão da esquerda para a direita considerando os ângulos de direção máxima. Em (b), estimação do ângulo de direção atual e os caminhos previsto com base neste (Becker et al, 2007).

Com os pré-caminhos obtidos, uma série de pontos eqüidistantes é escolhida para formar as possíveis posições dos obstáculos móveis, tratada aqui como nuvem de probabilidades. Todos esses novos valores no grid são armazenados em um mapa novo, assim é possível ter um mapa de leitura e um mapa com os pesos alterados com as posições futuras estimadas para que os cálculos de rota possam ser otimizados.

\subsection{VELOCITY OBSTACLE APPROACH}

O Velocity Obstacle Approach (VOA) foi proposto inicialmente por Fiorioni e Shiller (Fiorini et al, 1993), mas Prassler, Scholz, entre outros (Prassler et al, 1999, e Prassler et al, 2001) propuseram alguns melhoramentos posteriormente. Esse método foi implementado na década de 1990 no MAid - uma cadeira de rodas robótica capaz de movimentar-se em áreas estreitas, largas e até mesmo em estações de trem na hora do rush, desviando de forma autônoma de pedestres e outros obstáculos. O VOA consiste basicamente em três algoritmos: um para detecção de obstáculos, outro para 
monitoramento (motion tracking) e o último para geração de manobras evasivas através do controle de velocidade do robô (sua estrutura é apresentada na Fig. 12). Inicialmente é preciso obter um Cone de Colisão especifico para cada par veículo-obstáculo. Feito isto, calcula-se a condição equivalente para a velocidade absoluta do veículo.

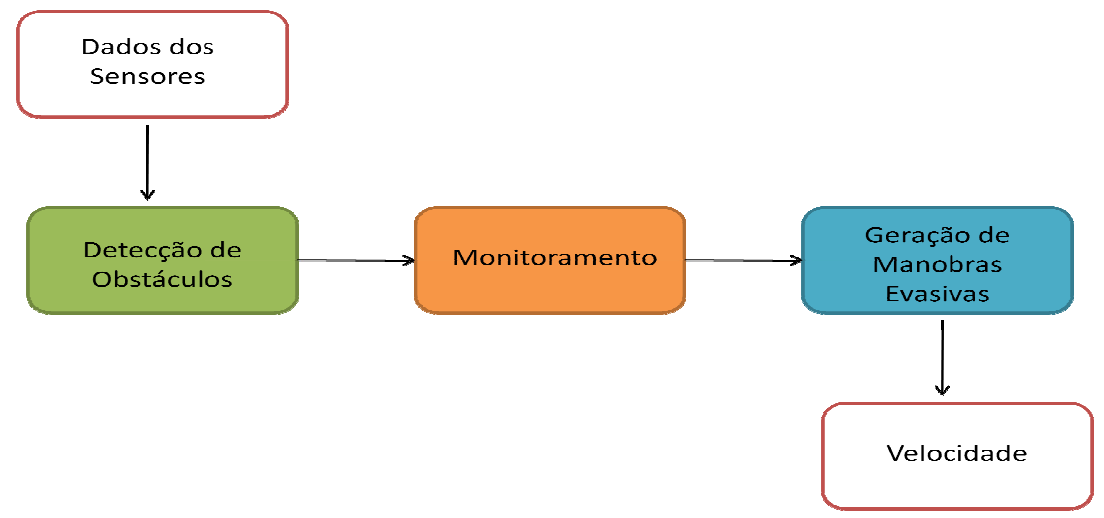

Figura 12: Estrutura do Velocity Obstacle Approach.

Por simplicidade, tanto o veículo, como todos os obstáculos (móveis e estacionários) são modelados como circunferências que levam em consideração suas dimensões reais. Dado um cenário com a presença de um veículo e um obstáculo, ambos são respectivamente representados pelos círculos $A$ e $B_{i}$, como mostrado na Fig. 13. Tem-se que num instante de tempo $t_{0}$, ambos têm velocidades representadas por $V_{A}$ e $\mathrm{V}_{\mathrm{Bi}}$. Assim, assumindo a representação do veículo como um ponto material (Â), é necessário que o raio do círculo $\mathrm{B}_{\mathrm{i}}$ (que representa o obstáculo) seja aumentado do valor do raio de $\mathrm{A}$, resultando no círculo $\hat{\mathrm{B}}_{\mathrm{i}}$. Assim:

$\hat{\mathrm{r}}_{\mathrm{Bi}}=\mathrm{r}_{\mathrm{Bi}}+\mathrm{r}_{\mathrm{A}}$

Depois que o cone de colisão $\left(\mathrm{CC}_{\mathrm{ABi}}\right)$ é calculado, ele é definido como o conjunto de velocidades de colisão entre $\hat{\mathrm{A}}$ e $\hat{\mathrm{B}}_{\mathrm{i}}$ :

$$
\mathrm{CC}_{\mathrm{ABi}}=\left\{\mathrm{V}_{\mathrm{ABi}} \mid \lambda_{\mathrm{ABi}} \cap \hat{\mathrm{B}} \neq \emptyset\right\}
$$

onde: $\mathrm{V}_{\mathrm{ABi}}$ é a velocidade relativa de $\hat{\mathrm{A}}$ com relação a $\hat{\mathrm{B}}_{\mathrm{i}}$ que é definida como:

$$
\mathrm{V}_{\mathrm{ABi}}=\mathrm{V}_{\mathrm{A}}-\mathrm{V}_{\mathrm{Bi}}
$$




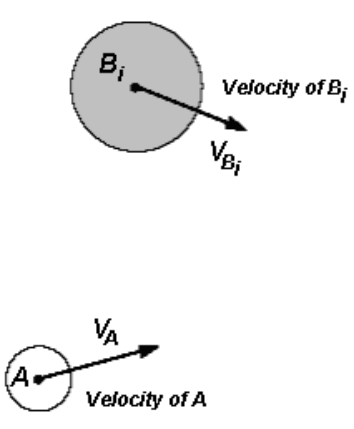

(a)

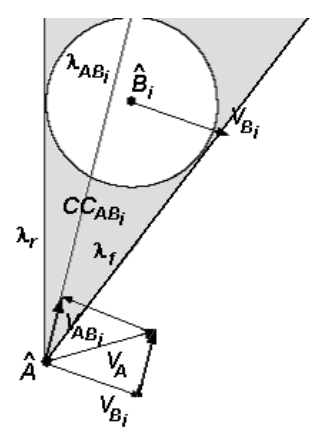

(b)

Figura 13: Ilustração do Velocity Obstacle Approach. Em (a) o veículo é representado por A e o obstáculo, por $B_{i}$. Em (b), o cone de colisão entre Â e $\hat{B}_{i}: C C A B_{i}$ (Megda, Esteves e Becker,

$\mathrm{Na}$ Figura $13, \lambda_{\mathrm{ABi}}$ é a linha de $\mathrm{V}_{\mathrm{ABi}}$. $\mathrm{O}$ cone $\mathrm{CC}_{\mathrm{ABi}}$ é representado pela área cinza com vértice em $\hat{A}$, margeado pelas duas tangentes $\lambda_{\mathrm{f}}$ e $\lambda_{\mathrm{r}}$ de $\hat{\mathrm{A}}$ a $\hat{\mathrm{B}}_{\mathrm{i}}$ (concêntricos a $\mathrm{B}_{\mathrm{i}}$ ), como mostrado na Figura 13-b. O cone de colisão representa o conjunto de velocidades relativas entre $\hat{A}$ e $\hat{B}_{i}$ que provocarão uma colisão. Com essa representação, qualquer velocidade relativa que esteja entre as duas tangentes a $\hat{B}_{i}, \lambda_{f}$ e $\lambda_{r}$ causará uma colisão entre $\mathrm{A}$ e $\mathrm{B}_{\mathrm{i}}$. Como $\mathrm{CC}_{\mathrm{ABi}}$ é específico para cada par veículo / obstáculo, para uma situação com múltiplos obstáculos, é mais simples calcular a melhor velocidade $\mathrm{V}_{\mathrm{A}}$ utilizando $\mathrm{VO}_{\mathrm{Bi}}$ ao invés de $\mathrm{CC}_{\mathrm{ABi}}$. $\mathrm{O} \mathrm{VO}_{\mathrm{Bi}}$ é obtido então pela translação do conjunto $\mathrm{CC}_{\mathrm{ABi}}$ entre os pontos $\mathrm{A}$ e $\mathrm{B}_{\mathrm{i}}$, pelo vetor $\mathrm{V}_{\mathrm{Bi}}$ :

$$
\mathrm{VO}_{\mathrm{Bi}}=\mathrm{CC}_{\mathrm{ABi}} \oplus \mathrm{V}_{\mathrm{B}}
$$

onde: $\oplus$ representa o operador soma vetorial de Minkowski ${ }^{3}$.

Após isso, cada $\mathrm{VO}_{\mathrm{Bi}}$ é combinado para formar:

$\mathrm{VO}=\cup_{\mathrm{i}=1}^{\mathrm{n}} \mathrm{VO}_{\mathrm{Bi}}$

onde: $\mathrm{n}$ é o número de obstáculos.

\footnotetext{
${ }^{3}$ A soma de Minkowiski de dois conjuntos A e B consiste de todos os pontos $\mathrm{c}$ que podem ser expressos como uma adição vetorial algébrica $\mathrm{c}=\mathrm{a}+\mathrm{b}$, onde os vetores $\mathrm{a}$ e $\mathrm{b}$ pertencem aos conjuntos $\mathrm{A}$ e $\mathrm{B}$, respectivamente. Se $A_{b}=\{a+b: a \in A\}$ denota que a translação do conjunto A pelo vetor $\mathrm{b}$, então a soma de Minkowski de A e B é igual ao conjunto união de todas as translações de $\mathrm{A}_{b}$ de $\mathrm{A}$, onde o vetor $\mathrm{b}$ varre o conjunto B (http://www.unibratec.com.br/revistacientifica/n1_artigos/n1_madruga.pdf, http://www.cgal.org/Manual/latest/doc_html/cgal_manual/Minkowski_sum_2/Chapter_main.html ).
} 


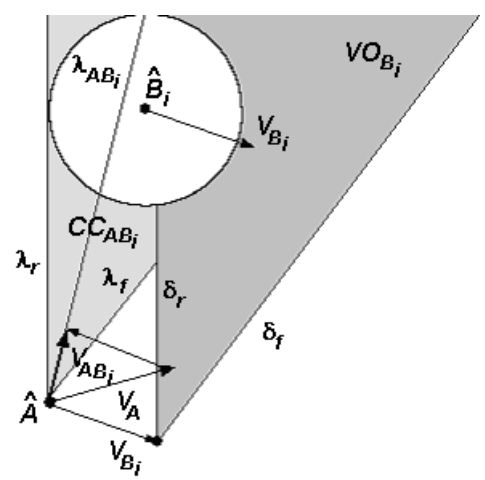

(a)

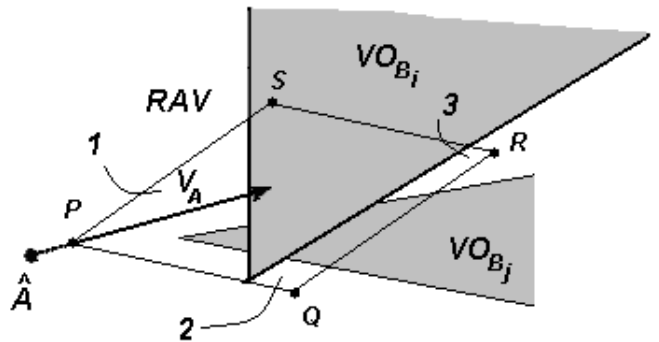

(b)

Figura 14: Ilustração Final do conjunto $V O B_{i}$ do Velocity Obstacle Approach (a). Em (b) é apresentado o conjunto de velocidades que podem ser atingidas (RAV): área interna ao polígono PQRS (Becker, Dantas e Macedo 2005).

O VO de A com relação ao obstáculo B é representado na Figura 14-a pela área cinza escura. Os vetores velocidade $\mathrm{V}_{\mathrm{A}}$ que estiverem dentro do conjunto $\mathrm{VO}$ são denominados velocidades perigosas, pois causarão uma colisão futura com os obstáculos. Por outro lado, os vetores velocidade $\mathrm{V}_{\mathrm{A}}$ que estiverem fora do conjunto VO, evitarão qualquer colisão. Vetores velocidade que atinjam a borda do conjunto VO, produzirão uma trajetória que margeará os obstáculos $\mathrm{B}_{\mathrm{i}}$. Assim, o uso desse método com um horizonte de tempo, $T_{h}$, garantirá que não ocorrerão colisões para instantes de tempo $\mathrm{t}<\mathrm{T}_{\mathrm{h}}$. Para garantir que as manobras podem ser executadas pelo veículo, deve-se considerar as características do mesmo, ou seja, deve-se verificar se o veículo possui o torque necessário para acelerar / frear de modo a atingir as velocidades desejadas no intervalo de tempo necessário para evitar as colisões. Assim, de modo similar ao DWA (Fox, Burgard, e Thrun, 1997), emprega-se um polígono que representa o conjunto de velocidades possíveis de serem atingidas (RAV - Reachable Avoidance Velocities), Fig. 14-b. As posições dos vértices $\mathrm{P}, \mathrm{Q}, \mathrm{R}$, e $\mathrm{S}$ dependem das velocidades e acelerações máximas que podem ser atingidas. Observando a Figura 14-b, verifica-se que o RAV pode ser composto por muitas áreas diferentes, na figura, pelas áreas 1 a 3. Essas áreas vão produzir diferentes comportamentos na trajetória do veículo. Por exemplo, sendo $\mathrm{V}_{\mathrm{A}}$ a velocidade atual do veículo, se o vetor velocidade escolhido para a manobra estiver posicionado na área 1 , isso resultará em desacelerar o veículo, para ficar atrás dos obstáculos $B_{i}$ e $B_{j}$. Por outro lado, selecionando velocidades em 2 ou 3 resultará em acelerar o veículo para ultrapassar o obstáculo $B_{j}$ pela esquerda, ou pela direita. $A$ escolha da velocidade é baseada em regras heurísticas. 


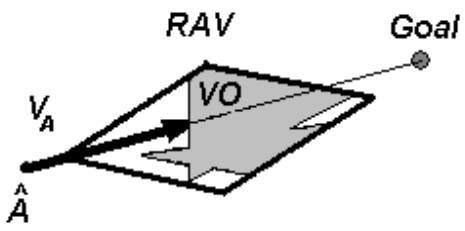

(a)

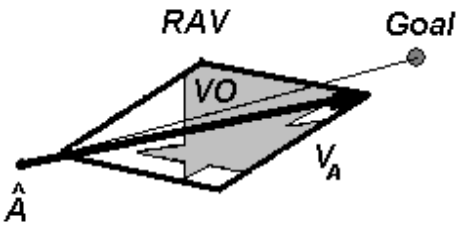

(b)

Figura 15: Heurística de seleção de velocidade: em (a) TG e em (b) MV (Becker, Dantas e Macedo 2005).

$\mathrm{Na}$ literatura é possível encontrar diversas estratégias heurísticas para selecionar a velocidade a ser empregada. Tome-se como exemplo as estratégias TG e MV, respectivamente, estratégias Towards Goal e Maximum Velocity (Fig. 15). A primeira escolhe a velocidade que mais se aproxima da linha entre a posição atual do robô e a posição final desejada (Fig. 15-a), enquanto que a segunda estratégia escolhe a velocidade mais elevada e próxima á linha entre a posição atual do veículo e a posição final desejada, reduzindo assim o tempo necessário para executar a trajetória (Fig. 15b).

\subsubsection{VELOCITY OBSTACLE APPROACH MODIFICADO}

Da mesma forma que a abordagem DWA, o algoritmo VOA normalmente se aplica a um polígono para representar o conjunto de velocidades possíveis de serem atingidas (RAV). Este conjunto é graficamente determinado, sobrepondo à velocidade obstáculo $\mathrm{VO}$ em um polígono que representa o conjunto de todas as velocidades e calcula a velocidade acessível por diferença com o conjunto RAV no espaço de velocidades. Em contraste, existe a abordagem denominada Modified Velocity Obstacle Approach (MVOA) (Becker, Dantas e Macedo 2005). Esta abordagem consiste em aplicar uma heurística que tenta manter uma velocidade de cruzeiro constante (valor de velocidade fixa que mantém o veículo em segurança durante o deslocamento de um ponto A até um ponto B), ou seja, o veículo deve manter constante o módulo de sua velocidade o maior tempo possível durante o caminho. Apenas no caso de uma manobra (por exemplo, uma curva acentuada, estacionamento, etc.) ou de uma colisão iminente, 
a direção da velocidade do veículo é alterada. Tendo em conta as restrições do veículo como dimensões, ângulos de direção, acelerações, e os limites de frenagem, é possível determinar os valores-limite em módulo da velocidade $\left\|\mathrm{V}_{A}\right\|$ e o ângulo de direção $\phi$ (no caso de um sistema autônomo, esses dados podem ser fornecidos anteriormente pela rotina de planejamento de trajetórias ou, no caso de um sistema integrado de apoio ou assistivo, fornecido pelo comportamento do condutor) que definem a área limitada por $\phi_{1}, \phi_{\mathrm{r}},\left\|\mathrm{V}_{\text {Amax }}\right\|$, e $\left\|\mathrm{V}_{\text {Amin }}\right\|$. Esta área representa as velocidades dos veículos acessíveis para o próximo período de tempo com base na saída de planejamento de trajetória (ou comportamento do condutor). Assumindo que as capacidades dinâmicas do veículo para translação e rotação são independentes, esta área é um setor de círculo como representado na Figura 16-a pela área cinza escuro. Seguindo a heurística, o procedimento MVOA tenta manter a velocidade do robô módulo $\left(\left\|\mathrm{V}_{A}\right\|\right)$ constante durante a manobra de evasão, variando sua direção $(\phi)$ dentro do intervalo $\left(\phi_{1}, \phi_{\mathrm{r}}\right)$.

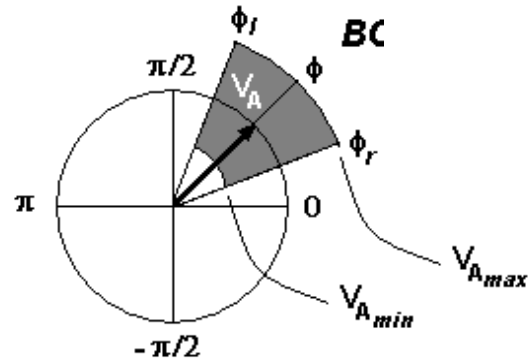

(a)

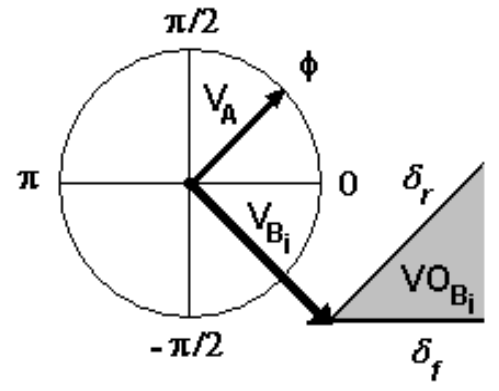

(b)

Figura 16: Procedimento MVOA: (a) o círculo de raio $\|V A\|$ representa o espaço de velocidades e a área cinza escuro limitada por $\phi_{b}, \phi_{r}, V_{A \max }$ e $V_{A m i n}$ representa o conjunto de velocidades possíveis. (b) O uso de $V O_{B i}$ para calcular as velocidades em direções perigosas DVDs (Becker, Dantas e Macedo 2005).

Da mesma forma que o VOA, o MVOA usa $\mathrm{VO}_{\mathrm{Bi}}$ no lugar de $\mathrm{CC}_{\mathrm{ABi}}$ a fim de calcular as velocidades em direções perigosas - DVDs (Dangerous Velocities Directions na Fig. 16-b). Os conjuntos de DVDs são obtidos com base na interseção entre o círculo que forma o espaço de velocidades e as duas linhas $\delta_{\mathrm{f}}$ e $\delta_{\mathrm{r}}$ que fazem fronteira com o $\mathrm{VO}_{\mathrm{Bi}}$ (Fig. 17-a). O arco de circunferência limitado por $\alpha_{1}, \alpha_{2}, \alpha_{3}$ e $\alpha_{4}$ representa os conjuntos (Fig. 17-b). Nesta figura qualquer velocidade cuja direção $(\phi)$ encontra-se dentro de $\left(\alpha_{1}, \alpha_{2}\right)$ ou $\left(\alpha_{3}, \alpha_{4}\right)$ causaria uma futura colisão entre o robô e o obstáculo $B_{i}$. 
Se não houver intersecção entre circulo que forma o espaço de velocidades e $\mathrm{VO}_{\mathrm{B}}$, não há colisão iminente. Em caso de múltiplos obstáculos, $\mathrm{VO}_{\mathrm{B}} \mathrm{S}$ múltiplas são usadas a fim de obter todos os conjuntos de velocidades em direções perigosas (Fig. 18).

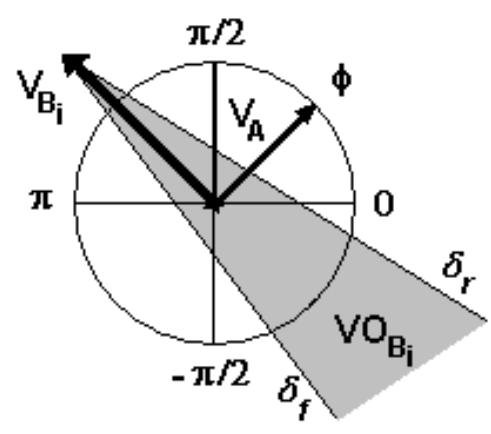

(a)

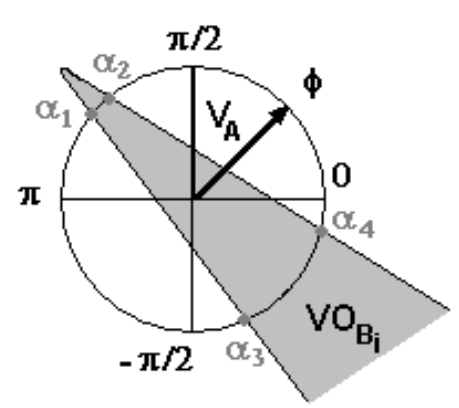

(b)

Figura 17: (a) e (b) conjunto de velocidades em direções proibidas calculadas no espaço de velocidades (Becker, Dantas e Macedo 2005).

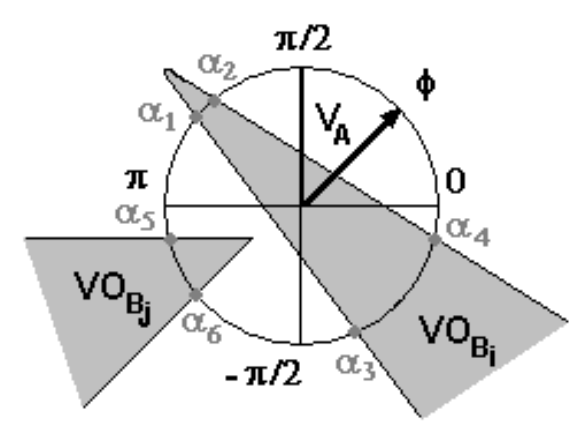

(a)

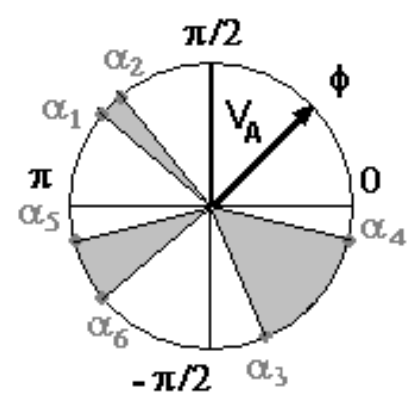

(b)

Figura 18: (a) dois obstáculos representados por dois $V O_{B}\left(V O_{B i}\right.$ e $\left.V O_{B j}\right)$. (b) Espaço de Velocidades e três conjuntos de velocidades em direções perigosas (Becker, Dantas e Macedo 2005).

Se não for possível evitar uma colisão variando apenas a direção de velocidade em $\left(\phi_{1}, \phi_{\mathrm{r}}\right)$, o procedimento MVOA verifica mudanças no módulo de velocidade do $\left\|\mathrm{V}_{A}\right\|$ e na direção com os limites $\phi_{1}, \phi_{\mathrm{r}}, \mathrm{V}_{A \max } \mathrm{e} \mathrm{V}_{\text {Amin }}$, à procura de possíveis velocidades que evitariam a colisão. A Figura 18 mostra o efeito da variação no módulo da velocidade sobre os conjuntos de DVDs. Se o veículo é acelerado, o intervalo definido para o DVD aumenta a partir de $\left(\alpha_{3}, \alpha_{4}\right)$ para $\left(\alpha_{3}{ }^{\prime \prime}, \alpha_{4}{ }^{\prime \prime}\right)$ e o intervalo $\left(\alpha_{1}, \alpha_{2}\right)$ é eliminado (Figura 19 - círculo II). Por outro lado, se o veículo é freado, ambos os 
intervalos definidos para o DVD são diminuídos de $\left(\alpha_{1}, \alpha_{2}\right)$ e $\left(\alpha_{3}, \alpha_{4}\right)$ para $\left(\alpha_{1}{ }^{\prime}, \alpha_{2}{ }^{\prime}\right)$ e $\left(\alpha_{3}{ }^{\prime}, \alpha_{4}{ }^{\prime}\right)$, respectivamente (Figura 19 - círculo III).

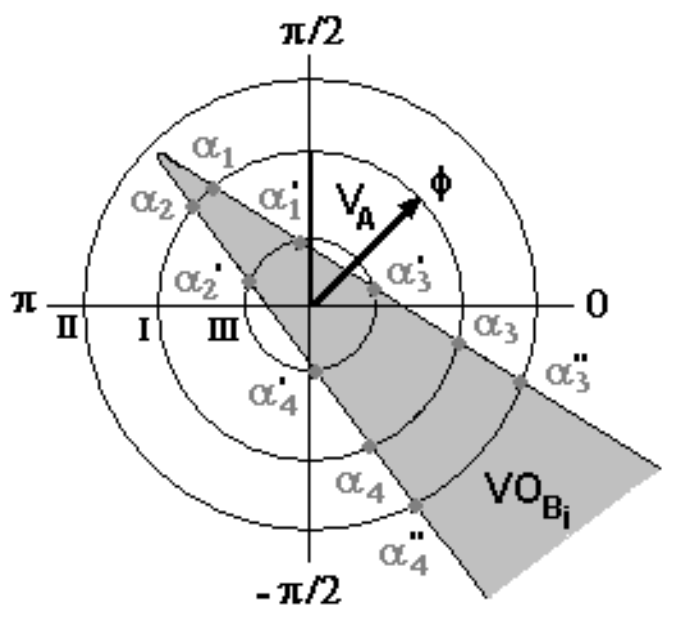

Figura 19: Efeito da variação do módulo de velocidade nos intervalos de DVDs. O círculo I representa a velocidade de cruzeiro, no círculo II o veículo é acelerado e no círculo III é freado (Becker, Dantas e Macedo 2005).

A determinação da velocidade que seria usada para evitar a colisão entre o veículo e os obstáculos é realizada por MVOA com base em algumas regras heurísticas. É utilizada uma heurística que resulta na passagem do veículo pelos obstáculos.

\subsection{ALGORITMO E*}

O algoritmo E* (Philippsen, 2004) é um método de planejamento de caminhos que tem capacidade de replanejamento dinâmico com custos reconfiguráveis nos caminhos calculados. Isso resulta em cálculos de trajetórias mais apropriadas para aplicações em ambientes dinâmicos. O $E^{*}$ utiliza um mapa constituído de células onde estão contidos pesos ou medidas de risco, que variam em relação aos obstáculos presentes. Isso possibilita o replanejamento dinâmico, ou seja, é possível readaptar a navegação de um robô móvel modificando o caminho que já foi calculado dependendo das mudanças ocorridas no ambiente. Basicamente, assume-se que quanto mais perto dos obstáculos, maiores são as medidas de risco, e conforme os obstáculos se movem os pesos são alterados. Como os caminhos são calculados por interpolação e não são 
restringidas as bordas do mapa, isso torna as trajetórias do veículo mais suaves (Philippsen, 2006).

O algoritmo funciona da seguinte forma (Philippsen, 2004):

- O grid é considerado com uma composição de células, onde todas têm formas idênticas e são primeiramente consideradas como espaço livre.

- A função de cálculo da trajetória começa na localização do goal (posição objetivo ou meta) e se propaga através do grid até um caminho ser encontrado.

- O robô reduz sua posição caminhando pela trajetória e diminuindo a distância até o goal.

Tem-se que o ambiente é representado por um grafo não direcionado $G$ incorporado na configuração do espaço $C$. No método existem muitas propriedades relacionadas aos nós $c \in G$, mas existem duas que são extremamente relevantes para o entendimento de seu funcionamento (Philippsen, 2006):

- O valor $v(\mathrm{c}) \geq 0$ representa a amostra do mapa em passagem de tempo contínua no nó c, ou a "altura" da função de navegação. Similar aos custos do caminho ideal no algoritmo $\mathrm{A}^{*}$;

- A dificuldade ou o custo de percorrer uma determinada configuração é codificado como custo transversal ou risco $r(c) \in(0,1)$. O menor valor de $r$ implica em maior velocidade. $\mathrm{O}$ custo é convertido em informações de meta $m(c)$ para permitir a interpolação de kernels (núcleos) diferentes.

Neste algoritmo não existem problemas com listas abertas, como as usadas em algoritmos como o $\mathrm{A}^{*}$ onde uma mudança no ambiente gera um novo processamento para um novo caminho, pois ele utiliza os mesmos princípios do algoritmo $\mathrm{D}^{*}$, onde conjuntos de nós podem entrar e sair da lista. Assim, pode-se imaginar que quando executado, o Algoritmo $E^{*}$ assemelha-se a uma onda que varre o gráfico do ambiente, não ficando presa a arestas e nós, mas considerando um contorno contínuo varrido desde a meta e percorrendo todo o ambiente e atravessando todas as células (como é ilustrado na Fig. 20 e Fig. 21). Neste caso, consideram-se os tempos de passagem nos nós como amostras de uma função contínua de navegação, no lugar de estender uma função discreta de distâncias para um domínio contínuo. No planejamento do caminho, 
o algoritmo E* utiliza uma adaptação do Level Set Method - LSM (Philippsen, 2004, Philippsen e Siegwart, 2005, Philippsen, 2006). O LSM fornece um algoritmo robusto baseado em grid para o cálculo da posição em função do tempo em uma curva de evolução.

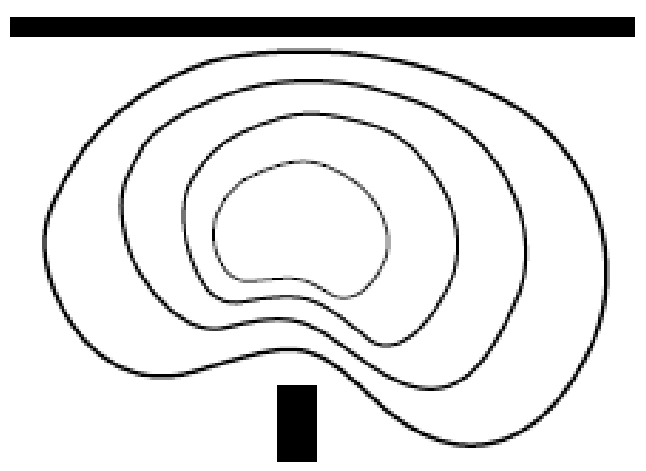

Figura 20: Ilustração da onda de propagação (wavefront) continua no domínio. Contornos são varridos por fora da meta, levando em contas as informações dos obstáculos. É importante ressaltar que fazendo a velocidade de propagação dependente da posição tem-se refletidas as propriedades do ambiente (Philippsen, 2004).

\subsubsection{ONDA DE PROPAGAÇÃO E UPWIND}

A frente da onda de propagação (Fig. 20) representa uma lista de nós, os quais aguardam expansão, ou seja, etapa elementar de propagação de um dado nó para os seus nós vizinhos. O planejamento prossegue até que a frente de onda fique vazia ou o nó que contém o robô seja encontrado. A frente de onda é ordenada ascendentemente, sendo a chave da lista projetada para resultar em uma ordem estrita de propagação upwind. Utilizando-se o tempo de travessia, rhs-value, em conjunto com o valor estimado de $v(c)$ para calcular a chave da lista como $\min (v(c), \operatorname{rhs}(c))$. Quando o valor de rhs e o valor do nó são iguais, o nó passa a ser chamado de localmente consistente. A onda de propagação tem a tarefa de impulsionar o algoritmo a um estado onde todos os nós são localmente consistentes.

A idéia de utilizar uma árvore geradora para rastrear o caminho a partir da posição do robô para a meta é estendida direto para um gráfico upwind $U$ com bordas únicas $\left(c_{1}, c_{2}\right) \in U \rightarrow\left(c_{2}, c_{1}\right) \notin U$. Isso permite recuperar o conjunto upwind $U(c)$ dos 
nós envolvidos no calculo de $v(c)$, como o conjunto downwind $D(c)$ de nós que foram influenciados por $v(c)$ durante a interpolação de seu valor. Assim, todos os descendentes de um nó podem ser determinados com suas informações do ambiente com posteriores alterações (Philippsen, 2006).

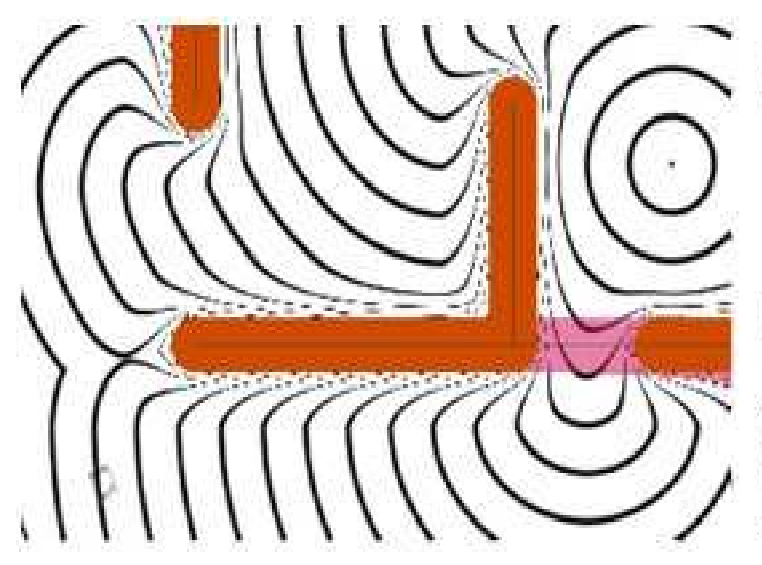

(a)

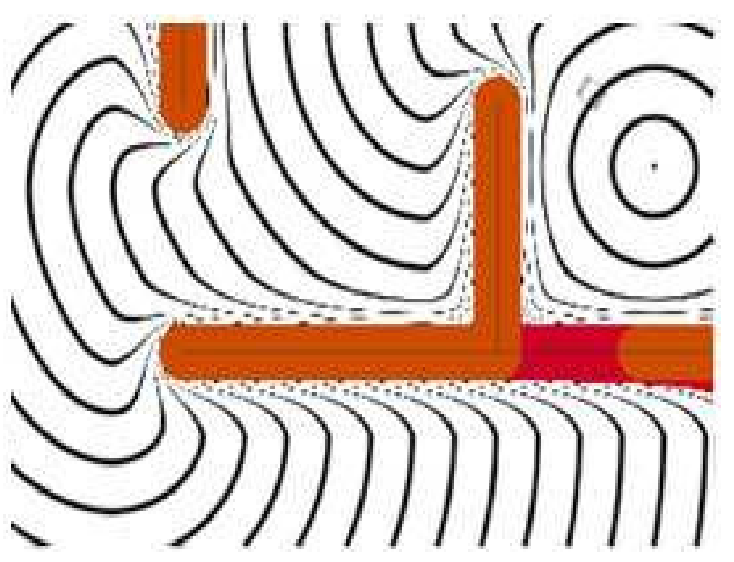

(b)

Figura 21: Ilustração da wavefront. (a) Algoritmo prestes a descobrir uma passagem bloqueada e (b) a função de navegação repara o mapa ${ }^{4}$.

\subsubsection{INTERPOLAÇÃO DE KERNELS}

Utilizando a formulação apresentada em (Philippsen, 2006), tem-se que um kernel de interpolação $k$ é uma função que estima o tempo de travessia de um nó com base no risco ou custo de atravessá-lo, em conjunto com os valores dos nós vizinhos.

$(u, B)=k(c, Q)$

onde: $u$ é o novo valor do nó $c, B \subseteq Q(c)$ é o conjunto de nós vizinhos utilizados no calculo de $u$, e $Q(c)$ é o propagador de $c$ no momento de expansão, isso garante que só são válidos os candidatos a vizinhos fornecidos pelo kernel.

$Q(c)=\{n \in N(c) \mid v(n)<\infty\}$

onde: $N(c)$ é o conjunto de nós vizinhos (adjacentes) de $c$.

\footnotetext{
${ }^{4}$ http://estar.sourceforge.net/papers/philippsen-estar-poster-iros07.pdf
} 
Nós que apresentem valores infinitos são obstáculos ou não foram expandidos ainda, como por exemplo, após a inicialização ou depois de um aumento de $r(c)$. Os valores de $Q$ são ordenados parcialmente pelo ascendente $v$ dos nós contidos:

$v\left(Q_{i}\right) \leq v\left(Q_{j}\right) \forall i<j$

onde: $Q_{i}$ denota as iéssimas entradas.

É possível que $Q$ esteja vazio ou contenha um único nó. Lidar com esse casos faz parte das propriedades de um kernel. Assim:

$\left\{\begin{array}{rr}(a) & u(c, Q)>v\left(Q_{1}\right) \\ (b) & u(c, Q) \leq u\left(c,\left\{Q_{1}\right\}\right) \\ (c) & u(c, Q=\{\})=\infty\end{array}\right.$

onde: (a) é a condição que garante a propagação upwind monotônica, (b) significa que a interpolação usada produz um valor menor do que escolher um movimento discreto (que pode ser necessário como recurso de solução mesmo na presença de mais de um propagador), e (c) que mostra que não é valida a propagação a menos que um nó vizinho não seja um nó com obstáculos que não é conhecido e possa ser alcançável. Outra condição é que $B$ deve refletir com precisão as informações utilizadas para o cálculo de $u$. Isso é importante, pois garante que as modificações no ambiente possam ser consistentemente propagadas para todos os nós envolvidos.

\subsubsection{O ALGORITMO}

A seguir é apresentado o pseudo-código descrito em (Philippsen et al,2007). A variável $g$ corresponde ao ponto alvo, $W$ corresponde à frente de onda, e chave(c) é a chave com a qual $c$ é inserido em $W$. O loop ComputePropagator(c) faz uso da equação 33, $\operatorname{Pop}(w)$ retira e retorna o nó de $W$ com maior valor e TopChave(W) retorna a chave do nó com valor mais alto ou valor $\infty$.

\section{1: $\quad$ Procedimento Main(c)}

2: $\quad$ Inicializar $r h s(c)=v(c)=\infty, \forall \mathrm{c} \in G$

3: $\quad$ Inicializar goal $r h s(g)=$ distância real

4: $\quad$ Inicializar $W \operatorname{com} g$

5: $\quad$ while $($ rhs $($ crobot $) \neq v($ crobot $))$ ou TopChave $(W)<v($ crobot $)$ do 
6: $\quad$ if $W=\{\}$ then

7: $\quad$ Goal $g$ não pode ser alcançado

8: $\quad$ end if

9: $\quad$ Propagar()

10: end while

11: $\quad$ Procedimento Reordenamento(c)

12: $\quad$ if $v(c)=r h s(c)$ then

13: $\quad$ if $c \in W$ then

14: $\quad$ remover $c$ desde $W$

15: $\quad$ end if

16: else

17: $\quad$ if $c \notin W$ then

18: $\quad$ inserir $c$ com chave $=\min (v(c), \operatorname{rhs}(c))$ em $W$

19: $\quad$ else if $\operatorname{chave}(c) \neq$ chave $=\min (v(c), \operatorname{rhs}(c))$ then

20: $\quad$ remover $c$ desde $W$

21: $\quad$ inserir $c$ com chave $=\min (v(c), \operatorname{rhs}(c))$ em $W$

22: $\quad$ end if

23: $\quad$ end if

24: $\quad$ Procedimento AtualizarVertice(c)

25: $\quad$ if $c \notin g$ then

26: $\quad \mathrm{Q} \leftarrow$ ComputarPropagador(c)

27: $\quad(r h s(c), B) \leftarrow k(c, Q)$

28: $\quad$ for $u \in U(c)$ do

29: $\quad$ remover $(\mathrm{u}, \mathrm{c}) \mathrm{de} \mathrm{U}$

30: $\quad$ end for

31: $\quad$ for $b \in B$ do

32: $\quad$ if $(c, b)$ then

33: $\quad$ remover $(c, b)$ de $U$

34: $\quad$ end if

35: $\quad$ agregar $(b, c)$ a $U$

36: end for

37: $\quad$ Reordenamento (c)

38: $\quad$ end if

39: $\quad$ Procedimento Propagar(c)

40: $\quad c \leftarrow \operatorname{Pop}(W)$

41: $\quad$ if $v(c)>r h s(c)$ then

42: $\quad v(c) \leftarrow r h s(c)$

43: $\quad$ for $n \in N(c)$ do

44: $\quad$ AtualizarV ertice(n)

45: end for

46: $\quad$ else

47: $\quad v(c) \leftarrow r h s(c)$

48: $\quad$ for $d \in D(c)$ do

49: $\quad$ Atualizar Vertice (d)

50: end for

51: Atualizar Vertice(c)

52: end if 


\subsection{CONSIDERAÇÕES FINAIS}

Neste capítulo foram apresentadas as técnicas utilizadas no monitoramento da área frontal do veículo de passeio. Foram descritos como os dados oriundos do sistema de medidas de distância, SICK LMS 291-S05, são utilizados para detecção e classificação dos obstáculos. Depois de detectados os obstáculos, é utilizada uma classificação em relação ao tamanho dos mesmos entre as classes pedestres e veículos. Após isso, foi explicada a técnica Velocity Obstacle Approach que neste caso será utilizada para determinação de direções proibidas para tráfego do veículo. E finalmente a técnica $E^{*}$ para planejamento de rota e recálculo de rota quando necessário foi apresentada. 


\section{Capítulo 4}

\section{RESULTADOS}

Neste capítulo são apresentados os resultados obtidos com os métodos utilizados nas rotinas que formam o algoritmo de monitoramento desenvolvido nesta pesquisa. Os dados utilizados foram do Campus 1 da ESSC-USP em São Carlos, obtidos com o sensor SICK LMS 291-S05 posicionado no pára-choque dianteirao do veículo de testes e com uma câmera posicionada acima do volante para captura das imagens que mostram o cenário em que os dados experimentais foram obtidos.

\subsection{IMPLEMENTAÇÃO DOS ALGORITMOS}

Para o monitoramento do ambiente ao redor do veículo de testes, foram desenvolvidas as rotinas de Trackers, Velocity Obstacle Approach e $E^{*}$. Através dos dados fornecidos pelo sensor laser foi possível detectar situações de risco e gerar trajetórias livres de colisões com pedestres e veículos. Todos os programas foram desenvolvidos em linguagem $\mathrm{C}++$ visando sua implementação futura embarcada no veículo de testes. Como o ambiente urbano apresenta múltiplos obstáculos dinâmicos que podem impossibilitar a detecção de outros obstáculos pelo sensor, como citado anteriormente, foi necessário que todos os obstáculos detectados fossem classificados e acompanhados em uma janela de tempo (mesmo que eles estivessem oclusos por outros obstáculos posicionados na frente do sensor). Com base nas rotinas de classificação foram geradas trajetórias livres de colisão visando evitar acidentes, assistindo o motorista em situações de risco iminente, como também foi feita a indicação de direções proibidas para esterçamento do veículo. 
Foram desenvolvidos dois visualizadores para teste dos algoritmos, o primeiro foi desenvolvido em OpenCv mas se mostrou ineficiente na medida em que os algoritmos ficaram mais complexos, pois a visualização dos resultados tornou-se muito lenta. O segundo visualizador foi desenvolvido em SDL e consegue mostrar os dados reais na freqüência de aquisição de 5 scans/seg. Neste trabalho serão mostradas imagens dos dois visualizadores.

\subsection{ALGORITMO TRACKERS}

Nessa seção é apresentado o desenvolvimento do algoritmo Tracker. A Fig. 22 apresenta um fluxograma resumido do programa para que fique clara a interação entre cada parte do mesmo. A seguir as rotinas que compõem o programa são brevemente explicadas.

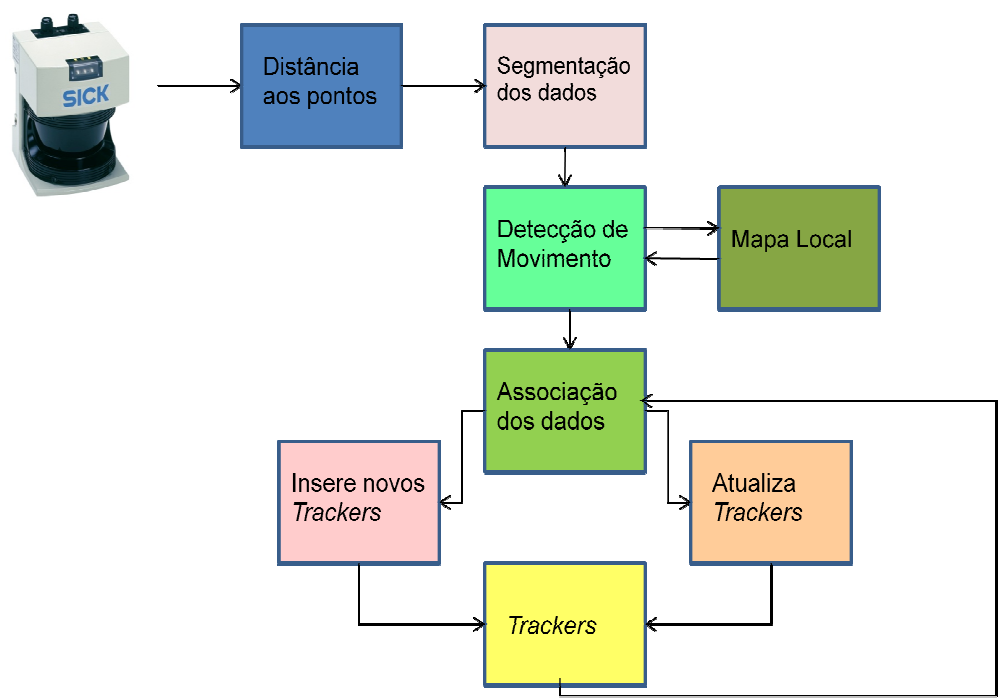

Figura 22: Fluxograma geral do programa de Trackers.

\subsubsection{SEGMENTAÇÃO}

Uma vez adquiridos os dados através do sensor SICK, é necessário realizar a segmentação dos mesmos a fim de selecionar e agrupá-los de acordo com os requisitos desejados. A cada leitura do sensor, é obtido um conjunto com 361 pontos. Cada ponto tem as informações de distância e ângulo entre o sistema de medidas de distância e o objeto detectado. Para aplicar os passos seguintes do algoritmo, as coordenadas dos 
pontos foram transformadas de coordenadas polares para cartesianas. O sistema de coordenadas usado tem como origem o local onde está o sensor, com eixo $x$ na direção em frente ao mesmo, e o eixo $y$ perpendicular ao eixo $x$, com orientação positiva para cima.

Para aplicar os próximos passos do acompanhamento (tracking) de objetos, foi necessário identificar quais pontos da leitura do sensor pertenciam ao mesmo objeto. Para essa tarefa foi utilizado o método "Point-Distance-BaSed" já descrito anteriormente. Neste método, os parâmetros aplicados são o de limiar de derivação para os dados raio inicial de $0,05 \mathrm{~m}$ e ângulo de $\pi / 60 \mathrm{rad}$. Os dados que não excedem a distância máxima calculada através da derivação dos dados e dos limiares são salvos e transformados em segmentos de pontos.

Os resultados obtidos foram satisfatórios, uma vez que os diferentes objetos foram, em sua maioria, bem distinguidos. Pode-se perceber pela Fig. 23 que foi possível encontrar e separar vários obstáculos. O problema desse método está na escolha da distância limiar entre pontos. Se for escolhido um valor que seja muito grande, por exemplo, 3m, dois objetos distintos podem ser considerados com um só (Fig. 23-a). Já se o valor for relativamente pequeno, por exemplo, $0,01 \mathrm{~m}$, um mesmo objeto pode ser separado em dois ou mais (Fig. 23-b).

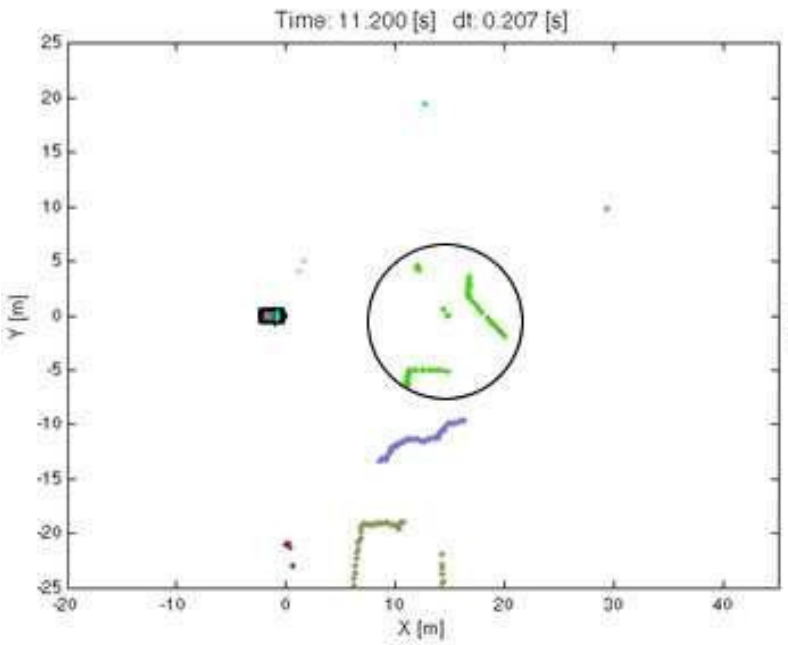

(a)

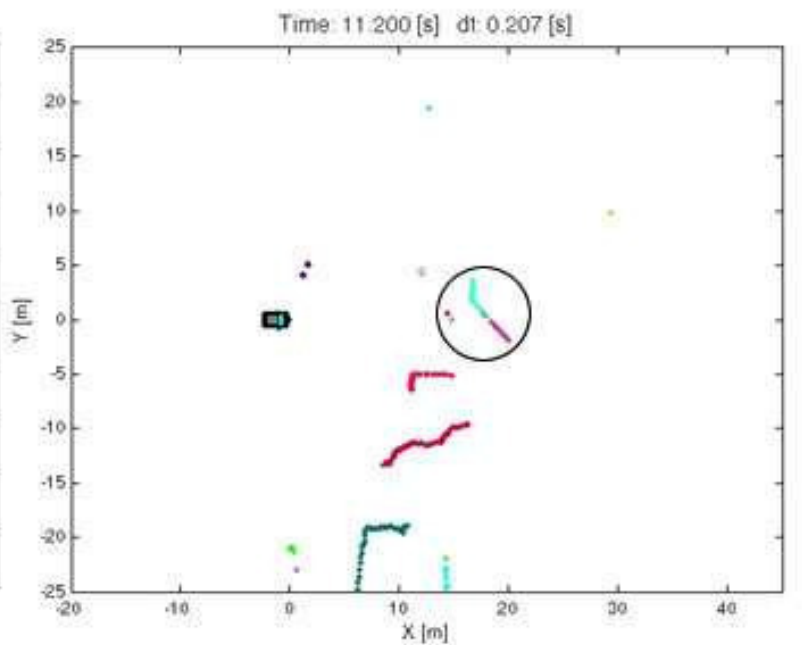

(b)

Figura 23: Segmentação com valores não convenientes da distância limiar. Em (a) quando a distancia limiar é muito grande, vários obstáculos são considerados com um, e em (b) quando a distância limiar é muito pequena um obstáculo é separado em vários. 
Na prática, o valor da distância limiar entre dois pontos, para que pertençam ao mesmo objeto, é obtido a partir de experimentos. Neste trabalho os valores de distancia limiar variaram de $0,05 \mathrm{~m}$ a $1,5 \mathrm{~m}$.

\subsubsection{DETECÇÃO, ACOMPANHAMENTO DE OBSTÁCULOS E NUVEM DE PROBABILIDADES}

Um passo essencial para o bom funcionamento do tracking de obstáculos é detectar as suas características dinâmicas. Para isso foi utilizada a técnica baseada em duas regras apresentadas no item 3.2.2. Basicamente, a idéia é comparar leituras subseqüentes de laser separadas por um intervalo de tempo conhecido, neste caso $0,4 \mathrm{~s}$ ou duas leituras do sensor. Assim, é possível diferenciar os pontos estáticos dos dinâmicos.

Para cada ponto na nova leitura, é calculada a sua distância aos pontos da leitura anterior, e essa diferença é avaliada de acordo com um valor limite. Como é mais simples detectar os obstáculos estáticos, o valor limite utilizado para estes é de $0,1 \mathrm{~m}$. Se um ponto está dentro do limite de deslocamento, ele provavelmente está parado. Fora desse valor são considerados pontos móveis. Porém, podem acontecer casos em que pontos diferentes de um mesmo objeto se sobrepõem em duas leituras, dando a falsa impressão de que estes estão parados. Isso acontece, por exemplo, quando é detectado um carro lateralmente durante seu deslocamento. Esse problema foi resolvido verificando o estado dinâmico anterior desses pontos. Se anteriormente eles foram classificados como pontos que se movem, eles são classificados novamente como móveis.

Entretanto, se não for encontrado nenhuma semelhança de pontos na comparação, não se pode garantir que o objeto está se movendo. Isso pode acontecer porque o objeto pode ter sido ocultado por outro na leitura anterior do sensor ou poder estar fora do alcance do sensor na leitura anterior. Para isso, foi utilizado um conceito que, determina uma região de área livre na primeira leitura. Essa área corresponde à região livre entre o robô móvel e os obstáculos. Se um ponto da segunda leitura não foi observado na primeira, porém está contido na área livre da primeira varredura, pode-se concluir que ele está em movimento. 
Para facilitar a comparação dos pontos, foi utilizado um mapa local. O tamanho do mapa foi escolhido de acordo com o alcance do sensor e possíveis utilizações futuras dos algoritmos em fusão com outros sensores, como também para melhorar a eficiência do algoritmo (Hossein, Mita e Long, 2010). Portanto tem-se um mapa de tamanho 8m x 8m. Como já foi dito, o mapa foi dividido em células com tamanho suficientemente pequeno para representar uma boa discretização do ambiente. No caso desse trabalho, cada célula possui $0,2 \mathrm{~m} \times 0,2 \mathrm{~m}$. Cada célula possui um valor entre 0 e 20 , sendo que 20 indica a maior probabilidade de existir um objeto na célula. Outra razão para a construção de um mapa local foi a facilidade da integração com o planejador de trajetória que também trabalha aliado ao algoritmo de tracking.

Uma vez aplicado o algoritmo de detecção de obstáculos, os resultados foram coerentes, sendo bem distinguidas as duas classes: pedestres e veículos. Para essa classificação foi utilizada a norma do desvio padrão (eq. 26), e comparado com um valor definido para pedestres de $0,3 \mathrm{~m}$.

Na Fig. 24 são apresentados os resultados de duas situações diferentes. Na Fig. 24-a e Fig. 24-c a detecção e acompanhamento de um pedestre que apresentou valores de $\sigma_{\text {norma }}$ variando entre $0,18 \mathrm{~m}$ a $0,27 \mathrm{~m}$, e na Fig. 24 -b e Fig. 24 -d, um veículo, com valores de $\sigma_{\text {norma }}$ variando entre $1,59 \mathrm{~m}$ a $3,78 \mathrm{~m}$. Como também é possível ver nos pontos em pretos e amarelos obstáculos estáticos, neste caso um veículo estacionado e uma placa.

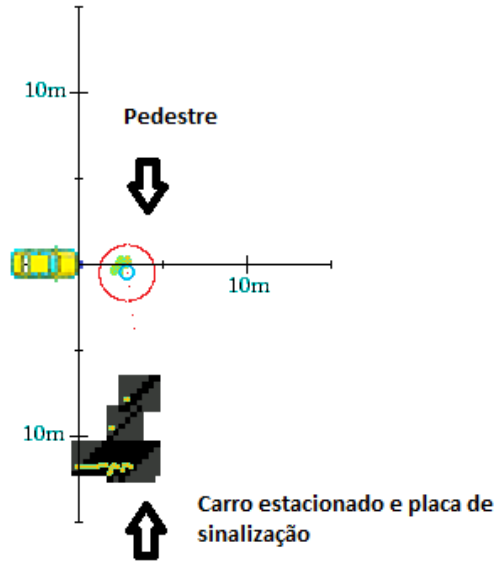

(a)

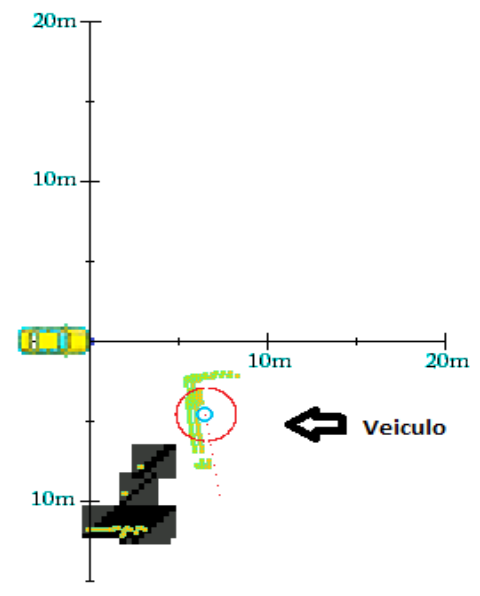

(b) 

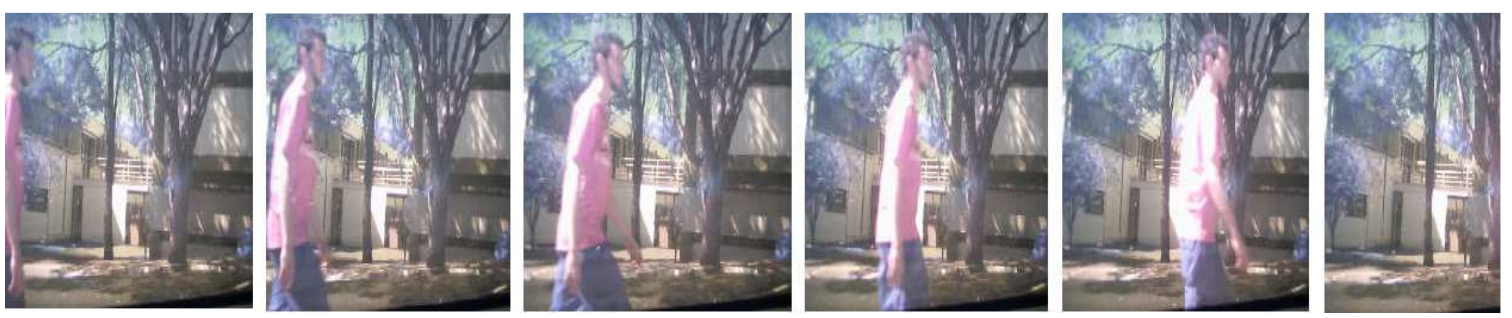

(c)
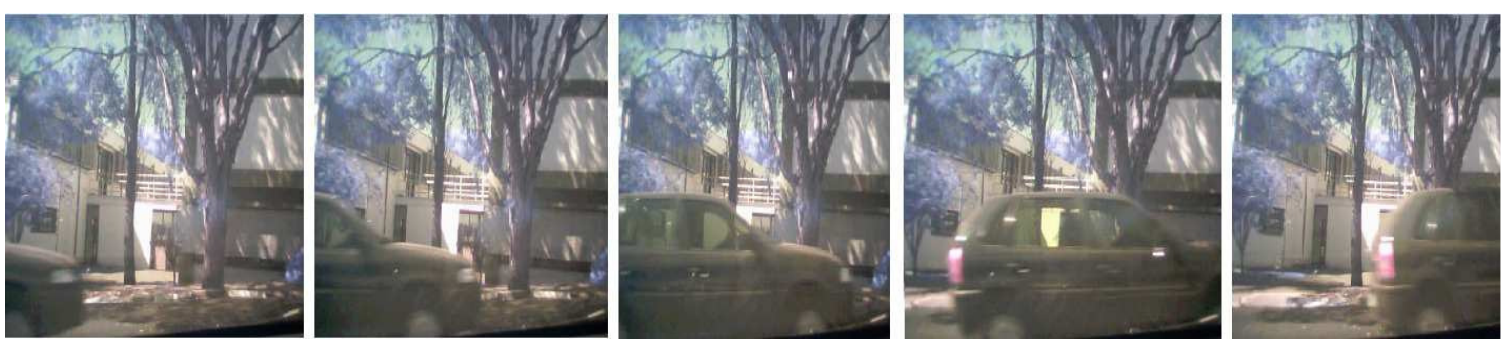

(d)

Figura 24: Exemplo de detecção e acompanhamento de uma leitura do sensor SICK LMS 291S05. (a) detecção de pedestre, (b) detecção de veículo, (c) imagens do pedestre detectado e classificado, (d) imagens do veículo detectado e classificado.

Pode-se observar que embora tanto o carro, como o pedestre tenham sido detectados corretamente no teste realizado acima, na Fig. 25, com outros dados, pode-se observar que uma grande região foi classificada como móvel e não o era (círculo verde). Nessa região no ambiente havia vegetação com altura variável que se movia com a força do vento presente durante o experimento. Por isso foi classificada como objeto móvel. Essa situação foi resolvida considerando primeiramente aquele conjunto de dados como obstáculos móveis porque esse tipo de obstáculo possui um movimento relativo. Em seguida, através das comparações entre as varreduras, como suas posições $x, y$ não apresentam grandes alterações, os mesmos passam a ser classificados como obstáculos estáticos. Esse problema também pode ser contornado através do uso de mapas georeferenciados da região em torno do veículo, o emprego de janelas de interesse nos dados coletados, como também através da utilização de sensores de visão para auxilio na detecção e classificação de obstáculos (Perrolaz et al, 2006). 


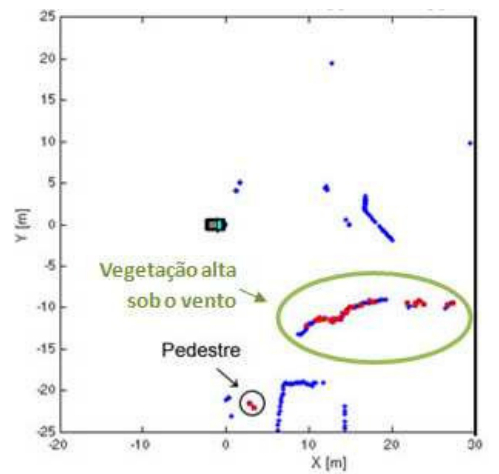

Figura 25: Detecção de vegetação alta sob ação do vento.

Na Fig. 26 é apresentado um cenário onde dois veículos se cruzam na frente do sensor. Pode-se perceber que como os dois foram detectados antes de cruzarem e são acompanhados, não ocorre problema algum até que ambos possam ser detectados novamente pelo sensor. Isso pode ser melhor visualizado observando as imagens apresentadas na Fig. 26-b.
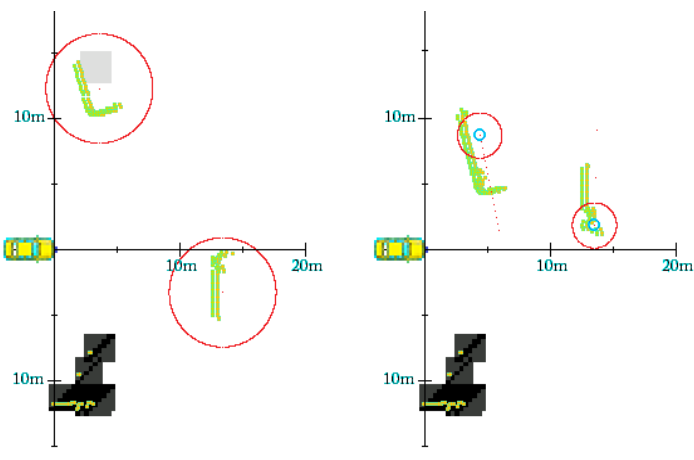
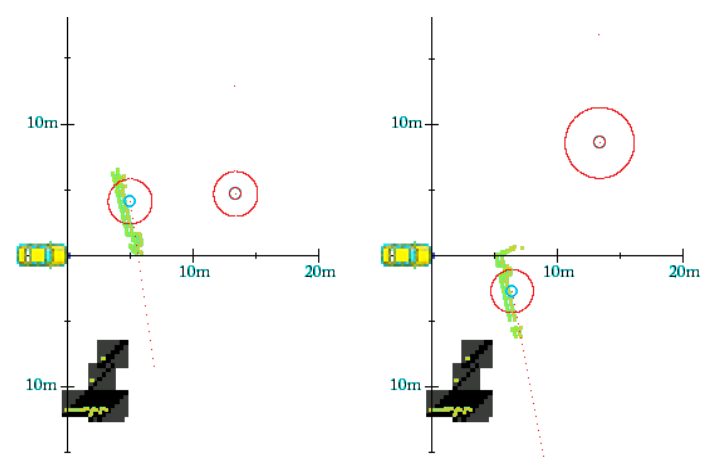

(a)
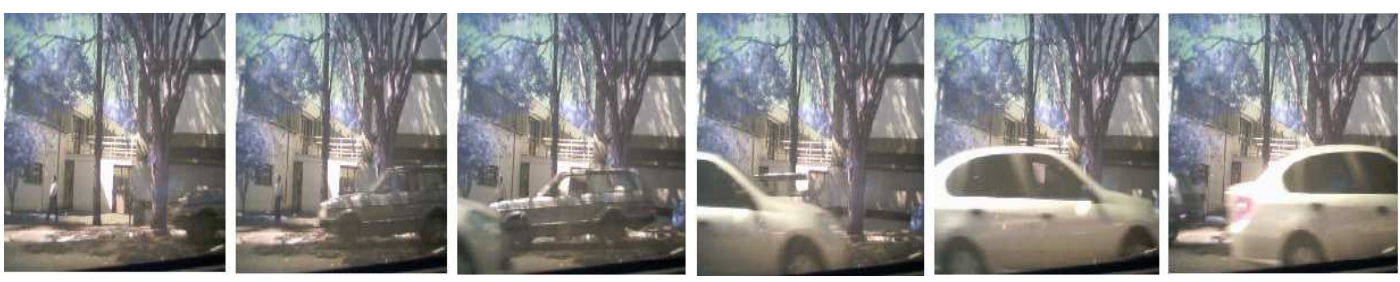

(b)

Figura 26: Cenário de cruzamento entre veículos.

Já na Fig. 27, é apresentado um exemplo em que muitos pedestres estavam caminhando próximos uns aos outros. Na Fig. 28, uma motocicleta é detectada, como a classificação é feita por tamanho, a mesma foi classificada como veículos com $\sigma_{\text {norma }}$ igual a $2,31 \mathrm{~m}$. O mesmo aconteceria com uma bicicleta, mas infelizmente nenhuma bicicleta passou em frente ao veículo de testes durante a coleta de dados realizada. 

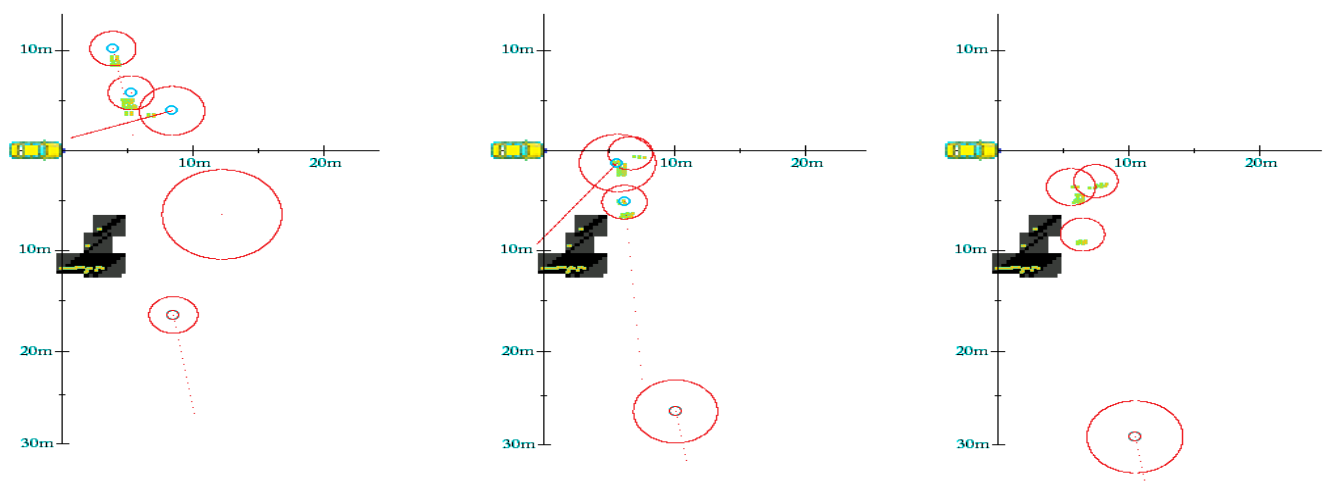

(a)
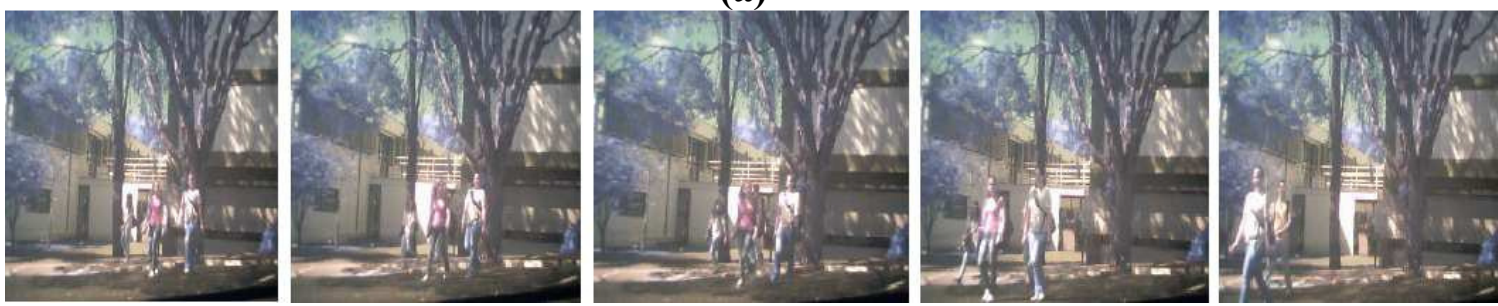

(b)

Figura 27: Exemplo de muitos obstáculos juntos, neste caso pedestres caminhando juntos.
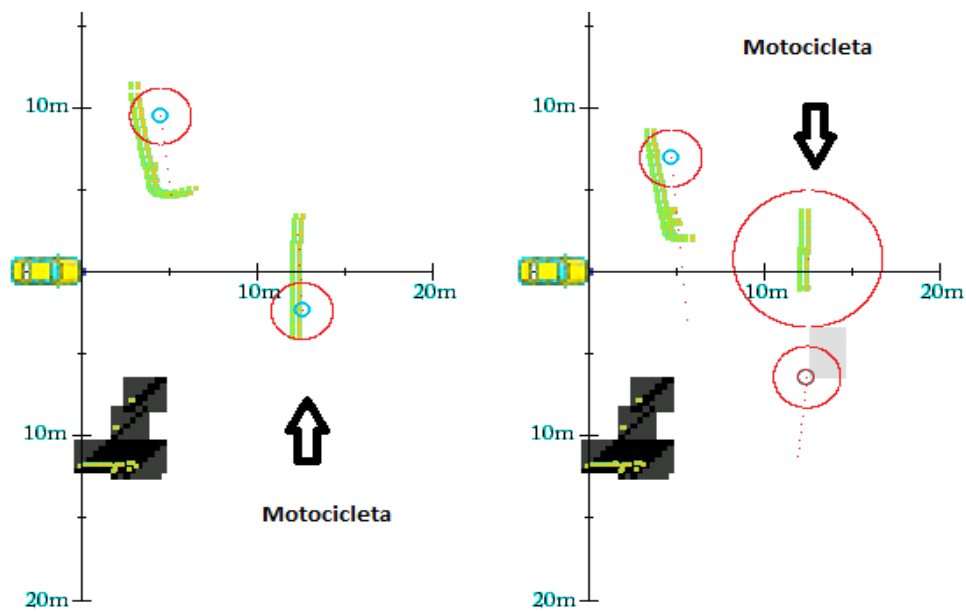

(a)
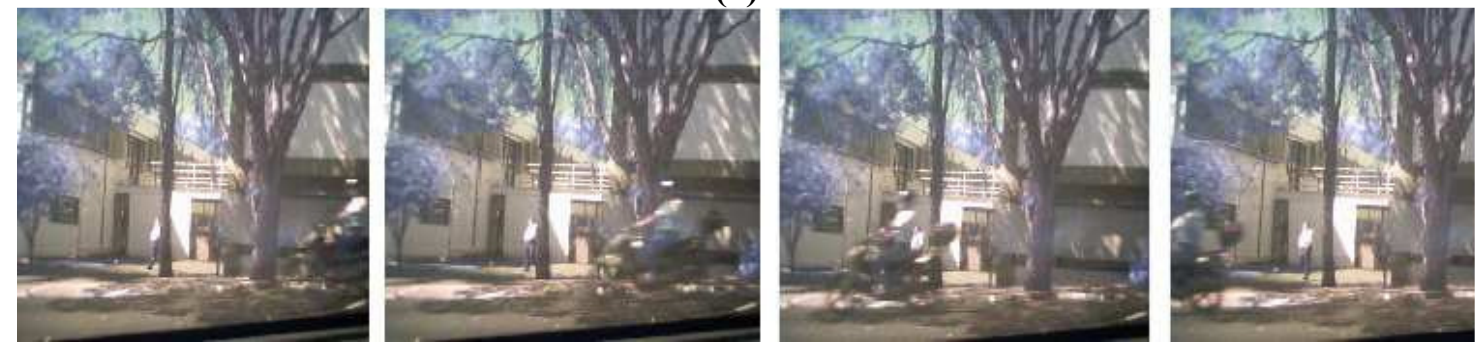

(b)

Figura 28: Motocicleta detectada, classificada como veículo e acompanhada pelo algoritmo. 
Para uma melhor manipulação dos obstáculos estáticos, os mesmos são acrescidos de $1 \mathrm{~m}$ em suas posições tanto na direção $x$ como na direção $y$ (pontos em preto sobrepostos por pontos em amarelo que representam as leituras do sensor apresentadas nas figuras). O objetivo deste procedimento foi garantir uma margem de erro de posição dos obstáculos estáticos e com isso, obter melhores resultados nos cálculos de direções proibidas e dos caminhos a serem percorridos. Isso pode também ser justificado devido aos erros inerentes de leitura do sistema de medidas de distância. Como o Algoritmo $E^{*}$ sempre busca a rota com menor custo não considerando as restrições de tamanho do veículo, caso o feixe do sensor SICK LMS 291-S05 incida sobre uma superfície que não possua boa capacidade de reflexão e ocorra falha entre os pontos do segmento de um obstáculo, podem ocorrer erros nas trajetórias.

Como visto no item 3.2.8 para cálculo das nuvens de probabilidades, foi usada a velocidade angular de um veículo conhecendo sua velocidade, ângulo de esterçamento, com valor máximo de 0,42 rad e a distância entre seus eixos, com valor de $3 \mathrm{~m}$. Com os modelos de trajetórias calculados e os obstáculos classificados, o mapa local pode ser modificado para conter as previsões de movimento. Como o veículo é representado como um ponto as probabilidades de ocupação do grid tem que ser aumentadas. Isto é realizado de forma iterativa depois de cada atualização do mapa, onde primeiro os obstáculos estáticos são considerados e aumentados de um raio aproximado ao comprimento do veículo. Então, considerando como raio mínimo o valor de $1 \mathrm{~m}$ e chegando até $2 \mathrm{~m}$, os pesos das células são modificados de tal forma que a 2 metros estão com valor nulo. Isso torna possível que o carro em movimento possa margear os obstáculos sem colidir com eles. A Fig. 29 apresenta os resultados em modo de visualização das nuvens de vários obstáculos. Com o algoritmo desenvolvido e o valor de alcance escolhido para o sensor, o custo computacional foi satisfatório, mantendo o programa na mesma freqüência com e sem os cálculos das nuvens, com tempo de execução de 0,26 s de cada iteração. 

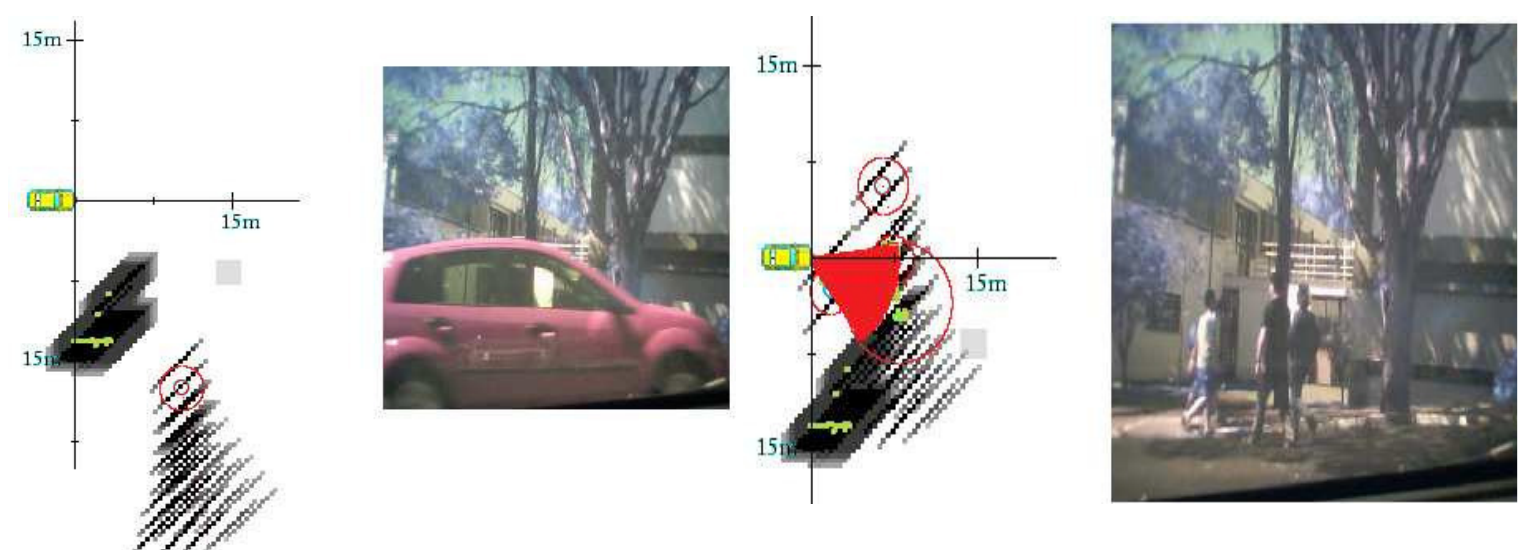

(a)

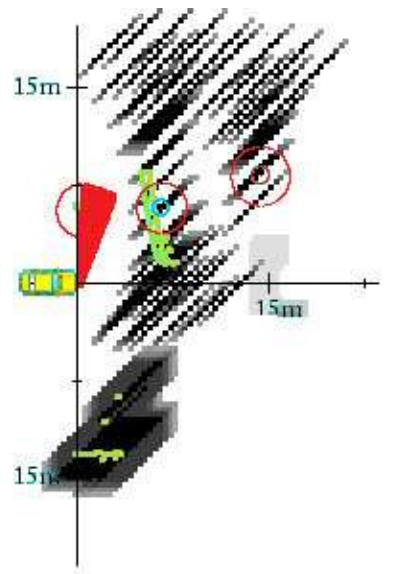

(b)
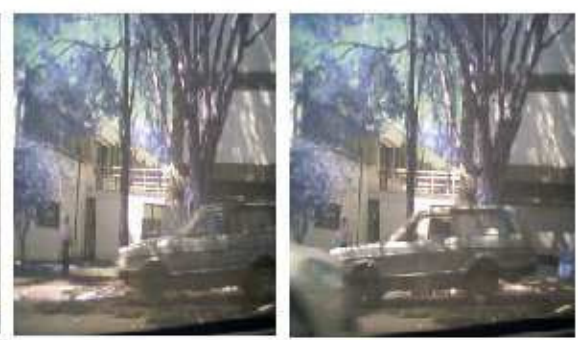
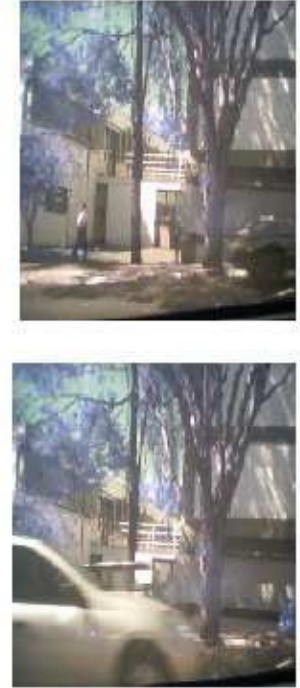

(c)
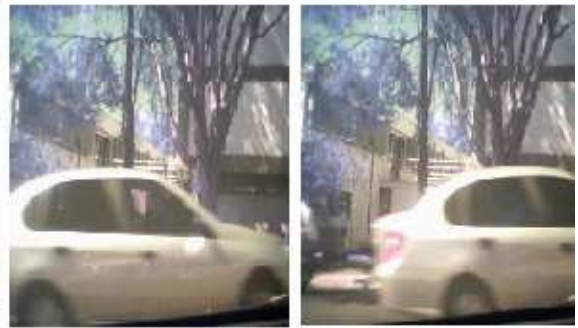

Figura 29: Exemplos de nuvens de probabilidades para (a) veículo, (b) agrupamento de pedestres e (c) carros que se cruzam em frente ao sensor.

\subsubsection{ALGORITMO VELOCITY OBSTACLE APPROACH}

A Figura 30 apresenta o fluxograma do algoritmo de detecção de direções proibidas utilizando a técnica de Velocity Obstacle Approach. 


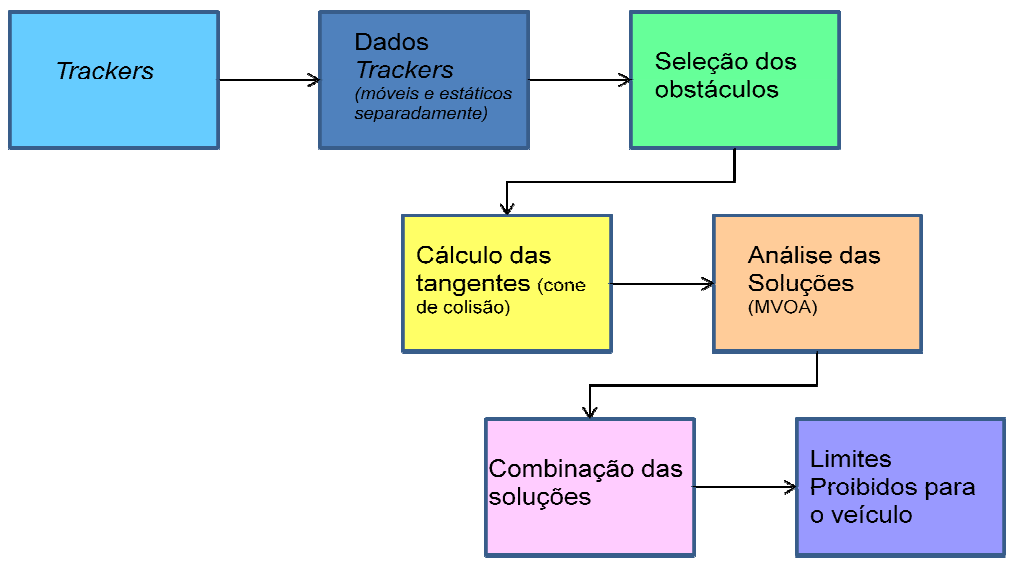

Figura 30: Fluxograma geral do programa de estimação de direções proibidas.

O algoritmo Velocity Obstacle Approach tem como dados de entrada os obstáculos previamente detectados e classificados no algoritmo Trackers. Desta forma, cada obstáculo (móvel ou estático) detectado será representado em forma de circunferências para então dar início ao procedimento descrito nos itens 3.3 e 3.3.1. Tem-se assim, os pares veículo-obstáculo para formação dos cones de velocidades. Antes de serem calculados os pares, os obstáculos são selecionados de acordo com a velocidade do veículo, variando de 1 a $11,1 \mathrm{~m} / \mathrm{s}$, considerando que essas serão velocidades seguras para tráfego do veículo dentro do campus da universidade. No caso deste algoritmo o veículo não pode ter velocidade nula, pois todos os cálculos se baseiam nas velocidades do carro e dos obstáculos.

Esses obstáculos serão analisados pelas rotinas do algoritmo e serão selecionados os de relevância para o movimento do veículo, sendo separados os obstáculos móveis dos estáticos. Somente são considerados os obstáculos dentro do campo de "visão do veículo" (Fig. 31), ou seja, dentro do raio mínimo (range) estabelecido apresentado na eq. (42) e os trackers que representam obstáculos cuja detecção foi impossibilitada devido à obstrução do sistema de medidas de distância.

range $=$ raiomin $+\frac{\text { velrobot }^{2}}{5}$

Nesta equação, o valor de raiomin é determinado pela largura da via, sendo esse valor obtido através de medições de via simples $(3 \mathrm{~m})$ e dupla $(6 \mathrm{~m})$ dentro do Campus 1 da USP em São Carlos. Esse alcance é utilizado para que o veículo possa trafegar, pois sem o mesmo, todas as direções podem se tornar proibidas devido ao ambiente muito dinâmico (Fig. 32). Além disso, o valor do range também é empregado para detecção de 
pedestres em calçadas ou outros veículos em cruzamentos. Mesmo que este valor se mostre maior que o alcance de 8m determinado para o sensor SICK LMS 291-S05, ele é mantido para que, por exemplo, futuramente em conjunto com um sistema de visão, possa se determinar até onde os obstáculos estão sendo considerados para o tráfego do carro.

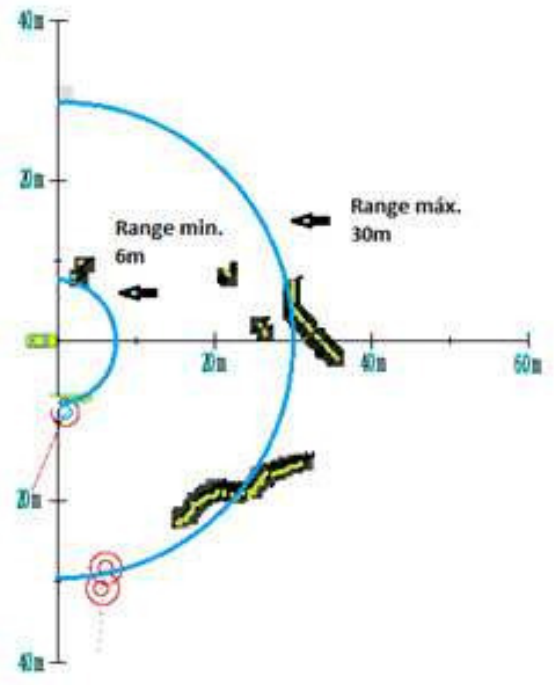

(a)

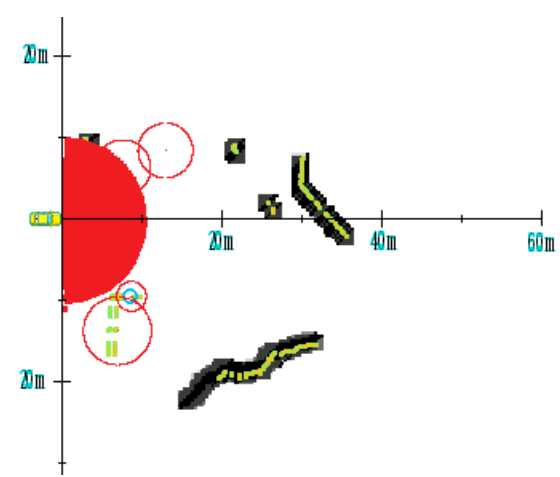

(b)

Figura 31: (a) Determinação do range mínimo e máximo para vias de 6 m de largura e velocidades do veículo variando de 1 a $11,1 \mathrm{~m} / \mathrm{s}$. Em (b) direção Proibida sem o uso do range.

Também na Eq. (42), o valor de velrobot representa a velocidade do veículo de testes, que no caso das rotinas testadas podem ser estabelecidas pelo usuário do visualizador, com variação de $1 \mathrm{~m} / \mathrm{s}$ até $11,1 \mathrm{~m} / \mathrm{s}$. Esses valores são utilizados para os cálculos das direções proibidas. Como foi utilizada a técnica MVOA, esses valores foram empregados para manter o veículo em velocidade de cruzeiro, só podendo ser modificados no início da visualização. Futuramente, quando as rotinas forem embarcadas no veículo, essas velocidades serão obtidas através da rede CAN do veículo e combinadas com dados de outros sensores embarcados, como, por exemplo, GPS, IMU e odometria.

Separados os obstáculos, as retas tangentes que partem do veículo em direção aos obstáculos serão calculadas formando dois grupos: um composto por obstáculos estáticos e o outro por obstáculos móveis. A seguir é feita a análise das soluções encontradas, ou seja, os obstáculos serão divididos em dois grupos tendo como parâmetro suas velocidades: em um grupo ficam os obstáculos com velocidades maiores que a do veículo e no outro, os com velocidades menores. Neste trabalho não são 
considerados os obstáculos com velocidade maior que a do veículo protótipo porque se supõe que os mesmos possam ultrapassá-lo sem risco de colisão (Fig. 32).

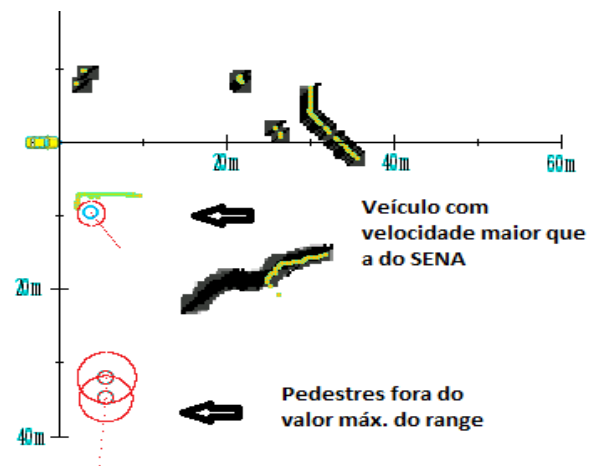

Figura 32: Exemplo de veículos com velocidades acima da considerada para o protótipo SENA e pedestres fora do alcance máximo para as direções proibidas.

Em seguida são calculados os ângulos entre os pares, e estes dados serão guardados em vetores. Com todas as variáveis calculadas, as soluções obtidas são combinadas adequadamente, sendo separadas em casos de intervalos de direção de movimentação proibidas onde o veículo não pode trafegar (ou seja, onde será necessário esterçar o veículo ou alterar sua velocidade) e casos de colisão inevitáveis (onde será necessária uma parada de emergência). Após essa separação, os dados são reorganizados em vetores que determinam os valores iniciais e finais de cada intervalo de direções proibidas para a movimentação do veículo (Fig. 33).

Nos casos de vegetação alta onde o algoritmo de trackers identifica temporariamente a mesma, o algoritmo VO também a identifica como obstáculo móvel (Fig. 33-d). Depois das direções proibidas determinadas o algoritmo de geração de manobras evasivas pode ser aplicado, mas essa abordagem não faz parte do escopo deste trabalho sendo deixada como sugestão de trabalho futuro.
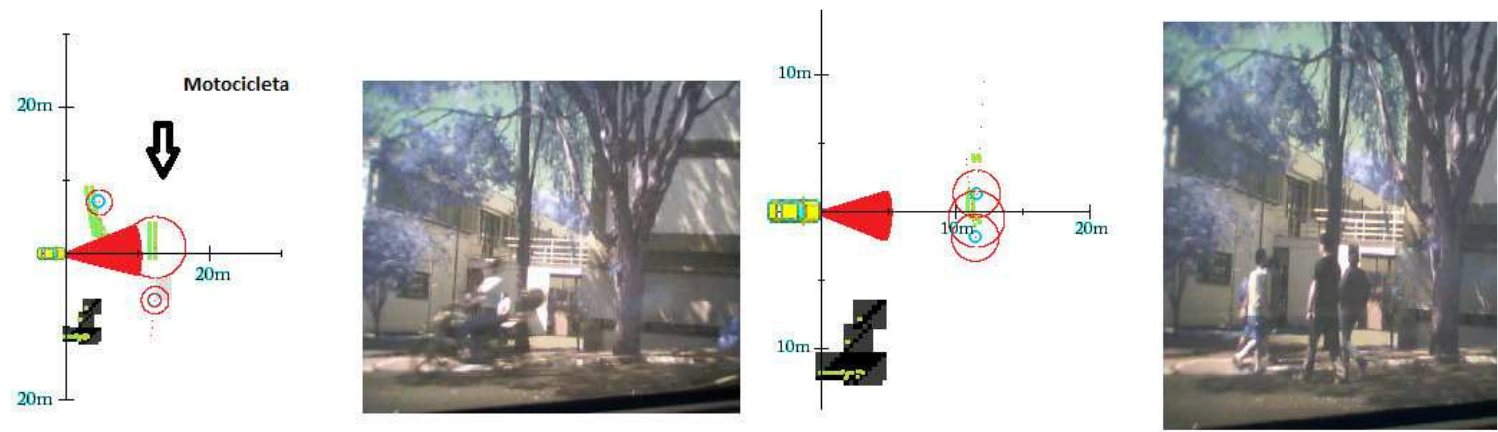

(a)

(b) 


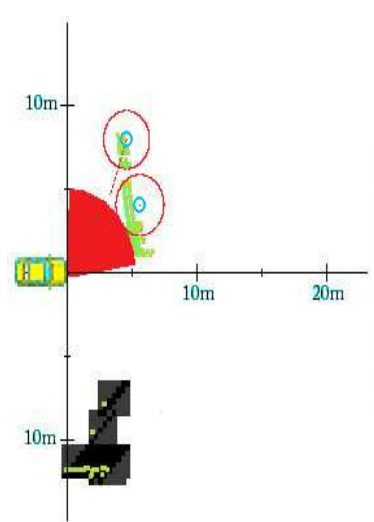

(c)

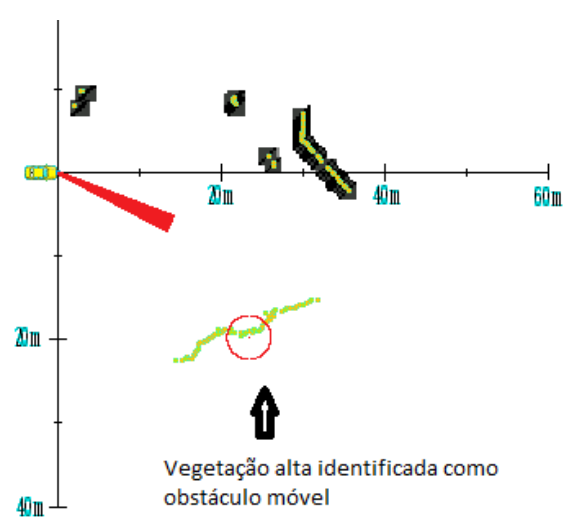

(d)

Figura 33: Exemplo de direções proibidas para tráfego do veículo, (a) detecção de motocicleta com velocidade abaixo de $11,1 \mathrm{~m} / \mathrm{s}$, (b) aglomeração de pedestres, (c) veículos com velocidade abaixo de $11,1 \mathrm{~m} / \mathrm{s}$, e (d) cones de indicação de direções proibidas em casos que vegetação alta é identificada temporariamente como obstáculo móvel.

\subsubsection{ALGORITMO E*}

Primeiramente o algoritmo $E^{*}$ foi testado em um mapa fictício com dimensões de $10 \times 7$ células, sendo cada célula considerada com $0,5 \mathrm{~m}$. Como pode ser observado na Fig. 34, o ambiente possui obstáculos estáticos (figuras brancas), ou seja, nestes pontos as células possuem um valor de custo maior que nas células livres (espaço em preto). Para cálculo da primeira rota com o mapa estático o programa levou 0,14 segundos.

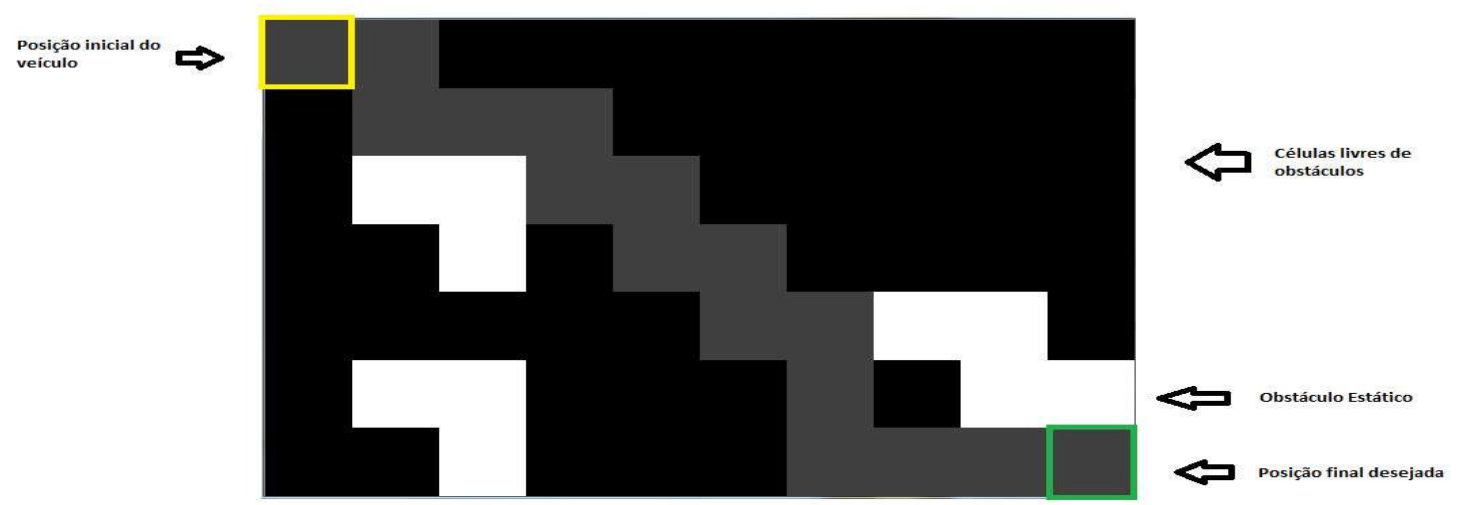

Figura 34: Primeira trajetória calculada para mapa estático.

No segundo caso foi adicionado ao ambiente um obstáculo que não existia anteriormente, fazendo com que o programa tivesse que realizar o recálculo da trajetória (replanning). Onde surgiu o obstáculo as células mudam de peso ou custo, saem de uma 
condição nula para um peso máximo, neste caso igual a 1 . O cálculo da nova trajetória é demonstrado na Fig. 35, e neste caso o tempo de processamento foi de 0,12 segundos.

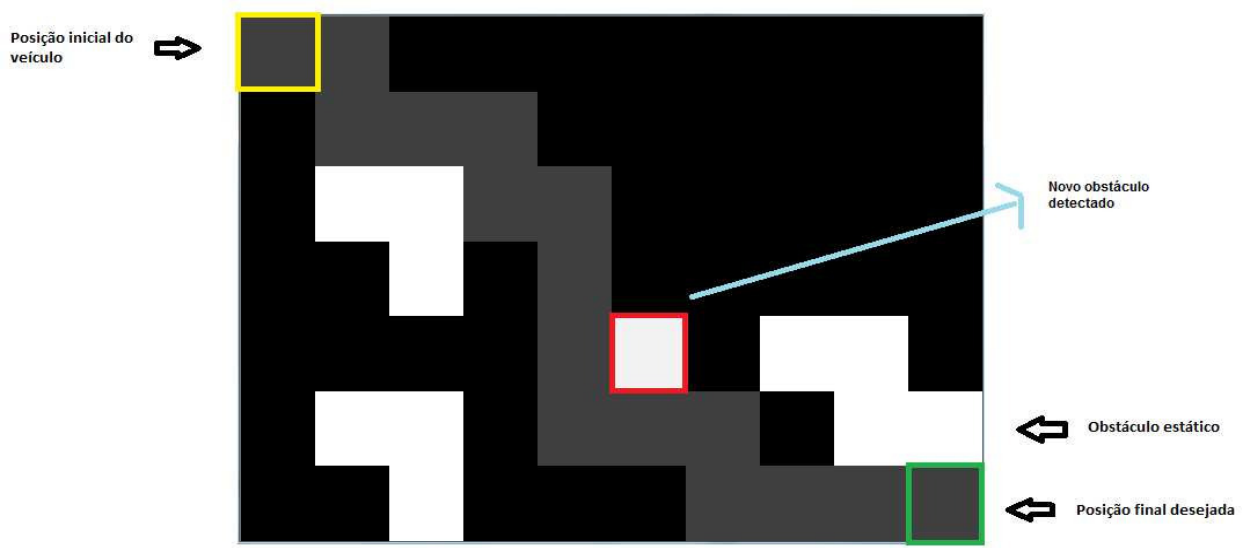

Figura 35: Trajetória calculada para mapa com novo obstáculo detectado.

Pode-se observar que o programa tem bons resultados tanto quanto ao tempo de processamento da rota calculada, mas isso para mapas relativamente pequenos. Depois de realizada a fusão entre todos os algoritmos propostos (Trackers, Velocity Obstacle e $\mathrm{E}^{*}$ ), foi possível observar que o algoritmo de rotas gasta mais tempo de processamento, sendo inviável ser embarcado no veículo de testes sem que seja feita uma otimização em seu código e aplicação de outras técnicas em conjunto, como o algoritmo de Dijsktra e mapas georeferenciados. A Fig. 36 mostra a fusão entre os algoritmos, sendo que a rota calculada com destino em $x=4 \mathrm{~m}$ e $y=2 \mathrm{~m}$ levou cerca de 3,21 minutos para ser gerada. $\mathrm{Na}$ primeira vez que o caminho precisou ser recalculado o programa levou cerca de 1,5 minutos para o cálculo da nova rota, após isso o programa trabalha na mesma freqüência dos outros algoritmos $(0,3 \mathrm{seg}$.).

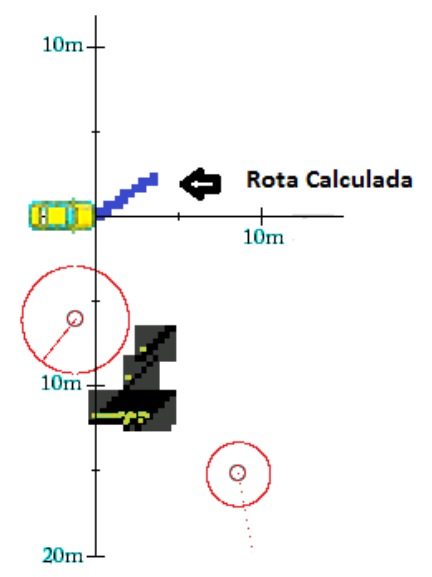

Figura 36: Cálculo da rota na fusão dos algoritmos.

O mesmo programa foi utilizado pelo aluno de mestrado José Miguel Vilca em sua dissertação (Vilca, 2011), para cálculo de rotas para robôs em formação. Foi 
realizada uma simulação computacional utilizando um mapa gerado pelo SICK com varredura de $180^{\circ}$ e alcance de $8 \mathrm{~m}$ do Laboratório de Sistemas Inteligentes (LASI), do Departamento de Engenharia Elétrica, EESC/USP. No primeiro teste tem-se o robô a uma velocidade de $0,1 \mathrm{~m} / \mathrm{s}$, o mapa com grid de célula de dimensão $0,5 \mathrm{~m}$ e obstáculos estáticos. No segundo teste, com as mesmas considerações iniciais foi inserido um novo obstáculo para o teste de replanning. A Fig. 37 mostra os resultados obtidos com as simulações. O tempo de processamento foi satisfatório, pois o robô Pionner simulado através da biblioteca ARIA e do software MobileSim fornecidos por MobileRobots pôde acompanhar a trajetória gerada sem risco de colisão (Vilca, 2011).

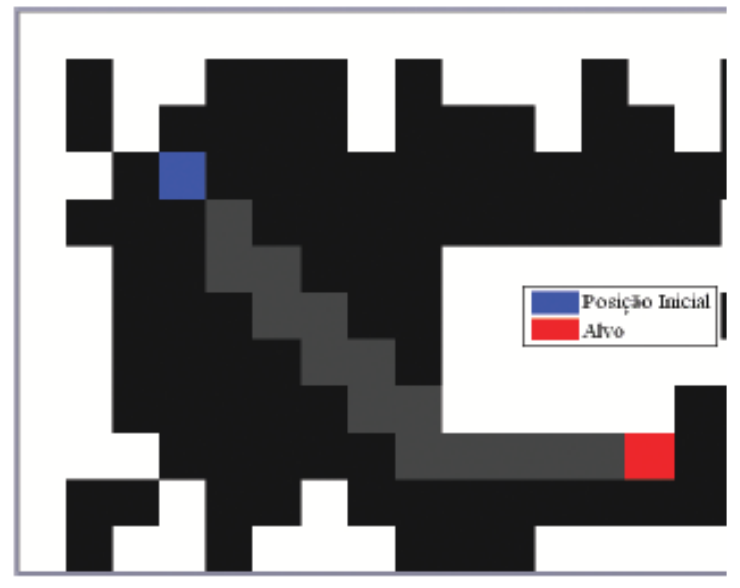

(a)

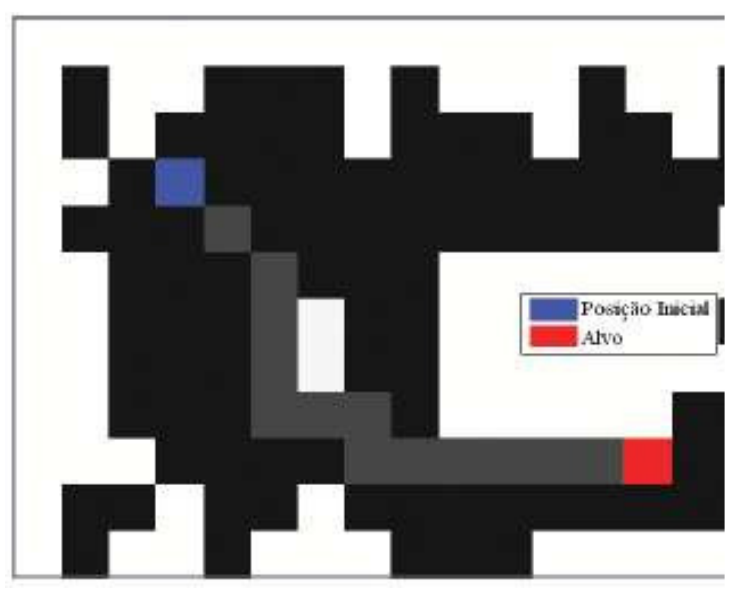

(c)

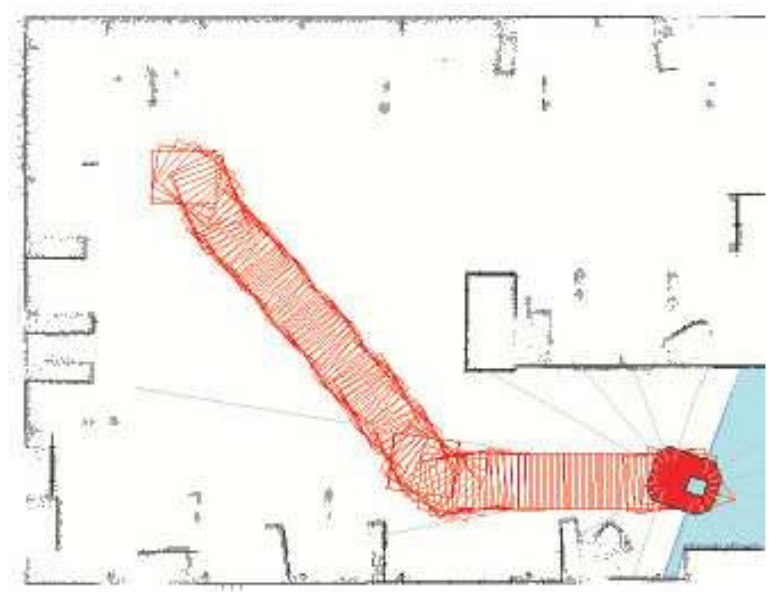

(b)

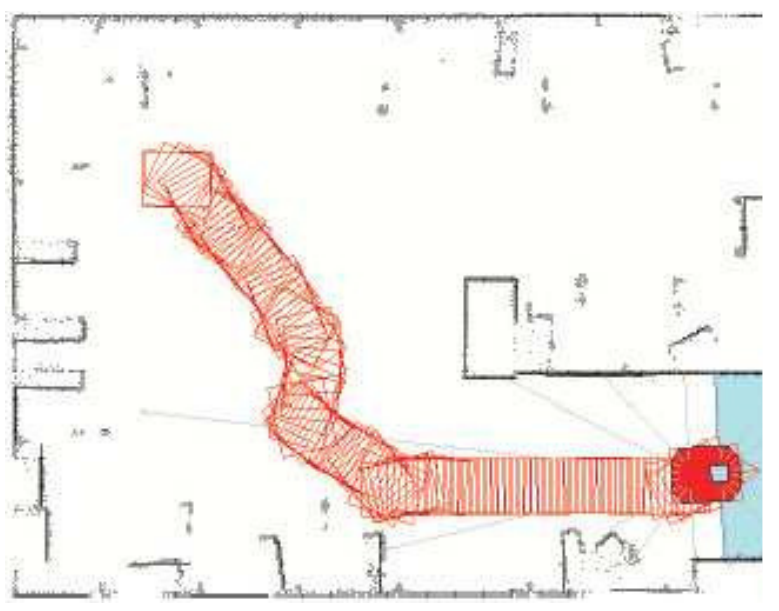

(d)

Figura 37: Testes de simulação com o robô Pionner. Resultados para o primeiro teste com o mapa estático (a) trajetória gerada pelo algoritmo $E^{*}$, (b) trajetória percorrida pelo robô, e no teste com o novo obstáculo estático (c) e (d) as mesmas situações (Vilca, 2011). 


\subsection{CONSIDERAÇÕES FINAIS}

Neste capítulo foram apresentados os resultados obtidos em cada algoritmo e também na fusão das três técnicas. Pôde-se observar que os resultados atenderam as expectativas, tendo sido detectados e classificados todos os obstáculos, as direções proibidas bem definidas e as trajetórias calculadas com trajeto suave em ambientes desconhecidos, e também com a capacidade de realizar o replanejamento da trajetória na presença de novos obstáculos estáticos ou móveis. Verifica-se a necessidade de otimização dos algoritmos desenvolvidos e até mesmo aplicação de outras técnicas e sensores para que os mesmos possam ser embarcados futuramente no veículo de testes. 


\section{Capítulo 5}

\section{CONCLUSÕES E PERSPECTIVAS FUTURAS}

Esta dissertação apresentou um estudo sobre algoritmos para monitoramento de ambientes urbanos que podem ser aplicados a sistemas de navegação para veículos de passeio autônomos. Os algoritmos de Trackers, Velocity Obstacle Approach e $\mathrm{E}^{*}$ foram desenvolvidos com o intuito de detectar, classificar e acompanhar obstáculos estáticos e móveis, como também indicar direções proibidas para esterçamento do veículo e cálculo de trajetórias suaves.

A pesquisa desenvolvida foi iniciada com o levantamento bibliográfico sobre técnicas de navegação em ambientes desconhecidos e para veículos autônomos. Verifica-se na literatura que existem muitas maneiras de se realizar este tipo de monitoramento, mas as três técnicas utilizadas neste trabalho foram escolhidas por terem sido simuladas em ambientes dinâmicos e por terem apresentado anteriormente bons resultados quando utilizadas em conjunto. Foi escolhido o sensor laser por facilidade de utilização, mais especificamente o sensor SICK LMS 291-S05 por ser largamente empregado em diversas pesquisas na área e por possuir erros de leitura muito pequenos quando comparados ao seu alcance máximo.

Sobre os algoritmos tem-se que o processo de segmentação foi implementado utilizando o método baseado na distância entre pontos. Os resultados obtidos foram satisfatórios, e por esse motivo, a implementação e teste do método baseado no Filtro de Kalman foi descartada. Em comparação ao PDBS, onde a dificuldade apresentada é o ajuste de alguns parâmetros off-line e a qualidade de resultados é satisfatória, então a aplicação do Filtro de Kalman não seria necessária (Rebai et al, 2009). 
Considerando que a convergência do Filtro de Kalman depende fortemente do número de pontos pertencentes a cada obstáculo e a cada segmento, isto tornaria o seu custo computacional superior ao PDBS.

O algoritmo para a detecção de obstáculos utiliza o método da comparação entre varreduras consecutivas. Ele se mostrou eficiente, porém, ainda existem casos em que os resultados não são consistentes. Para isso, um mapa local foi criado a fim de melhorar a classificação de obstáculos móveis e fixos. Futuramente, o uso de mapas georeferenciados de áreas urbanas com janelas de interesse pode auxiliar nessa tarefa.

Ter dados confiáveis do detector de obstáculos é um passo imprescindível para a realização da predição dos movimentos dos objetos. Por isso foi feito um aprimoramento na detecção dos movimentos dos obstáculos e a partir desses dados, foi realizado o acompanhamento e a predição dos movimentos dos objetos com a utilização do Filtro de Kalman.

Deve-se também ressaltar a importância da detecção, acompanhamento e predição dos movimentos de obstáculos móveis para a navegação de um veículo autônomo. Com esses dados, será possível obter os melhores caminhos a fim de evitar colisões, e assim, o principal pré-requisito de projeto será obedecido: a segurança do veículo e do ambiente a sua volta. A fusão entre os algoritmos de Trackers e Velocity Obstacle foi realizada, o que contribuiu para um melhor resultado na navegação do veículo. Assim, foi possível determinar as direções proibidas para o veículo trafegar, o que permite evitar colisões do veículo de testes com os obstáculos do ambiente. A implementação do VO também possibilita o desenvolvimento futuro de rotinas para geração de manobras evasivas e de controle de velocidade do veículo.

Neste trabalho, optou-se pelo desenvolvimento do Algoritmo $E^{*}$ pela possibilidade de se obter trajetórias mais suaves através da interpolação de pontos e também pelo replanejamento de rota quando na presença de novos cenários no ambiente. Esse algoritmo demonstrou bons resultados apesar do custo computacional encontrado (como foi ressaltado nos resultados). Por isso, um trabalho futuro a ser realizado é a otimização de seu código e o seu emprego em conjunto com o algoritmo de Dijsktra e um mapa georeferenciado dos Campi da USP em São Carlos para torná-lo mais eficiente. Além disso, tendo em vista que o LabRoM adquiriu novos sensores, incluindo câmeras CCD e sensores laser multi-layers que permitem 
leitura tridimensional da região em torno do veículo de testes, as rotinas desenvolvidas devem ser adaptadas para o emprego de dados desses sensores.

Também como trabalhos futuros pode-se citar a realização de testes em condições climáticas diversas, como em dias de chuva ou com neblina e durante a noite, pois todos os testes realizados durante esta pesquisa ocorreram em dias de sol. A conexão com a rede CAN do veículo de testes para obtenção de dados, como velocidade do veículo, ângulo de esterçamento, ângulo de direção, que nesta pesquisa foram simulados, foi realizada no final desta pesquisa. Assim, também é necessário testar o emprego destes dados nos algoritmos. Para finalizar, deve-se frisar que uma importante frente a ser desenvolvida é a utilização de visão computacional para melhorar a classificação dos obstáculos, podendo assim aumentar a quantidade de classes e modelos (p.e.: introduzindo as classes e modelos de motocicletas, bicicletas, ônibus, caminhões, etc.), como também para permitir a detecção de placas de sinalização, vias e faixas. 


\section{REFERÊNCIAS}

ARAÚJO, R. L. C., LACERDA, V. M. (2009). Detecção e Classificação de Pedestres e Automóveis Utilizando Sensor Laser e Câmera Monocular. Trabalho de Conclusão de Curso, EESC - USP, São Carlos, Brasil.

BECKER, M.(2000). Aplicação de Tecnologias Assistivas e Técnicas de Controle em Cadeiras de Rodas Inteligentes. Tese de doutorado, Campinas, Brasil, pp. 103-109.

BECKER, M., DANTAS, C. M., MACEDO, W. P., (2005). Obstacle Avoidance Procedure for Mobile Robots. $18^{\text {th }}$ International Congress of Mechanical Engeneering, Ouro Preto, Brasil, pp. 250-257.

BECKER, M., HALL, R., JENSEN, B., KOLSKI, S., MACEK, K., SIEGWART, R., JENSEN, B., (2007). The use of Obstacle Motion Tracking for Car-like Mobile Robots Collision Avoidance in Dynamic Urban Environments. XII International Symposium on dynamic of Mechanics - DINAME, Brasil.

BECKER, M., HALL, R., KOLSKI, S., MACEK, K., SIEGWART, R., JENSEN, B., (2009). 2D Laser-based Probabilistic Motion Tracking in Urban-like Environments. Journal of the Brazilian Society of Mechanical Sciences and Engineering, v. 31, p. 83-96.

BECKER, M., KOLSKI, S., JENSEN, B., MAČEK, K., WEINGARTEN, J., LAMON, P., SIEGWART, R. (2007). Car-Like Mobile Robots: Soon or Latter a Reality on Our Streets. Proceedings of the $6^{\circ}$ Brazilian Conference on Dynamics, Control and Their Applications.

BENREguiEG, M., HOPPENOt, P., H MAAREF, H., COlle, E., BARRET, C., (1997). Fuzzy navigation strategy: application to two distinct autonomous mobile robots. Robotica V1. 15, pp 609 - 615, Printed in the United Kingdom, Cambridge University Press. 
BLAIS, F., (2004). Review of 20 years of range sensor development. Journal of Electronic Imaging, Canada. January, pp. 231-240.

BLANC, C., TRASSOUDAINE, L., AND GALLICE, J., (2005). EKF and particle filter track to- track fusion: a quantitative comparison from radar/lidar obstacle tracks. Proc. of 8th Int. Conf. on Information Fusion, vol. 2, pp. 25-28.

BORENSTEIN, J., KOREN, Y., (1991). The vector field histogram - fast obstacle avoidance for mobile robots. IEEE Journal of Robotics and Automation, vol. 7, n. 3, pp. $278-288$.

BORGES, G., ALDON, M., (2004). Line Extraction in 2D Range Images for Mobile Robotics. Journal of Intelligent and Robotic Systems, p. 267-297.

BOSELLI, G., (2009). Estudos Técnicos Mapeamento das Mortes por Acidentes no Trânsito no Brasil. Confederação Nacional de Municípios, Área de Estudos Técnicos, Brasília.

BROCK, O., KHATIB, O., (1999). High speed navigation using the global dynamic window approach. Proceedings of the 1999 IEEE International Conference on Robotics \& Automation, Detroit, MI, pp. 341-346.

BROOKHUIS, K. A., WAARD, D., JANSSEN, W. H., (2001). Behavioural Impacts of Advanced Driver Assistance Systems - an overview. EJTIR, 1, no. 3, pp. 245 - 253.

C-ELROB, (2011). Disponível em: < http://www.c-elrob.eu/>, acesso em 30 abr. 2011.

CHIEH-CHIH, C., THORPE, W., (2002). Simultaneous localization and mapping with detection and tracking of moving objects. IEEE International Conference on Robotics and Automation (ICRA), pp. 2918-2924.

CHRISTENSEN, H. I., HAGER, G. D., (2008). Sensing and Estimation. Springer Handbook of Robotics. Ed. Springer, Berlin Heidelberg. 
DARPA GREAT CHALLENGE, (2005). Disponível em: <http://www.darpa.mil/ grandchallenge05/>, acesso em 01/07/08.

DELSART, V., FRAICHARD, T., (2008). Navigation Dynamic Environments Using Trajectory Deformation. IEEE/RSJ International Conference on Intelligent Robots and Systems. pp. 226 - 233.

DIETMAYER, K., SPARBERT, J., STRELLER, D., (2001). Model based Object Classification and Object Tracking in Traffic scenes from Range Images. Proceedings of IV IEEE Intelligent Vehicles Symposium.

DIJSKTRA, E. W. (1959). A Note on two problems in connexion with graphs. Numerische Mathematik, Berlin, v.1, p.269-271.

DISCANT, A., ROGOZAN, A., RUSU, C., BENSRHAIR, A., (2007). Sensors for Obstacle Detection - A Survey. $30^{\text {th }}$ International Spring Seminar on Electronics Technology, pp. 100-105.

ELFES, A., (1989). Using Occupancy Grids for Mobile Robot Perception and Navigation, Computer, vol. 22, no. 6, pp. 46-57, IEEE Computer Society Press.

ELROB, (2006). Disponível em: < http://www.elrob2006.org/>, acesso em 01/07/08.

FAHIR, O., (2008), Optimal Fuzzy Control of Autonomous Robot Car. $4^{\text {th }}$ International IEEE Conference "Intelligent Systems, pp. 4.62-4.65.

FAROOQ, U., AMAR, M., UL HAQ, E., ASAD, M. U., ATIQ, H. M., (2010). Microcontroller Based Neural Network Controlled Low Cost Autonomous Vehicle. Second International Conference on Machine learning and Computing (ICMLC), pp. 96.

FENABRAVE, ASSESSORIA ECÔNOMICA, (2009). Balanço Semestral 2009 do Setor da Distribuição de Veículos Automotores no Brasil, Setembro. 
FERGUSON, D., DARMS, M.; URMSON, C., (2008). Detection, Prediction, and Avoidance of Dynamic Obstacles in Urban Environments, Proceedings of the 2008 IEEE Intelligent Vehicles Symposium, June, pp. 1149-1154.

FERGUSON, D., STENTZ, A., (2005). Field D*: An Interpolation-based Path Planner and Replanner, Proceedings of the International Symposium on Robotics Research (ISRR).

FERGUSON, D., STENTZ, A., (2006). Using Interpolation to Improve Path Planning: The Field D* Algorithm, Journal of Field Robotics 23(2), pp. 79-101.

FIORIONI, P. AND SHILLER, Z., (1993). Motion Planning in Dynamic Environments using the Relative Velocity Paradigm, Proceedings of the 1993 IEEE International Conference on Robotics \& Automation, Atlanta, pp. 560-565.

FISHER, R. B., KONOLIGE, K., (2008). Range Sensors, Springer Handbook of Robotics. Ed. Springer, Berlin Heidelberg.

FOX, D., BURGARD, W. AND THRUN, S., (1997). The Dynamic Window Approach to Collision Avoidance, IEEE Robotics \& Automation Magazine, pp. 23-33.

GARNIER, P., NOVALES, C., LAUGIER, C., (1995). An hybrid motion controller for a real car-like robot evolving in a multi-vehicle environment, Proceedings of the Intelligent Vehicles '95 Symposium, pp. 326 - 331, Detroit, USA.

HALL, R., (2006). The use of Motion Tracking for Mobile Robot Collision Avoidance in Outdoor Environments, Semester Project, École Polytechnique Fédérale de Lausanne.

HOSSEIN, T.N.N., MITA, S., LONG, H., (2010). Multi-Sensor Fusion for Autonomous Vehicle Navigation through Adaptive Particle Filter. IEEE Intelligent Vehicles Symposium, University of California, San Diego, pp. 752-759. 
HUANG, M., ZHANG, R., MA, Y., YAN, Q., (2010). Research on Autonomous Driving Control Method of Intelligent Vehicle Based on Vision Navigation. International Conference on Computational Intelligent and Software Engineering (CiSE), pp. 1-7.

IBGE - INSTITUTO BRASILEIRO DE GEOGRAFIA E ESTATÍSTICA, (2008). Projeção da População do Brasil por Sexo e Idade - 1980-2050. Disponível em: $<$ http://www.ibge.gov.br/home/>, acesso em 26 mar. 2011.

INGRAND, F., LACROIX, S., LEMAI-CHENEVIER, S., PY, F., (2007). Decisional Autonomy of Planetary Rovers. Journal of Field Robotics 24(7), pp.559-580.

KALMAN, R.E., (1960). A new approach to linear filtering and prediction problems. Trans. of ASME, J. Basic Engineering, Vol. 82, pp. $34-45$.

KHEYRURI, H., FREY, D., (2010). Comparison of People Detection Techniques from 2D Laser Range Data. Disponível em: $<$ http://ais.informatik.unifreiburg.de/teaching/ws09/robotics2/projects/>, acesso em 20 fev. 2010.

KMIOTEK, P., RUICHEK, Y., (2008). Multisensor fusion based tracking of coalescing objects in urban environment for an autonomous vehicle navigation. In: Proceedings of IEEE International Conference on Multisensor Fusion and Integration for Intelligent Systems, Seoul, Korea, pp. 52-57.

KOHLER, M. (1997). Using the Kalman Filter to track Human Interactive Motion modeling and initialization of the KF for translational motion. TR 629. Informatik VII, Universität Dortmund, Germany.

LEE, K., (2001). Reactive navigation for an outdoor autonomous vehicle. Master Thesis, University of Sydney.

LEE, K., EHSANI, R., (2008). Comparison of two 2D laser scanners for sensing object distances, shapes, and surface patterns. Computers and Electronics in Agriculture 60. pp. 250-262. 
LEONARD, J. J., DURRANT-WHYTE, H. F., (1992). Directed Sonar Sensing for Mobile Robot Navigation. Boston: Kluwer Academic Publishers.

LlORCA, D. F., MilANÉS, V., AlONSO, I. P., GAVILÁN, M., DAZA, I. G., PÉREZ, J., SOTELO, M. A.,(2011). Autonomous Pedestrian Collision Avoidance Using a Fuzzy Steering Controller. IEEE Transactions on Intelligent Transportation Systems. pp. 390-401.

LONG, L. N., HANFORD, S. D., JANRATHITIKARN, O., SINSLEY, G. L., MILLER, J. A.,(2007). A Review of Intelligent Systems Software for Autonomous Vehicles. IEEE Symposium on Computational Intelligence in Security and Defense Applications (CISDA). pp. 69-76.

LUMELSKY, V., STEPANOV, A., (1990). Path-Planning Strategies for a Point Mobile Automaton Moving Amidst Unknown Obstacles of Arbitrary Shape. Autonomous Robot Vehicles. New York, Spinger-Verlag.

MENDES, A., BENTO, L.C., NUNES, U., (2004). Multi-target Detection and Tracking with a Laserscanner. IEEE Intelligent Vehicles Symposium. pp. $796-801$.

MOBILEMAGAZINE, (2006). Disponível em: $<$ http://www.mobilemag.com/content/100/354/C6610/>, acesso em 01 out. 2009.

MORAS, J., CHERFAOUI, V., BONNIFAIT, P., (2010). A lidar Perception Scheme for Intelligent Vehicle Navigation. $11^{\text {th }}$ International conference of Control, Automation, Robotics and Vision. pp. 1809 - 1814.

MOVAREC, H.P. AND ELFES, A., (1985). High Resolution Maps from Wide Angle Sonar, IEEE Conference on Robotics and Automation, Washington D.C., pp. 116121.

NHTSA, Traffic Safety Facts, (2009). disponível em: <http://www.nhtsa.dot.gov/>, acesso em 10 mar. 2011. 
NILSSON, N., (1980). Principles of Artificial Intelligence, Tioga Publishing Company, pp. $72-88$.

O ESTADO DE SÃO PAULO, (2007). Mortes no trânsito se igualam a homicídios, disponível em: $<$ http://www.estadao.com.br/estadaodehoje/20080618/not_imp191518,0.php>, acesso em 30 abr. 2011.

O ESTADO DE SÃO PAULO, (2011). Em 10 anos, morte em acidente de moto cresce 754\%, disponível em: <http://www.estadao.com.br/noticias/geral,em-10-anos-morteem-acidente-de-moto-cresce-754,705418,0.htm>, acesso em 30 abr. 2011.

ÖZGÜNER, Ü., STILlER, C., REDMILL, K., (2007). Systems for Safety and Autonomous Behavior in cars: The DARPA Grand Challenge Experience, Proceedings of the IEEE, Vol. 95, No. 2.

PERrollaZ, M., LABAYRADE, R., ROYÈRE, C., HAUTIÈRE, N., AUBERT, D., (2006). Long Range Obstacle Detection using Laser Scanner and Stereovision. In: Intelligent Vehicles Symposium, Tokyo, Japan, pp. 182-187.

PINHEIRO, E., KUBO, C. C., RANGEL, M. S., ARCARI, T. A., DIAS, C. G., (2009). Navegação Autônoma de um Agente Inteligente: Um Estudo Comparativo Usando Lógica Fuzzy e Algoritmo de Busca A*, pp 87 - 98, Exacta, São Paulo, v. 7, 2009.

PHILIPPSEN, R., (2006). A light formulation of the $E^{*}$ interpolated path replanner. Technical report, Autonomous Systems Lab. Ecole Polytechnique Federale de Lausanne.

PHILIPPSEN, R., JENSEN, B., SIEGWART, R., (2007). Towards Real-Time SensorBased Path Planning in Higly Dynamic Environments. Autonomous Navigation in Dynamic Environments, Vol. 35, pp. 135-148. 
PHILIPPSEN, R., KOLSKI, S., MACEK, K., SIEGWART, R., (2007). Path Planning, Replanning, and Execution for Autonomous Driving in Urban and Offroad Environments. Proc. of The Workshop on Planning, Perception and Navigation for Intelligent Vehicles (ICRA).

PHILIPPSEN, R., SIEGWART, R., (2003). Smooth and Efficient Obstacle Avoidance for a Tour Guide Robot. Proceedings of the IEEE International Conference on Robotics and Automation (ICRA 2003), Taipei, Taiwan.

PHILIPPSEN, R., SIEGWART, R., (2005). An Interpolated Dynamic Navigation Function. Proceedings of the IEEE International Conference on Robotics and Automation (ICRA 2005), pp. 3782-3789.

PRASSLER, E., SCHOLZ, J., STROBEL, M., FIORINI, P., (1999). An Intelligent (Semi-) Autonomous Passenger Transportation System, IEEE, ISBN 0-7803-4975-X, pp. 374-379.

PRASSLER, E., SCHOLZ, J., FIORINI, P., (2001). A Robotic Wheelchair for Crowded Public Environments. IEEE Robotics \& Automation Magazine, pp. 38 - 45.

PRASSLER, E., SCHOLZ, J., FIORINI, P., (1999). Navigating a Robotic Wheelchair in a Railway Station during Rush Hour, The International Journal of Robotics Research, pp. 711-727.

PREMEBIDA, C.; NUNES, U., (2005). Segmentation and Geometric Primitives Extraction from 2D Laser Range Data for Mobile Robot Applications. Acta de. Coimbra: Universidade de Coimbra, 2005.

RAMÍREZ, J. M.; GÓMEZ-GIL, P.; LARIOS, F. L., (2007). A Robot-vision System for Autonomous Vehicle Navigation with Fuzzy-logic Control using Lab-View. Electronics, Robotics and Automotive Mechanics Conference (CERMA 2007), pp. 295-302. 
REBAI, K., BENABDERRAHMANE, A., AZOUAOUI, O., OUADAH, N., (2009), Moving Obstacles Detection and Tracking with Laser Range Finder. International Conference on Advanced Robotics (ICAR 2009), pp. 1-6.

ROBERT, M., (2004). Tracking Moving Objects From a Moving Vehicle Using a Laser Scanner. Carnegie Mellon University. Disponível em: $<$ http://www.cs.cmu.edu/ ram/resume/datmo_report.pdf $>$, acesso em: 18 de dezembro de 2009.

SANTOS, S., FARIA, J., SOARES, F., ARAUJO, R., NUNES, U., (2003). Tracking of Multi-Obstacles with Laser Range Data for Autonomous Vehicles. Proc. 3rd National Festival of Robotics Scientific Meeting (ROBOTICA), pp. 59-65.

SAZDOVSKI, V., SILSON, P. M. G., (2010). Inertial Navigation Aided by VisionBased Simultaneous Localization and Mapping. IEEE Sensors Journal, pp.1646 1656.

SCHWARTZ, J. D., MILAM, M., (2008). On-line Path Planning For an Autonomous Vehicle in an Obstacle Filled Environment. Proceedings of the 47th IEEE Conference on Decision and Control, pp. 2806 - 2813.

SICK Product Database. Disponível em: <http://www.sick.com/>, acesso em: 15 de dezembro de 2009.

SIEGWART, R., NOURBAKHSH, I., (2011). Introduction to Autonomous Mobile Robots. The MIT Press, Cambridge, Massachusetts, London, England, pp. 480.

SINGH, S., SIMMONS, R., SMITH, T., STENTZ, A., VERMA, V., YAHJA, A., SCHWEHR, K., (2000). Recent Progress in Local and Global Traversability for Planetary Rovers. IEEE International Conference on Robotics and Automation, San Francisco, USA.

SPARC, (2011). Disponível em: < http://www.esafetysupport.org/>, acesso em 10 mar. 2011. 
ULRICH, I. AND BORENSTEIN, J., (1998). VFH+: Reliable Obstacle Avoidance for Fast Mobile Robots. Proceedings of the 1998 IEEE International Conference on Robotics \& Automation, Leuven, Belgium, pp. 1572-1577.

ULRICH, I. AND BORENSTEIN, J., (2000). VFH*: Local Obstacle Avoidance with look-ahead Verification. Proceedings of the 2000 IEEE International Conference on Robotics \& Automation, San Francisco, CA, pp. 2505-2511.

VILCA, J.M., (2011). Estudo de Coordenação de robôs móveis com Obstáculos. Dissertação de Mestrado. Escola de Engenharia de São Carlos, São Paulo.

WANG, C.C. AND THORPE, C., (2002). Simultaneous localization and mapping with detection and tracking of moving objects. Proc. of the IEEE Int. Conf. on Robotics and Automation - ICRA 2002, Vol. 3, pp. 2918-2924.

WOLF, D.F., SIMÕES, E.V., OSÓRIO, F.S., JUNIOR, O.T., (2009). Robótica Móvel Inteligente: da Simulação às Aplicações no Mundo Real, Vol. 1, São Carlos, Brasil.

WUTHISHUWONG, C., SILAWATCHANANAI, C., PARNICHKUN, M., (2009). Navigation of an Intelligent Vehicle by using Stand-alone GPS, Compass and Laser Range Finder. Proceedings of the 2008 IEEE International Conference on Robotics and Biomimetics. pp- $2121-2126$.

XU, Z., ZHUANG, Y., CHEN, H., (2006). Obstacle Detection and Road Following using Laser Scanner. In: Proceedings of the $6^{\text {th }}$ Word Congress on Intelligent Control and Automation, Dalian, China. pp. 8630-8634.

YOON, J., CRENE III, D. D., (2008). LADAR based Obstacle Detection in an Urban Environment and its Application in the DARPA Urban Challenge. International Conference on Control, Automation and Systems 2008. pp- 581 - 585. 
Yu, C., Zhang, D., (2007). Obstacle Detection on a Four-Layer Laser Radar. In: Proceedings of the IEEE International Conference on Robotics and Biomimetics, Sanya, China. pp. 218-221. 